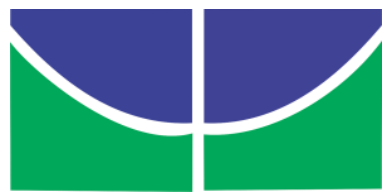

Universidade de Brasília

Faculdade de Saúde

Departamento de Nutrição

Programa de Pós-Graduação em Nutrição Humana

GIOVANNA SOUTINHO ARAÚJO

\title{
Práticas Parentais Alimentares e sua Relação com o Consumo de Alimentos na Infância
}

Brasília - DF 


\author{
UNIVERSIDADE DE BRASÍLIA \\ FACULDADE DE CIÊNCIAS DA SAÚDE \\ DEPARTAMENTO DE NUTRIÇÃO \\ PROGRAMA DE PÓS-GRADUAÇÃO EM NUTRIÇÃO HUMANA
}

GIOVANNA SOUTINHO ARAÚJO

Dissertação apresentada como requisito parcial para a obtenção do Título de Mestre em Nutrição Humana pelo Programa de Pós-Graduação em Nutrição Humana da Universidade de Brasília

Orientadora: Dr. ${ }^{\underline{a}}$ Renata Alves Monteiro

Brasília

2015 
Araújo, Giovanna Soutinho.

Práticas Parentais Alimentares e sua Relação com o Consumo de Alimentos na Infância/ Giovanna Soutinho Araújo. Brasília, 2015 $158 \mathrm{f}$. : il.

Dissertação (mestrado) - Universidade de Brasília - UnB, Faculdade de Ciências da Saúde, Departamento de Nutrição, Programa de Pós-Graduação em Nutrição Humana, 2015.

Inclui bibliografia.

Orientadora: Profa. Dra. Renata Alves Monteiro, Departamento de Nutrição Humana. 


\section{PRÁTICAS PARENTAIS ALIMENTARES E SUA RELAÇÃO COM O CONSUMO DE ALIMENTOS NA INFÂNCIA}

Dissertação de Mestrado avaliada pela seguinte Banca Examinadora

Prof. Dra. Renata Alves Monteiro (presidente)

Programa de Pós-Graduação em Nutrição Humana,

Departamento de Nutrição Universidade de Brasília

Prof. Dra. Danielle Cabrini Mattos (membro)

Programa de Pós-Graduação em Nutrição Humana,

Departamento de Nutrição Universidade de Brasília

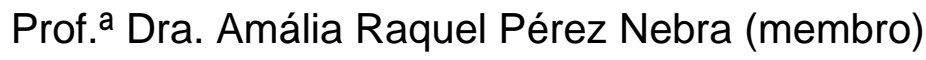
Faculdade de Ciências da educação e saúde (FACES) Centro Universitário de Brasília - UniCEUB

Prof. ${ }^{a}$ Dra. Karin Eleonora Savio de Oliveira (suplente)

Programa de Pós-Graduação em Nutrição Humana,

Departamento de Nutrição Universidade de Brasília 
Dedicatória

Dedico esse trabalho à minha família, ao meu amor, aos meus amigos queridos e à todas as mães que lutam para dar o melhor aos seus filhos. 


\section{Agradecimento}

Em primeiro lugar, agradeço à Deus, que com sua grandeza e bondade infinita nos proporciona a vida e a oportunidade de contemplar as maravilhas de sua criação.

À espiritualidade pela presença constante, pela proteção e por me ajudar a ser uma pessoa melhor. Em especial, agradeço à Dra. Isis e à Irmã Rosália, que, com suas experiências sobre a infância, me inspiram e contagiam ainda mais.

À minha orientadora, Renata Monteiro, por me inspirar desde a graduação, por ter abraçado comigo esse tema, por acolher e respeitar, por seus sábios conselhos, pela paciência e pelo incentivo.

À minha família amada, especialmente à minha mãe. Palavras não são suficientes para demonstrar a minha gratidão eterna. $\mathrm{O}$ seu apoio, carinho e amor são fundamentais. Vó, tios e primos, como eu os amo!

Ao meu melhor amigo, companheiro, parceiro e amor, que sempre esteve ao meu lado, me ajudando, me consolando, me amando e enfrentando comigo todos os medos e desafios. Sem você e o seu apoio incondicional, isso não seria possível.

Às lindas do OPSAN (Marília, Maína, Débora, Alice, Linda e claro, Babi, Nat e Lu, eternas lindas do OPSAN!) e aos estagiários pela amizade, pelo carinho, pelo aprendizado de todo dia e principalmente pelo enorme apoio. Vocês fazem o trabalho ser diversão!

À Betta, pela compreensão e pela inspiração. A minha admiração por você não tem tamanho! Só tenho a agradecer pelo que você faz pela nutrição e por nós do OPSAN.

Aos membros da banca de qualificação pelas sábias considerações, pelo apoio e pelo olhar cuidadoso que tiveram com meu trabalho. 
À Ana Spaniol, Mari Delgado e Izabela pela ajuda prestativa e o carinho sempre em atender sempre que precisei.

Ao professor Eduardo, irmão do tio Antenor, que com toda a gentileza e paciência, cedeu algumas horas do seu tempo para me passar um pouquinho do seu vasto conhecimento sobre estatística.

À Amanda Branquinho, Karin e Rita, que me acolheram com esse tema durante a graduação e, em especial à Amanda, que esteve ao meu lado e me ensinou tanto durante o período de TCC.

Aos amigos do REMA e por todos os outros amigos que estiveram ao meu lado por todo esse tempo e que compreenderam as minhas ausências. Vocês fazem a vida mais colorida e me ajudam a ser uma pessoa melhor!

Às queridas do Alecrim e do Aerar, que me fizeram fugir da zona de conforto e abrir o olhar para novos horizontes.

Agradeço de todo o coração a todas as mães que participaram deste estudo e a todos os amigos que ajudaram na divulgação do questionário. Nada disso seria possível sem vocês!

Todos vocês são parte dessa conquista! Meu esterno agradecimento! 
"Coloque o seu coração em tudo o que fizer e seus planos darão certo" 


\section{Resumo}

A infância é uma fase determinante para o estabelecimento de práticas e hábitos alimentares que podem persistir durante toda a vida. A família, por sua vez, exerce forte influência no comportamento alimentar infantil, na formação dos hábitos e consequentemente no estado nutricional das crianças. Os pais influenciam a alimentação por meio da disponibilidade de alimentos em casa, pelo uso de práticas de alimentação e pelo seu próprio comportamento alimentar. Práticas parentais alimentares são estratégias de comportamentos específicos dos pais que empregam o controle sobre o que, quanto e quando as crianças comem. Devido sua importância, instrumentos de avaliação dessas práticas têm sido cada vez mais relatados na literatura, com o objetivo de investigar como elas influenciam no comportamento alimentar e no estado nutricional infantil. No entanto, no Brasil esses estudos ainda são escassos. Dessa forma, o presente estudo tem o objetivo de determinar as práticas alimentares maternas e como elas influenciam o consumo de alimentos de crianças de 18 meses a 8 anos. De modo a atingir tal objetivo, propuseram-se dois estudos, sendo o primeiro com o objetivo de validar um instrumento de compreensão das práticas parentais de alimentação infantil para a população brasileira e o segundo associar as múltiplas práticas alimentares maternas e outros determinantes ao consumo de frutas e hortaliças por crianças de 18 meses a 8 anos. O método de pesquisa se deu por um estudo transversal do tipo survey realizado com mães, por meio de um instrumento autopreenchido disponibilizado online, via Internet. Participaram do primeiro estudo 844 mães, que responderam uma versão traduzida-retraduzida e validada culturalmente do Comprehensive Feeding Practices Questionnaire (CFPQ), um instrumento de avaliação que aborda as múltiplas práticas parentais. Os dados obtidos foram submetidos a validação estatística por meio de análise fatorial exploratória. A solução fatorial final foi caracterizada por 9 fatores e 39 itens (KMO $=0,830$ e 56,5\% de variância), sendo considerado adequado para o uso no Brasil. O segundo estudo foi realizado com a participação de 681 mães, que preencheram um instrumento autoadministrado, contendo questões relacionadas aos hábitos alimentares infantis, práticas parentais e outros hábitos de vida relacionados à alimentação, bem como consumo alimentar da mãe e da criança. Os resultados mostraram que o consumo materno é um forte preditor do consumo de alimentos saudáveis pela criança. A frequência de compra de alimentos não saudáveis e a idade da criança também apareceram como preditores do consumo de frutas e hortaliças, no entanto apresentando associação inversa. Assim, considera-se que o presente trabalho fornece uma contribuição importante para a literatura sobre processos psicológicos de práticas parentais alimentares e potencial prevenção para obesidade infantil e que o objetivo de determinar as práticas maternas no Brasil e como elas influenciam o consumo de alimentos por crianças de 18 meses a 8 anos foi cumprido.

Palavras-chave: comportamento alimentar, práticas parentais, infância, formação de hábitos alimentares, influência materna 


\begin{abstract}
Early childhood is an essential stage for establishing the feeding practices and habits, which may persist throughout the lifetime. The Family, in its turn, has a strong influence on children's alimentary behaviour, habits formations, and consequently on the children's nutritional status. Parents influence diet through the availability of food at home, by their feeding practices, and their own eating behaviour. Parenting feeding behaviours are specific strategies that parents use to control over what, how much and when their children eat. Because of its importance, practices of assessment tools have been increasingly reported in the literature in order to investigate how they influence the feeding behaviour and nutritional status. However, in Brazil these studies are still scarce. Thus, this study aims to determine the maternal feeding practices and how they influence food intake of children from 18 months to 8 years. In order to achieve this goal, two studies are proposed, the first to validate a tool of understanding the parental feeding practices of infants for the Brazilian population, and the second to associate multiple maternal dietary practices and other determinants of consumption of fruits and vegetables by children 18 months to 8 years. The search method is given by a cross-sectional survey type mothers carried out by means of a selfadministered instrument available on-line. Participated in the first study 844 mothers who answered a translated-back-translated and culturally validated by the Comprehensive Feeding Practices Questionnaire (CFPQ), an assessment tool that addresses the multiple parenting practices. The data were submitted to statistical validation through exploratory factor analysis. The final factor solution was characterized by 9 factors and 39 items (KMO $=0,830$ and $56,5 \%$ of variance), considered suitable for use in Brazil. The second study was conducted with the participation of 681 mothers, who completed a self-administered instrument, containing issues related to children's eating habits, parenting and other life habits related to food, as well as mother and child food consumption. The results showed that the maternal consumption is a strong predictor of the consumption of healthy food for the child. The frequency of buying unhealthy foods and the child's age also appeared as predictors of consumption of fruits and vegetables, however an inverse association was presented. Thus, it is considered that the present work provides an important contribution to the literature on psychological processes of food parenting practices and potential prevention to childhood obesity and that the goal of determining maternal practices in Brazil and how they influence food consumption by children 18 months to 8 years was fulfilled.
\end{abstract}

Keywords: feeding behaviour, feeding, childhood, eating habits formation, maternal influence. 


\section{Lista de Figuras}

Figura 1 - Níveis de influência sobre os hábitos alimentares 22

Figura 2 - Fatores de influência dos pais sobre o consumo alimentar da criança

Figura 3 - Modelo conceitual da influência parental no comportamento alimentar da criança e subsequente status de peso - adaptado de Birch e Davison (35).

Figura 4 - Etapas de tradução e adaptação cultural de um instrumento, de acordo com Beaton et al (2000). 48

$\underline{\text { Artigo } 2}$

Figura 5 - Perfil de consumo de frutas, verduras cozidas, salada e a média de hortaliças por crianças de 18 meses a 8 anos. 100

Figura 6 - Perfil de consumo de frutas, verduras cozidas, salada crua e a média de hortaliças pelas mães. 100 


\section{Lista de Tabelas}

Tabela 1 - Participação da amostra por região do Brasil. 55

Tabela 2 - Características sociodemográficas da população do estudo "Validação do instrumento Comprehensive Feeding Practices Questionnaire (CFPQ) com mães brasileiras".

Tabela 3 - Participação da amostra por unidade federativa do Brasil. 57

Tabela 4 - Características sociodemográficas da população do estudo "Práticas maternas e outros determinantes relacionados ao consumo de frutas e hortaliças por crianças de 18 meses a 8 anos". 58

Tabela 3 - Cálculo do Coeficiente de Variedade de Conteúdo de cada item $\left(\mathrm{CVC}_{\mathrm{c}}\right)$ e do questionário $\left(\mathrm{CVC}_{\mathrm{t}}\right)$ e apresentação da classificação das dimensões teóricas pelos juízes 72

Tabela 4 - Matriz fatorial Pattern. 77

Tabela 5 - Média, desvio padrão, assimetria e curtose (achatamento) dos 9 fatores do CFPQ e das 3 escalas de atitude relacionadas. 80

Tabela 6 - Correlações (Pearson) entre os nove fatores. 81

Tabela 7 - Correlações (Pearson) entre os fatores do CFPQ e escalas de atitudes relacionadas.

Tabela 8 - Comparação da estrutura fatorial de estudos realizados conduzindo a análise fatorial no CFPQ. 84

Tabela 11 - Correlação de Pearson entre o consumo de verduras cozidas, salada crua, frutas e os determinantes relacionados à alimentação infantil........ 101

Tabela 12 - Etapas do método stepwise da RM para predição do consumo de Frutas e determinantes da alimentação infantil. 102

Tabela 13 - Etapas do método stepwise da RM para predição do consumo de verdura e determinantes da alimentação infantil. 104 
Tabela 14 - Etapas do método stepwise da RM para predição do consumo de salada crua e determinantes da alimentação infantil. .............................. 105

Tabela 15 - Correlação Pearson entre o consumo de verduras cozidas, salada crua e frutas e variáveis Independentes. 152 


\section{Lista de Quadros}

Quadro 1 - Estágios de desenvolvimento infantil e suas principais influências em relação ao comportamento alimentar. (Proposto por Gibson et al (1)) ....... 23 


\section{Sumário}

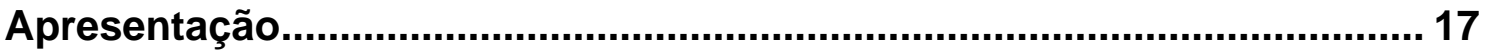

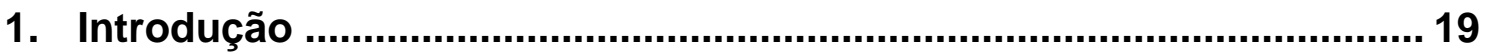

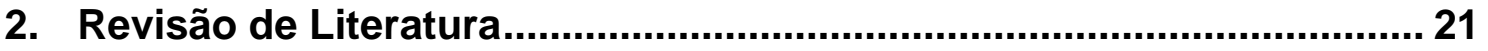

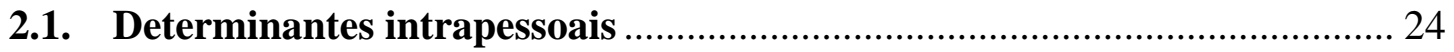

2.2. Determinantes interpessoais .................................................................. 26

2.2.1. Controle da alimentação pelos pais................................................... 29

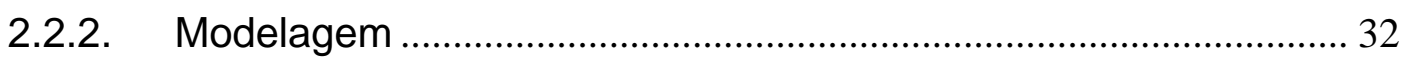

2.2.3. Ambiente: Disponibilidade e acesso de alimentos em casa.......... 34

2.2.4. Uso da comida como recompensa .................................................... 34

2.2.5. Controle da alimentação feito pela criança ........................................ 36

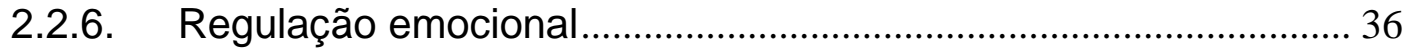

2.2.7. Incentivo ao equilíbrio e variedade: Eu incentivo uma alimentação equilibrada e variada ..................................................................................... 37

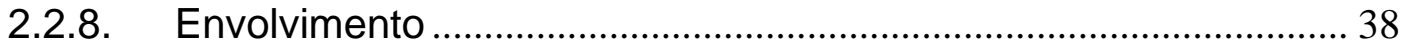

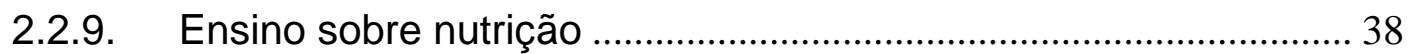

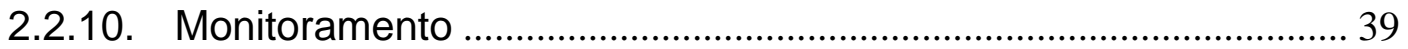

2.2.11. Compartilhamento de refeições em família ..................................... 40

2.3. Determinantes situacionais ....................................................................... 41

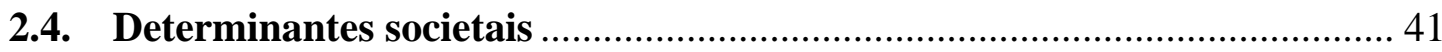

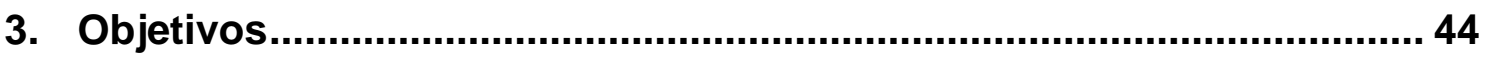

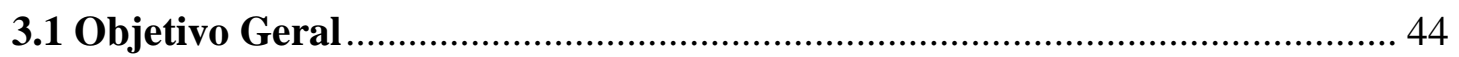

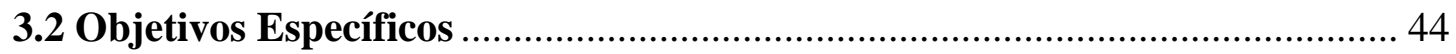

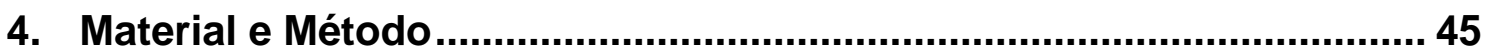

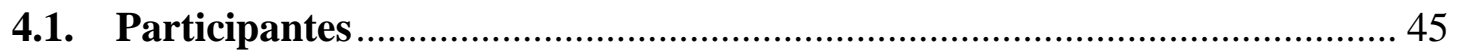

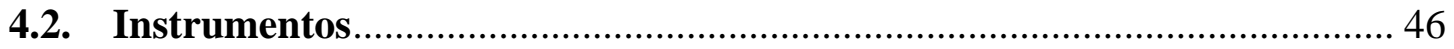




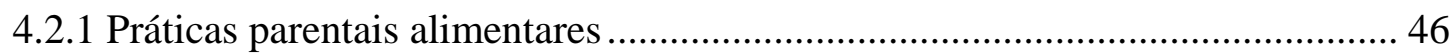

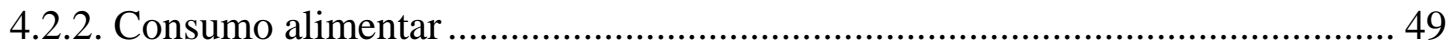

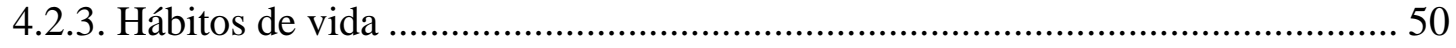

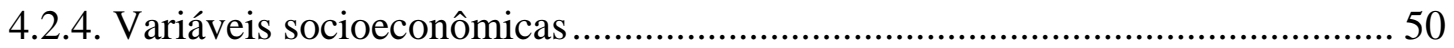

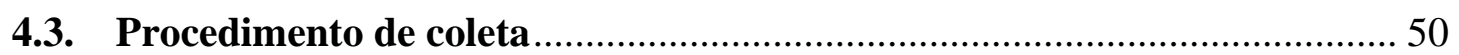

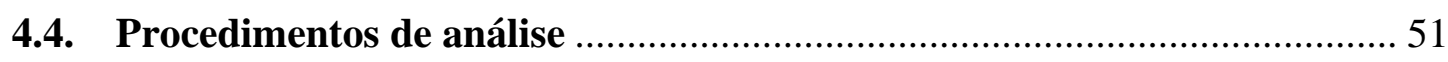

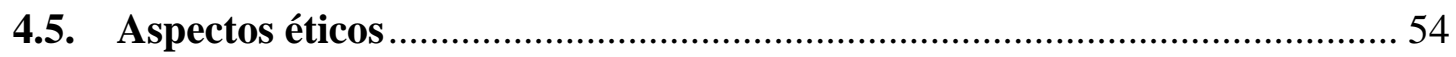

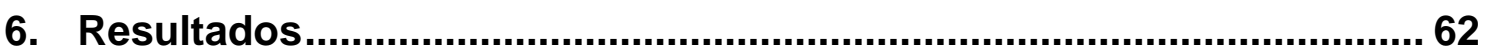

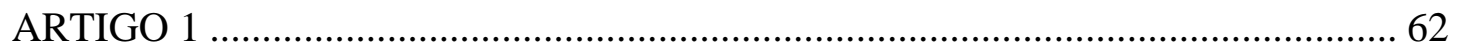

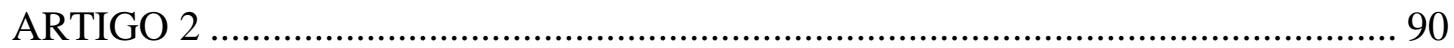

7. Considerações finais .......................................................................113

8. Referências Bibliográficas ................................................................. 117

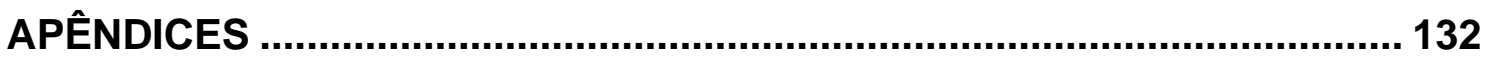

Apêndice A - Instrumento aplicado (Online) ............................................. 133

Apêndice B - Termo de Consentimento Livre e Esclarecido ...................... 147

Apêndice C - Modelo fatorial final: CFPQ adaptado para a população

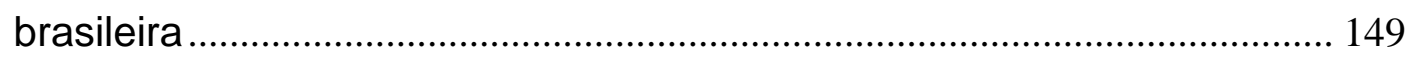

Apêndice D - Tabela de Correlação Pearson entre o consumo de verduras cozidas, saladas crua e frutas e variáveis independentes......................... 152

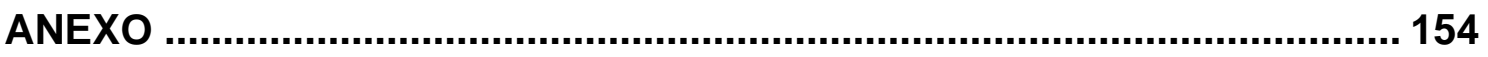

Anexo 1 - CFPQ original em inglês......................................................... 155 


\section{Apresentação}

As motivações para a realização desta dissertação surgiram desde a graduação em Nutrição, com o crescente interesse pela alimentação infantil e os fatores que estão relacionados a ela. Considerando a infância como sendo um período de constante desenvolvimento e aprendizado, em que as crianças estão descobrindo o mundo e se descobrindo como seres pertencentes ao mundo, ressalta-se a importância das intervenções de saúde serem realizadas desde tenra idade. Os hábitos alimentares ainda estão em formação e podem perdurar durante toda a vida, assim como questões de saúde e estado nutricional. Além disso, mudanças de hábitos na infância são mais flexíveis do que na fase adulta.

Reconhecendo o importante papel da família e principalmente dos pais na formação dos hábitos alimentares, iniciou-se a ideia de se entender melhor como eles influenciam a alimentação das crianças e, a partir disso, como as suas práticas poderiam ser potencializadas no sentindo de promover saúde e alimentação saudável para seus filhos, formando adultos saudáveis no futuro.

Essas motivações se tornam ainda maiores frente ao cenário epidemiológico e alimentar atual, com o crescente aumento do sobrepeso e obesidade, inclusive na infância e mudanças de hábitos alimentares tradicionais, como frutas e hortaliças, para excesso de alimentos ultraprocessados, concomitante com hábitos de vida acelerados e pouca valorização do cozinhar, de se alimentar à mesa e em família.

Levando esses aspectos em consideração, de modo a atingir os objetivos traçados, essa dissertação está estruturada da seguinte forma:

Primeira Parte: Composta por introdução, referencial teórico, objetivos e métodos. Nesta parte serão abordados os aspectos que justificam a elaboração da pesquisa, sua relevância teórica e descrição detalhada de como o trabalho foi realizado em termos metodológicos. O referencial teórico aborda os determinantes que influenciam a alimentação infantil, com ênfase nos determinantes interpessoais e mais especificamente, nas práticas parentais e sua relação com a alimentação das crianças. 
Segunda Parte: Serão apresentados dois artigos científicos como resultados do presente estudo. Os artigos foram elaborados em formato adequado para que sejam submetidos a revistas cientificas da área, a saber:

Artigo 1: Intitulado Validação do instrumento Comprehensive Feeding Practices Questionnaire (CFPQ) com mães brasileiras. Este artigo tem como proposta a validação de um instrumento de práticas parentais para a população brasileira, partindo do pressuposto que não existem instrumentos no Brasil que investiguem as diversas práticas parentais, sendo um assunto muito pouco discutido no país. Este artigo será submetido à revista Appetite (Qualis A2).

Artigo 2: Intitulado Práticas de alimentação maternas e outros determinantes relacionados ao consumo de frutas e hortaliças por crianças de 18 meses a 8 anos de idade. Com esse artigo, propõem-se apresentar as práticas maternas a partir do instrumento traduzido e validado e outros determinantes da alimentação infantil e como eles estão relacionados ao consumo de frutas e hortaliças pelas crianças. Este artigo será submetido à revista The Journal of Pediatrics (Qualis A1).

Terceira parte: São feitas considerações finais sobre os resultados apresentados no estudo.

Considerando a relevância do tema, o presente trabalho propõem-se a trazer contribuições importantes para a população infantil e para a saúde coletiva. 


\section{Introdução}

A infância é uma fase determinante para o estabelecimento de práticas e hábitos alimentares que persistem durante toda a vida $(1,2)$. É nesse período que ocorre o desenvolvimento e crescimento infantil, ao mesmo tempo em que está associado à saúde do adulto $(3,4)$, podendo representar um dos principais fatores de risco para doenças crônicas, como obesidade, diabetes tipo 2 (5) e doenças cardiovasculares (6) a longo prazo. Portanto, a educação e os cuidados alimentares devem começar desde cedo (7).

Além disso, dietas pobres e sedentarismo durante a infância estão relacionados ao aumento do sobrepeso e obesidade infantil (8). A prevalência de excesso de peso na infância tem aumentado substancialmente nas últimas décadas (9), sendo caracterizada como uma epidemia mundial. No Brasil, uma em cada três crianças com idade entre cinco e nove anos apresentam sobrepeso, de acordo com os dados da Pesquisa de Orçamento Familiar (POF) realizada em 2008 (10). Em outro estudo de base populacional, realizado em 2006, constatou-se uma prevalência de excesso de peso para altura de 7,3\% em menores de cinco anos (11).

O papel da família, sua forte influência no comportamento alimentar infantil, formação de hábitos alimentares e, consequentemente, no peso de crianças, é uma área de crescente interesse e tem-se mostrado importante na prevenção e no tratamento da obesidade infantil (12). Os pais influenciam na preferência alimentar das crianças e em seu padrão alimentar por meio da disponibilidade de alimentos em casa, pelo o uso de práticas de alimentação e pelo seu próprio comportamento alimentar (13).

As mães, por sua vez, exercem um importante papel no comportamento alimentar infantil a partir do momento em que tendem a exerce a atribuição de principais cuidadoras das crianças (14), estando em interação diretas com seus filhos em várias situações familiares, incluindo as refeições, e são predominantemente responsáveis pela alimentação das crianças (15). Além disso, seu poder de influência pode começar desde antes do nascimento da criança, durante a gravidez, pois há evidências de que aromas da dieta da mãe 
podem ser transmitidas para o bebê pelo líquido amniótico. Depois, os sabores e aromas de alimentos consumidos pelas nutrizes são transmitidos pelo leite materno (16).

Apesar das práticas parentais e maternas serem usadas com a melhor das intenções, elas podem ter efeitos positivos ou negativos em relação à formação de hábitos e comportamentos alimentares saudáveis e no peso das crianças $(12,17)$.

Tendo isso em vista, identificar as práticas parentais de alimentação e a complexidade de fatores que influenciam o comportamento alimentar de crianças e adolescentes é importante para auxiliar o desenvolvimento de intervenções efetivas para promoção de hábitos alimentares saudáveis de crianças, além da prevenção e tratamento da obesidade infantil.

Assim, o objetivo do presente estudo foi caracterizar as práticas maternas relacionadas à alimentação e outros determinantes sociodemográficos do consumo de frutas e hortaliças de crianças de 18 meses a 8 anos. 


\section{Revisão de Literatura}

A Infância é um período crítico para o desenvolvimento de hábitos alimentares e comportamentos que duram por toda a vida (1). Práticas inadequadas de alimentação infantil estão relacionadas, por exemplo, com maior ganho de peso, com o sobrepeso e baixa performance na escola $(18,19)$.

O excesso de peso e a obesidade infantil representam impactos negativos para a saúde da criança estando relacionados a dificuldades respiratórias, risco aumentado de fraturas, hipertensão, doenças cardiovasculares, resistência à insulina e maior estigmatização social (20), além de representarem um risco mais elevado de obesidade e doenças não transmissíveis na fase adulta (21).

No Brasil, o sobrepeso infantil triplicou desde a década de 1970 (22). O aumento da prevalências da obesidade infantil é reconhecido como um grave problema de saúde pública de relevância global (23). Esse cenário evidencia a necessidade de se compreender os hábitos e práticas alimentares na infância, com o objetivo de promoção da saúde e proteção do sobrepeso e obesidade infantil, direcionando o foco de intervenções para esse grupo e suas causas.

Com base em Bourdieu (24) e seu conceito de construção social do habitus, entende-se hábito alimentar como o conjunto de concepções, atitudes e práticas alimentares adquiridos por meio de experiências vivenciadas e pelo estabelecimento da relação com os alimentos. Em crianças, essas experiências incluem a exposição e acesso ao alimento, o condicionamento associativo, as práticas e comportamentos alimentares dos pais, a modelagem, a publicidade de alimentos, e principalmente através de processos de socialização. E assim, a fase pré-escolar deve receber atenção especial, já que as crianças estão particularmente sensíveis à aprendizagem sobre a aceitação dos alimentos (25).

Assim, para entender os hábitos e preferência alimentares infantis, é necessário compreender as premissas acerca da rede de influências da alimentação. Considerando a natureza multicausal envolvida na formação dos hábitos alimentares, Story et al (26) classificam tais níveis de influência em quatro categorias, sendo elas: 
a) Determinantes intrapessoais, fatores relacionados a escolhas e comportamentos alimentares incluindo atitudes, preferências e fatores biológicos e demográficos;

b) Determinantes interpessoais (ou ambiente social), que incluem interações com a família, amigos, entre outros na comunidade, e podem influenciar as escolhas alimentares através de mecanismos como modelagem, suporte social e normas sociais;

c) Determinantes situacionais, que incluem o ambiente onde pessoas comem ou procuram alimentos. A configuração física dentro da comunidade influencia quais alimentos estão disponíveis e acessíveis (Ex.: escolas, creches, restaurantes, lojas de conveniência); e

d) Determinantes societais exercem um papel indireto, mas têm um importante efeito em como as pessoas se alimentam, incluindo fatores socioeconômicos, normas culturais, publicidade de alimentos e políticas de alimentação e agricultura.

Story et al (26) ressaltam ainda que o hábito alimentar influencia e é influenciado pela interação dos quatro níveis, e o indivíduo tem posição ativa na construção do hábito. A figura 1 ilustra este modelo.

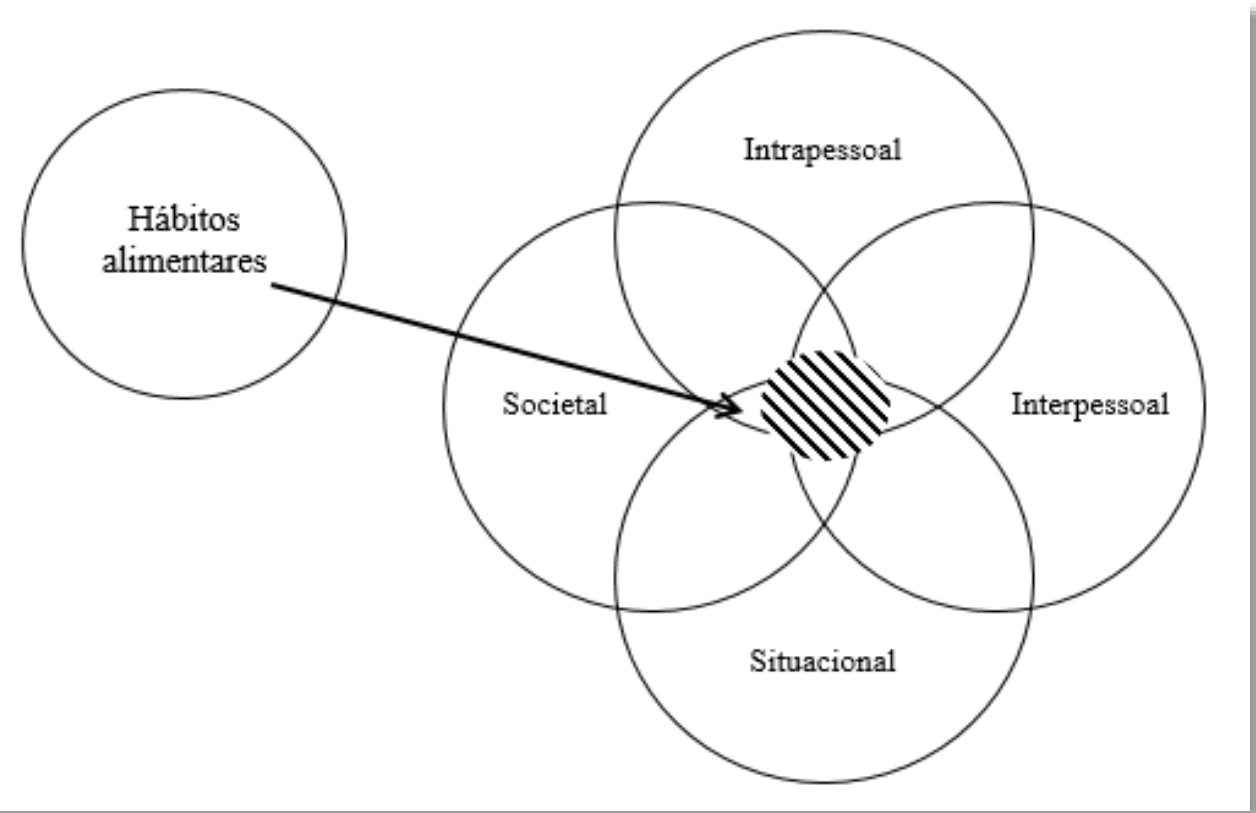

Figura 1 - Níveis de influência sobre os hábitos alimentares. 
O comportamento alimentar pode ser influenciado por um complexo conjunto de aspectos sensoriais, psicológicos, genéticos, temperamentais e sociais (família, pais, pares), culturais, ambientais e aspectos aprendidos. Gibson et al (1) investigaram as estratégias psicológicas e educacionais aplicadas aos comportamentos alimentares de crianças e propuseram um quadro que mostra os estágios de desenvolvimento infantil e as principais influências do comportamento alimentar de crianças (quadro 1). Essas influências serão discutidas a seguir.

Quadro 1 - Estágios de desenvolvimento infantil e suas principais influências em relação ao comportamento alimentar. (Proposto por Gibson et al (1))

\begin{tabular}{|c|c|c|c|c|}
\hline \multicolumn{5}{|c|}{ Influências dos Estágios de desenvolvimento } \\
\hline $\begin{array}{l}\text { Durante } \\
\text { Gestação }\end{array}$ & $\begin{array}{l}\text { 0-6 meses } \\
\text { (aleitamento } \\
\text { exclusivo) }\end{array}$ & $6-9$ Meses & 8 - 18 Meses & $\begin{array}{l}\text { Primeiros } \\
\text { anos }\end{array}$ \\
\hline $\begin{array}{c}\text { Genética }^{1} \text { e } \\
\text { dieta da }\end{array}$ & Genética $^{1}$ & 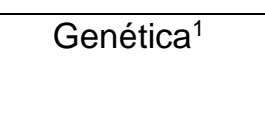 & Genética $^{1}$ & Genética $^{1}$ \\
\hline \multirow[t]{7}{*}{$m a ̃ e^{\star 2}$} & $\begin{array}{l}\text { Dieta da mãe } \\
\text { Duração da }\end{array}$ & $\begin{array}{l}\text { Gostar/ não } \\
\text { gostar inatos }\end{array}$ & $\begin{array}{c}\text { Gostar/ não gostar } \\
\text { inatos }^{1}\end{array}$ & $\begin{array}{l}\text { Neofobia } \\
\text { alimentar }^{1}\end{array}$ \\
\hline & $\begin{array}{c}\text { amamentação ou } \\
\text { alimentação por } \\
\text { fórmula }\end{array}$ & $\begin{array}{l}\text { Exposição do } \\
\text { alimento }^{3}\end{array}$ & $\begin{array}{l}\text { Práticas parentais } \\
\text { alimentares }^{2}\end{array}$ & $\begin{array}{c}\text { Práticas } \\
\text { parentais } \\
\text { alimentares }^{2}\end{array}$ \\
\hline & $\begin{array}{l}\text { Ambiente } \\
\text { alimentar da } \\
\text { família }^{3}\end{array}$ & $\begin{array}{c}\text { Duração da } \\
\text { amamentação } \\
\text { ou alimentação } \\
\text { por fórmula }\end{array}$ & $\begin{array}{l}\text { Exposição do } \\
\text { alimento }^{3} \\
\text { Comportamento } \\
\text { alimentar dos pais }{ }^{2}\end{array}$ & $\begin{array}{c}\text { Comportamento } \\
\text { alimentar dos } \\
\text { pais }^{2}\end{array}$ \\
\hline & & $\begin{array}{l}\text { Alimentação } \\
\text { complementar } \\
\text { Ambiente }\end{array}$ & $\begin{array}{c}\text { Comportamento } \\
\text { alimentar dos } \\
\text { irmãos }\end{array}$ & $\begin{array}{c}\text { Comportamento } \\
\text { alimentar dos } \\
\text { irmãos }^{2}\end{array}$ \\
\hline & & $\begin{array}{l}\text { alimentar da } \\
\text { família }^{3}\end{array}$ & Estilo parental² & Estilo parental $^{2}$ \\
\hline & & & $\begin{array}{l}\text { Duração da } \\
\text { amamentação ou } \\
\text { alimentação por }\end{array}$ & $\begin{array}{c}\text { Ambiente } \\
\text { alimentar da } \\
\text { família }^{3}\end{array}$ \\
\hline & & & fórmula & $\begin{array}{c}\text { Modelagem dos } \\
\text { professores/ } \\
\text { cuidadores }^{2}\end{array}$ \\
\hline
\end{tabular}


Ambiente alimentar

da família ${ }^{3}$

Modelagem de

professores e

cuidadores $^{2}$

*tanto planejamento fetal quando exposição de sabor e nutrientes por líquido amniótico

** por sabor transferido para o leite materno consumido

1 - Determinante intrapessoal

2 - Determinante interpessoal

3 - Determinante situacional

\subsection{Determinantes intrapessoais}

As influências intrapessoais são exemplificadas por fatores biológicos, como sexo e idade, fome, aspectos genéticos e hereditários, preferências alimentares e conhecimento e atitude sobre nutrição (8).

O consumo alimentar infantil é fortemente determinado pelas preferências alimentares. Estudos evidenciam que a preferência por frutas e hortaliças, por exemplo, foi um significante preditor para o consumo desses alimentos $(27,28)$. De acordo com Cooke (29), as crianças gostam do que elas conhecem e comem o que eles gostam.

A infância é um período crítico para o estabelecimento de padrões de consumo, hábitos alimentares e preferências alimentares (30). As preferências representam os alimentos que as crianças gostam e poderiam selecionar para comer dentre opções alternativas. Elas determinam as escolhas alimentares na infância, podendo se estender ao longo da vida. Essas escolhas estão relacionadas à composição e a qualidade da alimentação das crianças $(30,31)$.

Existem predisposições genéticas para se gostar ou não de determinados alimentos. Além disso, a sensibilidade de gostos e sabores podem ser herdados (32). Evidências sugerem que os neonatos aceitam melhor o sabor doce e rejeitam sabores azedos e amargos (33). Por volta dos 4 meses de idade, as crianças começam a expressar também a preferência por sabores salgados (34). 
No entanto, a preferência de crianças menores não é só inata, mas também pode ser fruto de processo de aprendizagem. Ou seja, as preferências alimentares podem ser influenciadas por predisposições biológicas e familiaridade de alimentos como resultado das experiências vividas $(1,35)$.

As crianças tendem a preferir alimentos familiares no seu ambiente. Assim, o consumo alimentar pode ser influenciado pela disponibilidade, acesso e exposição de alimentos em casa, (36), além da cultura, ambiente escolar, vendas locais e também pela televisão (31).

A exposição repetida dos alimentos é importante para o desenvolvimento de preferências por novos alimentos (37). A criança precisa ser exposta e ter experiência com novos alimentos para que possa se assegurar de que eles não tenham consequências desagradáveis depois da ingestão (20).

Evidências sugerem que a familiaridade com sabores e aromas se dão ainda no ambiente intrauterino, já que o aroma de alimentos consumidos pela mãe pode ser transmitido via líquido amniótico. Depois que nascem, continuam sendo expostos à experiências sensoriais durante o aleitamento materno, pois os bebês amamentados são expostos a sabores variados que vêm da dieta da mãe e são transmitidos pelo leite (20).

Um estudo sugere que a exposição a variedade de sabores pela amamentação pode facilitar a aceitação de alimentos sólidos durante o período de introdução alimentar, com bebês amamentados mostrando maior aceitação a novos alimentos do que aqueles amamentados com fórmula (38).

Cooke et al (39) notaram que a exposição de frutas e vegetais durante 0 período de introdução complementar está associado com subsequente aumento da frequência de consumo de frutas e hortaliças de crianças de 2 a 6 anos. Esse estudo respalda os achados de Skinner et al (40), que observaram dietas similares em crianças que foram expostas a uma ampla variedade de frutas durante os primeiros 2 anos de vida.

$\mathrm{Na}$ subseção que se segue serão apresentados os determinantes interpessoais que influenciam os hábitos alimentares infantis. 


\subsection{Determinantes interpessoais}

O desenvolvimento das preferências alimentares das crianças, além dos fatores inatos, é fortemente influenciado pela família e pelo ambiente. A família é a instituição social primária de influência das crianças. Então, é provável que muitos fatores de risco modificáveis para a obesidade infantil e hábitos alimentares inadequados tenham raízes substanciais dentro do contexto familiar (12).

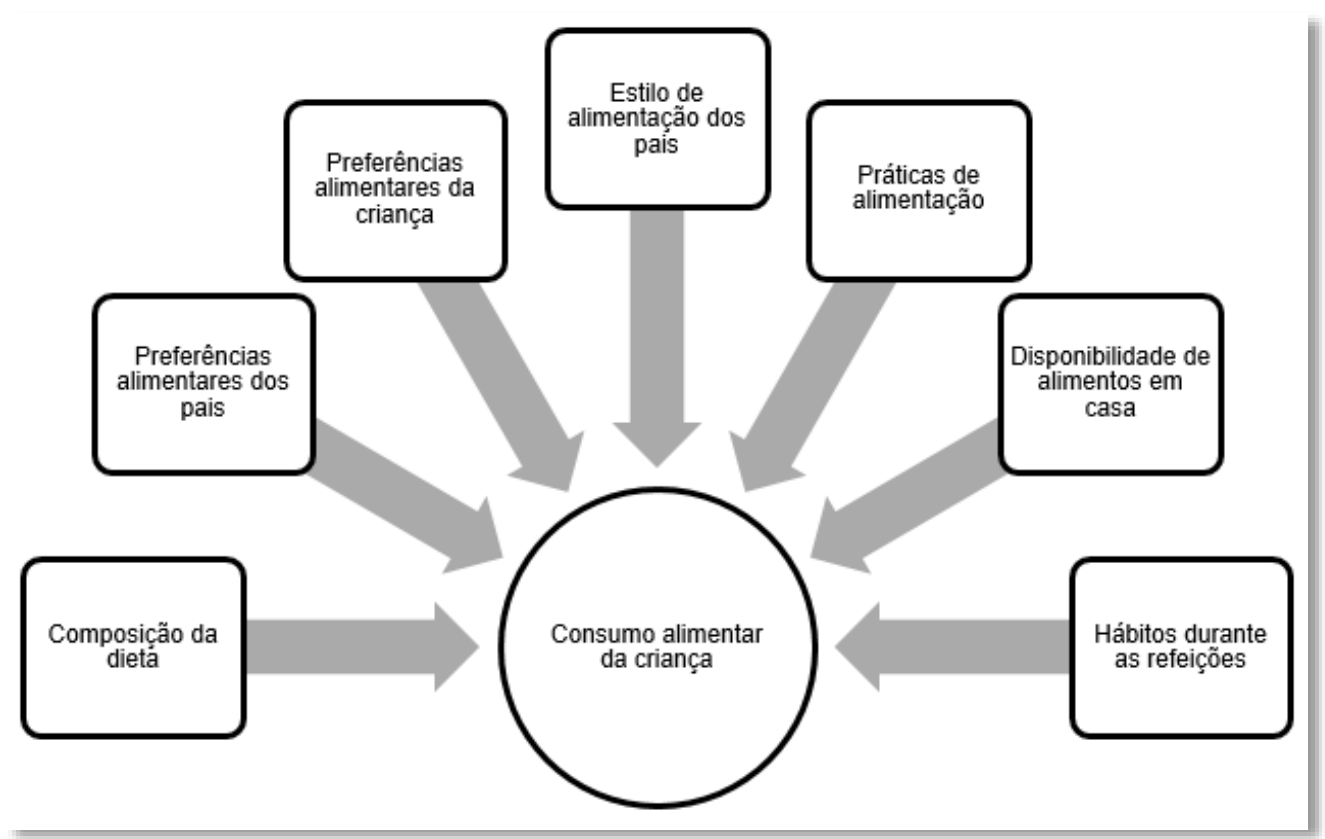

Figura 2 - Fatores de influência dos pais sobre o consumo alimentar da criança

O ambiente familiar influencia o consumo alimentar das crianças por meio de ampla variedade de fatores, como o estilo de alimentação dos pais, composição da dieta, preferências alimentares dos pais e das crianças, práticas dos pais de alimentação da criança, disponibilidade de alimentos em casa, consumo de alimentos fora ou de refeições feitas em casa e hábito e comportamento durante as refeições. Além disso, a família pode influenciar o consumo energético da criança, padrão e preferência por atividade física, encorajamentos da criança a ser ativa, hábitos de televisão, entre outros (41).

No entanto, essa influência dos pais sobre a alimentação das crianças não pode ser considerada exclusivamente unidirecional (41). De fato, as crianças, principalmente as menores, dependem dos pais para o acesso e 0 
consumo de alimentos e são influenciados por eles, no entanto, a resposta do comportamento da criança para esses alimentos também tem certa influência sobre o comportamento dos pais e da alimentação na casa. As preferências alimentares das crianças influenciam os alimentos que são disponibilizados em casa e oferecidos a eles, assim como as práticas parentais de alimentação $(31,41)$.

Ventura e Birch (12) propõem um modelo das vias de influência dos pais caracterizada por três construtos: os pais, a alimentação da criança e o peso da criança.

Os pais influenciam e são influenciados pelo peso e pela alimentação da criança por meio de estilos e práticas alimentares. A alimentação da criança contempla os seus estilos de alimentação, preferências alimentares e ingestão energética e o peso da criança inclui os índices de peso ou de mudança de peso da criança (12).

A literatura reconhece dois tipos de condutas parentais relacionadas à alimentação infantil: os estilos e as práticas parentais. Os estilos parentais de alimentação são descritos como o resultado de atitudes e comportamentos de interação com a criança no momento da refeição, com comportamentos alimentares característicos associado as eles. Representam uma característica dos pais e o clima emocional nas quais as práticas são aplicadas, variando de acordo com as dimensões de afeto, capacidade de resposta, exigência e grau de controle do comportamento da criança, sendo que os pais podem ser classificados como autoritários, indulgentes, negligentes ou autoritativos (democrático) (35). São um subtipo espercífico de estilos parentais que, com um sentido mais amplo, são caracterizados pela maioria das interações com a criança nos diferentes contextos e que pode refletir no momento da alimentação, embora não seja sempre o caso. Uma mãe que apresente regras estritas sobre o consumo de alimentos, tornando o momento da alimentação momentos disciplinares, por exemplo, poderia ser descrita como tendo um estilo autoritário de alimentação, mas não necessariamento um estilo parental autoritário em outros domínios parentais (42). Porém, estilos parentais de alimentação não são objetos deste trabalho. 
As práticas parentais alimentares, por sua vez, podem ser utilizadas pelos pais com diferentes estilos parentais ou estilo de alimentação (42). São estratégias de comportamentos específicos dos pais que variam de acordo com as suas preocupações sobre alimentação infantil e empregam o controle sobre o que, quanto e quando as crianças comem, podendo estar relacionadas a fatores extrínsecos, como o ambiente, ou intrínsecos, como a preocupação com o peso da criança (12). A Figura 3 apresenta de forma ilustrativa a influência parental no comportamento alimentar da criança e subsequente status de peso e suas vias de interação (adaptado de Birch e Davison (35)).

Exemplos desses comportamentos incluem a pressão para a criança comer, o uso da comida como recompensa, restrição ao acesso de selecionados alimentos ou grupos de alimentos, modelagem ou uso da comida como pacificador ou controle (12). As práticas podem diferir entre irmãos em uma mesma família, dependendo da idade da criança, do sexo, do comportamento alimentar e do peso, por exemplo, sendo assim, responsivas ao contexto (35).

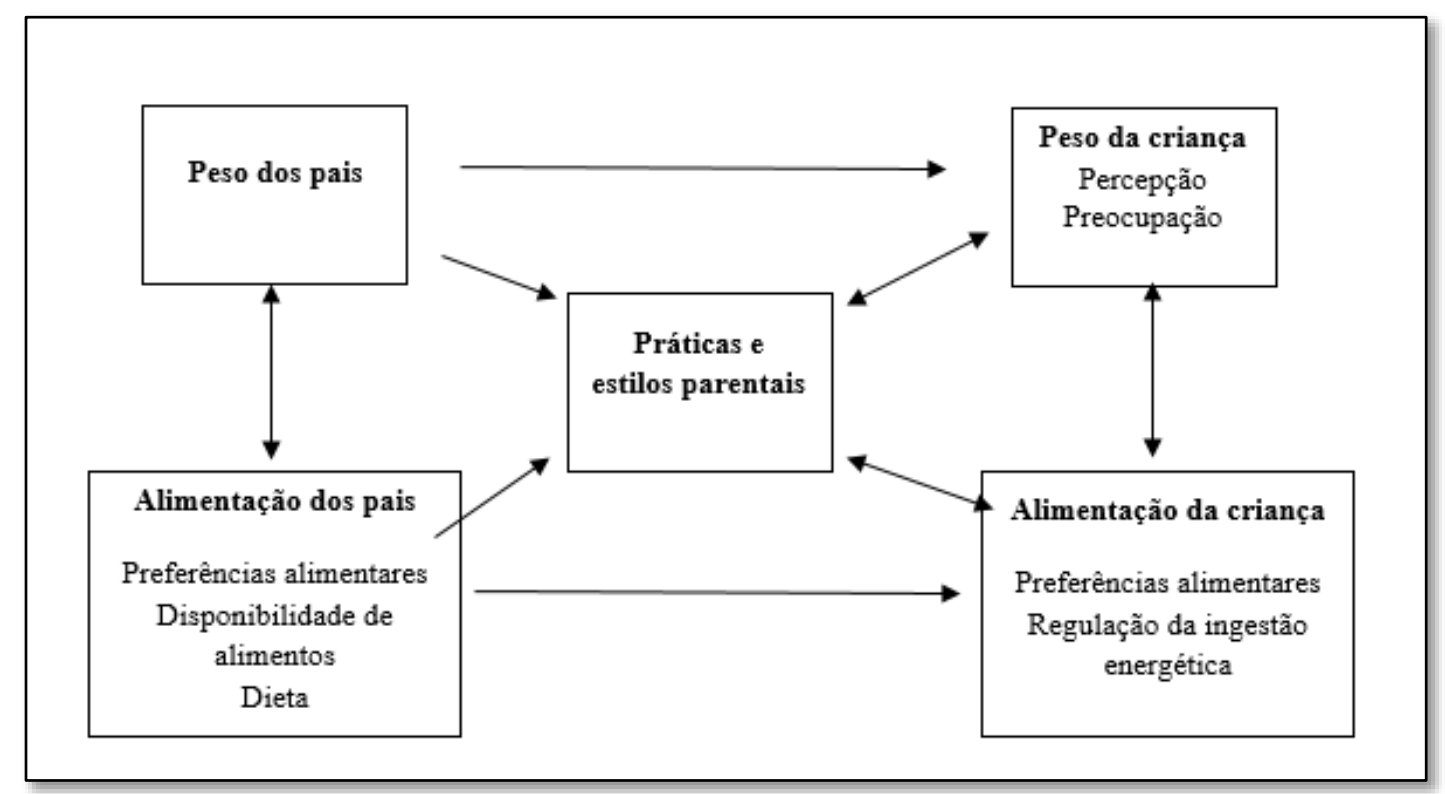

Figura 3 - Modelo conceitual da influência parental no comportamento alimentar da criança e subsequente status de peso - adaptado de Birch e Davison (35).

Devido à importância das práticas parentais, muitos pesquisadores têm criado e validado instrumentos de avaliação dessas práticas, com o objetivo de estudar o seu impacto sobre o consumo alimentar das crianças, preferências alimentares, estilos de alimentação ou aspectos antropométricos (42-44). 
As práticas parentais mais predominantemente estudadas são o uso de restrição e controle da ingestão alimentar, avaliadas pelo Child Feedind Questionnaire (CFQ), desenvolvido por Birch e colaboradores (43). Este instrumento foi elaborado para avaliar as percepções parentais e preocupações em relação à obesidade infantil, assim como as atitudes e práticas de alimentação da criança. No entanto, ele se limita a utilizar as práticas de restrição, pressão para comer e monitoramento dos pais.

Assim, frente à necessidade de um entendimento mais completo das interações que compões as práticas do pais, em 2007 Musher-Eizenmann e Holub (46) desenvolveram um instrumento que se propõe a avaliar os comportamentos de alimentação infantil dos pais de forma mais abrangente, com base no CFQ e no Preschooler Feeding Questionnaire (PFQ) (47).

O Comprehensive Feeding Practices Questionnaire (46) avalia 12 práticas de alimentação infantil que podem ser utilizadas pelos pais, sendo elas: pressão, restrição para manter a saúde, restrição para manter o peso, exemplo dos pais, ambiente, uso da comida como recompensa, controle da criança, regulação emocional, incentivo ao equilíbrio e variedade, envolvimento, ensino sobre nutrição e monitoramento. Essas práticas serão apresentadas a seguir em maiores detalhes.

\subsubsection{Controle da alimentação pelos pais}

Embora práticas de controle da alimentação dos filhos seja largamente utilizadas pelos pais com a intenção de garantir uma alimentação balanceada, estudos têm apresentado efeitos indesejáveis dessas práticas, estando indiretamente associados com o excesso de peso em crianças (41).

De acordo com Costanzo e Woody (48) os pais são mais propensos a exercer níveis mais elevados de controle quando estão preocupados com o desenvolvimento, saúde e/ou peso da criança, quando percebem problemas para comer ou problemas de peso, com base no histórico familiar ou em outros fatores de risco ou quando não acham que a criança é capaz de ter auto controle de sua alimentação. 
Birch e colaboradores (43), descrevem dois tipos de controle da alimentação:

1. Restrição: restringir o acesso da criança a alimentos não saudáveis ou a quantidade de alimento; e

2. Pressão para comer: pressionar a criança a comer alimentos saudáveis (comumente frutas e hortaliças) e pressão para comer maior quantidade de comida.

Evidências mostram que pais que exercem maior grau de controle sobre a ingestão de seus filhos, possuem crianças que demonstram habilidade diminuída em regular a sua ingestão energética. (49).

No entanto, esses efeitos não são consenso. Wardle e colaboradores (45), em um estudo com mães obesas e não obesas de crianças, ressaltaram o fato de que certa utilização do controle é provavelmente parte essencial do gerenciamento da alimentação infantil.

Ogden, Reynolds e Smith (50), por sua vez, mostram que além de restringir e pressionar a criança a comer mais ou de forma mais saudável, existem outras formas menos evidentes de controle da alimentação infantil como, evitar ambientes que vendem alimentos não saudáveis e/ou evitar a compra de alimentos não saudáveis para casa, ou ainda limitar o consumo de alimentos não saudáveis na frente da criança.

A restrição e a pressão para comer são contemplados em diversos tipos de instrumentos para avaliação do controle dos pais $(35,45)$ e são largamente estudados, quando comparados à outras práticas parentais. Em contraste, 0 segundo tipo de controle, menos detectado pela criança, não é medido pelas escalas já existentes, mas também possuem um papel importante na forma como os pais influenciam o comportamento alimentar das crianças e podem ser estratégias mais efetivas do que restrições "evidentes", aonde as crianças sabem que os alimentos estão sendo retidos (50). A seguir, os dois tipos de controle da alimentação, restrição e pressão para comer, serão detalhados.

- Restrição: "Coma menos! Desse jeito você vai engordar! " 
Evidências mostram que a utilização da restrição da alimentação está associada com maior peso infantil (50-53). O aumento do desejo pelos alimentos restringidos $(52,54)$ e o fato de comer na falta de fome em crianças pequenas também apresentaram relação com essa prática $(55,56)$.

Em um estudo de revisão realizado em 2008, de seis artigos transversais avaliados sobre a restrição da alimentação infantil, todos tiveram associação com a alimentação. Estudos Iongitudinais mostraram relação entre o aumento do consumo de alimentos restringidos pelas crianças e o excesso de peso e maior ganho de peso infantil, além do aumento do consumo de alimentos palatáveis, que são, na grande maioria das vezes, alimentos não saudáveis (12)

A restrição também apresenta impacto no consumo de alimentos saudáveis. Coulthard e Blisset (57) apresentam uma relação negativa entre a restrição materna e o consumo de frutas e hortaliças.

- Pressão para comer: "Só saia da mesa quando terminar todos os vegetais do prato".

O uso frequente de pressão para comer está associado à diminuição da preferência da criança pelo alimento no qual está sendo pressionada, além da redução de sua ingestão (12). Estudos mostram ainda que a pressão para comer, apesar de apresentar associação positiva com a ingestão alimentar da criança $(58,59)$, pode ter uma associação inversa com o seu peso (60-63) e associação positiva com maior duração da refeição (59), além de menor qualidade e variedade de alimentos consumidos (13).

O uso dessa prática é mais comumente relatado por pais que percebem seus filhos como muito magros (64) e/ou crianças com seletividade alimentar $(65,66)$ com o objetivo de aumentar sua ingestão calórica. Pais que percebem seus filhos como acima do peso relatam menos uso de pressão durante a alimentação $(61,67)$.

Fisher e colaboradores (13) encontraram que o consumo de frutas, hortaliças e nutrientes por meninas de 5 anos esteve negativamente associada com o uso da pressão, indicando que a pressão para comer pode não ser restrita a frutas e hortaliças, mas pode se estender ao consumo de outros alimentos 
saudáveis, ricos em nutrientes. Esse resultado também foi encontrado no estudo longitudinal realizado por Gregory, Paxton e Brozovic (68), o qual apresentou que o uso da pressão para comer por mães de crianças de 1 ano esteve associada com menor frequência de consumo de frutas e hortaliças 1 ano depois.

Além disso, evidências mostram que essa prática pode estar relacionada à diminuição da habilidade de auto regulação da ingestão da criança $(69,70)$.

Batsell and Brown (71) e Batsell (72) sugerem que crianças que percebem que estão sendo forçadas a consumir certos alimentos desenvolvem uma "aversão" para eles, pois elas os associam com experiências negativas de alimentação. Por outro lado, em um estudo realizado por Zeinstra et al (17), o uso da pressão para comer esteve positivamente relacionado ao consumo de hortaliças e inversamente associado ao consumo de frutas, achados também encontrados por Wind et al (73). O primeiro autor explica esse fato por conta da preferência inata por sabores doces, de forma que a pressão para comer pode resultar em reactância ou diminuição da motivação interna de consumir frutas, mas como sabores mais amargos, no caso dos vegetais, são geralmente rejeitados pelas crianças, a motivação externa, no caso a pressão para comer, podem trazer efeitos positivos no consumo desses alimentos.

Gregory, Paxton e Brozovic (68) complementam o fato de que a pressão para comer pode ser uma estratégia efetiva num primeiro momento, mas que as crianças podem aprender a resistir à pressão com o passar do tempo, tendo um impacto negativo no consumo de alimentos pressionados.

\subsubsection{Modelagem}

Evidências sugerem que 0 papel da modelagem parental no comportamento alimentar infantil é de grande importância (74). Observar um modelo confiável se alimentando de determinado alimento aumenta as chances de crianças provarem esse alimento, por facilitação social. Depois de degustar repetidamente esse alimento, as crianças são mais propensas a aceitá-lo em sua dieta $(75,76)$. 
Vários estudos tem mostrado a relação positiva entre a modelagem de alimentos saudáveis pelos pais e a ingestão alimentar de crianças e o aumento da preferência por frutas e hortaliças $(39,77,78)$. Essa prática também pode estar associada ao alcance de recomendações alimentares adequadas pelas crianças (74). Estudos longitudinais suportam as evidências de estudos transversais de que a modelagem de consumo de alimentos saudáveis prediz dietas saudáveis de crianças com o passar do tempo $(79,80)$.

No entanto, os efeitos da modelagem não são necessariamente benéficos sempre: a criança também pode modelar alimentação não saudável observando seus pais ou pares (1).

Em um estudo transversal de crianças em idade escolar, a modelagem dos pais percebida pelos filhos apareceu correlacionada significativamente com o consumo de frutas e hortaliças e a intenção de consumi-los pela criança (81). Esses achados corroboram com o estudo desenvolvido por Gregory, Paxton e Brozovic (68).

Destaca-se ainda que estudos experimentais têm mostrado que ver outras pessoas comendo determinado alimento é mais eficaz ao fazer com que crianças experimentem novos alimentos do que simplesmente apresentá-lo a elas. (75). No entanto, nem todos os estudos têm achados semelhantes. Matheson, Robinson, Varandy \& Killen (60), por exemplo, encontraram que o papel da modelagem parental de alimentos saudáveis não é significantemente associado com a ingestão de alimentos saudáveis pelas crianças. Outros estudos encontraram associação significativa dessa prática com o consumo de frutas e hortaliças em crianças em apenas um dos sexos ou dependendo de sua classificação do estado nutricional $(82,83)$.

Estudos indicam ainda que essa estratégia pode ser mais ou menos eficaz dependendo do relacionamento entre o modelo e o observador e a resposta emocional do modelo (84). Isso pode ser explicado, por exemplo, em um estudo experimental com crianças de 3 a 5 anos de idade, em que a modelagem só teve sucesso em aumentar a aceitação das crianças se o modelo expressasse 
perceptível deleite ao experimentar o alimento, sendo que a modelagem silenciosa não foi efetiva (85).

\subsubsection{Ambiente: Disponibilidade e acesso de alimentos em casa}

Práticas parentais que aumentam a disponibilidade de alimentos saudáveis em casa é um importante fator de influência para o consumo de alimentos saudáveis pela criança. A ingestão de frutas e vegetais pelos pais, por exemplo, pode ser um indicador de aumento da disponibilidade e acesso de frutas e hortaliças em casa (79).

Crianças tendem a escolher alimentos que the são familiares e estejam disponíveis em casa, pois estes são expostos mais constantemente e estão inseridos em sua rotina $(86,87)$. Pesquisas realizadas por Cullen et al (80) e Birch e Fisher (20) ressaltam o fato, mostrando que a ingestão de frutas e hortaliças é mais elevada se estes alimentos são disponíveis e prontos para o consumo em casa, opinião compartilhada também por Patrick e Nicklas (86).

O aumento da disponibilidade de alimentos saudáveis (principalmente frutas e hortaliças) em casa tem sido mostrado como forte preditor do consumo de frutas e hortaliças em crianças em idade escolar e adolescentes (88). Além disso, a acessibilidade da criança e a exposição de alimentos saudáveis, assim como suas preferências por frutas e hortaliças são determinantes para 0 consumo desses alimentos (13).

\subsubsection{Uso da comida como recompensa}

Usar a comida como recompensa é um meio comum para incentivar determinado comportamento. No entanto, estudos têm mostrado que essa prática pode ter efeitos negativos para o comportamento alimentar (89). Principalmente quando o uso da comida como recompensa pelo pais está relacionada a alimentos pouco saudáveis $(90,91)$ e consumo de refrigerantes (90).

A utilização de alimentos como consolo ou recompensa dos pais (90) pode estar relacionado a fatores associados à alimentação pouco saudável ou ganho de peso em crianças. Oferecer comida como recompensa ou como punição 
coloca importância indevida em certos alimentos e pode ter efeitos negativos que levam à obesidade ou comportamentos alimentares indesejáveis (30).

O uso de alimentos como reguladores de emoção também está associado com a redução da capacidade de regular a ingestão energética, principalmente relacionada às sensações de fome e saciedade (46). Sugere-se ainda que as recompensas extrínsecas incentivam um bom comportamento apenas transitoriamente (89).

Esse tipo de prática pode resultar em uma diminuição da motivação interna da pessoa ao executar determinada tarefa quando realizado sem recompensa, sendo perdido o interesse pelo comportamento recompensado. Assim, recompensas extrínsecas precisariam ser continuamente oferecidas para que haja motivação para realizar essa determinada tarefa ou comportamento (92-94). No entanto, os pais muitas vezes alegam sucesso no uso desse tipo de estratégia (95).

Em um experimento realizado por Mikula (94), em que crianças de 4 a 7 anos que comessem um alimento $x$ seriam recompensadas com um alimento $Y$, foi observado que a preferência e a escolha aumentou para 0 alimento $Y$, enquanto a preferência pelo alimento $\mathrm{x}$ diminuiu imediatamente, mas retornou 6 meses depois. Em um estudo similar, usando "snack foods" como moderador, observou-se que a preferência pelo alimento $X$ foi diminuída, mas a preferência pelo "snack food" não aumentou (96).

Em contraponto, em um estudo com crianças de 3 a 5 anos, o efeito de receber um alimento como recompensa e receber atenção de um adulto quando comendo determinado alimento foram comparados. Os resultados mostram que a preferência pelo alimento aumentou em ambas as condições e permaneceu 6 meses depois (97).

Recompensar a criança pelo consumo de determinados alimentos (exemplo, "se você comer o brócolis, poderá comer sobremesa") está relacionada com o aumento do consumo desse primeiro alimento (69), no entanto, a preferência por ele tende a diminuir $(92,98)$. Porém, sugere-se que usar recompensa pode ser uma boa estratégia para encorajar a escolha de 
alimentos saudáveis, desde que a recompensa não seja um alimento não saudável (1).

O elogio verbal tem um apelo intrínseco, bem como conveniente, e pode estar relacionado com o aumento da preferência por alimentos saudáveis. Além disso, alimentos como frutas e hortaliças devem ser expostas, quando possível, com uma aparência visual mais atrativa às crianças, chamando atenção para esses alimentos e, consequentemente, aumentando o seu consumo (99).

\subsubsection{Controle da alimentação feito pela criança}

Essa prática caracteriza-se pela permissão dos pais para que as crianças controlem sua alimentação (46). Permitir que crianças pequenas controlem suas próprias escolhas alimentares pode estar relacionado ao consumo de alimentos não saudáveis e ter um efeito negativo sobre a qualidade das refeições da família. Essa prática também pode estar relacionada ao uso de comida como recompensa $(46,100)$.

Um estudo com pais de crianças de 3 a 6 anos realizado no Irã revelou que crianças com maiores níveis de controle infantil da alimentação comiam menos frutas, hortaliças e produtos lácteos (101).

Hoer e colaboradores (100), em um estudo qualitativo com pais de crianças de 3 a 5 anos, observaram que o controle da criança nas refeições provavelmente afeta negativamente a auto eficácia dos pais e a qualidade do ambiente alimentar, ou seja, os pais sentem menos que podem afetar positivamente o comportamento da criança. Assim, são mais propensos a dar o que os filhos desejam e evitam oferecer certos alimentos considerados saudáveis.

Kiefner-Burmeister e colaboradores (102) evidenciaram ainda que mães com crianças do sexo masculino foram significativamente mais propensas a permitir que seu filho controle sua própria alimentação do que do que mães com crianças do sexo feminino.

\subsubsection{Regulação emocional}

Define-se regulação emocional como comer em resposta a emoções ou sentimentos negativos, como ansiedade, depressão, raiva e solidão, por 
exemplo, com o objetivo de diminuir sofrimento (103). Em adultos e adolescentes, essa prática está associada com ganho de peso, obesidade e maior consumo de doces com alta densidade energética e alimentos salgados $(104,105)$. Porém, pais de crianças menores, de 2 a 6 anos, relatam mais o baixo consumo de alimentos do que comer em excesso em resposta a aspectos emocionais (106).

Um recente estudo realizado com crianças de 5 a 7 anos mostrou que as crianças expostas ao procedimento de indução emocional consumiram significativamente mais calorias do que as crianças no grupo controle (107). No entanto, em estudo semelhante com crianças de 3 a 5 anos não foram encontradas significativas diferenças de ingestão de calorias entre crianças no grupo experimental ou controle. No entanto, quando essas crianças foram observadas 2 anos depois, encontrou-se efeito significativo da manipulação emocional de consumo de snacks na falta de fome (108).

Determinadas práticas de alimentação parental, como a restrição e recompensa de crianças com alimentos estão relacionadas a alimentos palatáveis como ferramentas que podem ser usadas para aliviar sentimentos negativos (108). Essa prática pode ensinar as crianças a usar o alimento de forma não nutritiva e tem sido mostrado que aumenta a ingestão energética em momentos de estresse (108).

\subsubsection{Incentivo ao equilíbrio e variedade: Eu incentivo uma alimentação equilibrada e variada}

O incentivo dos pais ao equilíbrio e variedade é caracterizado pelo incentivo dos pais para que crianças comam uma alimentação equilibrada e com ampla variedade de alimentos e está associada ao aumento do consumo de alimentos variados e saudáveis (109).

O consumo de uma alimentação equilibrada e variada é recomendada tanto pelo Guia Alimentar para a População Brasileira (110), quanto pelo Guia Alimentar para Crianças Menores de 2 anos (111) e está relacionado à promoção da alimentação saudável e formação de hábitos alimentares adequados.

De acordo com Kalantari e Doei (101), maiores níveis de incentivo ao equilíbrio e variedade estiveram relacionados ao maior consumo de grãos pelas 
crianças. Esses autores destacam ainda que essa prática é uma das abordagens mais comumente utilizadas pelas mães.

O incentivo está relacionado também com menores níveis de seletividade alimentar em uma amostra de crianças de 3 a 6 anos de idade (112). Em relação ao IMC, em um estudo realizado na França e nos Estados Unidos, verificou-se que o maior IMC da criança foi relacionado ao menor incentivo ao equilíbrio e variedade. Além disso, mães com maior IMC relataram menor uso dessa prática.

\subsubsection{Envolvimento}

Essa prática é definida como o incentivo dos pais para que as crianças se envolvam na seleção e preparo de alimentos (46). O envolvimento de crianças e adolescentes na compra, escolha e preparo dos alimentos está relacionado a aquisição de bons hábitos alimentares. Por meio da experiência vivenciada e pelo aumento da exposição dos alimentos, incentiva-se que eles conheçam e experimentem novos alimentos, conheçam novas formas de preparo, além de obter mais informações sobre os alimentos, como de onde eles vêm e como são produzidos. Outro aspecto importante de envolver as crianças no preparo é o ensinamento prático do compartilhamento de responsabilidades (110).

Em um estudo realizado por Carnel e colaboradores, com pais de crianças de 3 a 5 anos (113), observou-se que muitos pais davam a chance para que as crianças escolhessem o que comer, por exemplo, selecionando qual cereal queriam para o café da manhã ou o que queriam para o almoço entre uma gama de opções. As crianças poderiam participar tanto da escolha das compras de alimentos quanto o que comer dentre os alimentos comprados. No entanto, poucas crianças foram estimuladas a participar do preparo de alimentos.

Apesar dos benefícios dessa prática, em um estudo realizado com mães de crianças de 3 a 12 anos de idade, mães de meninas relataram significativamente maior envolvimento do que mães de menino (114).

\subsubsection{Ensino sobre nutrição}

Consiste no ensino dos pais sobre o valor nutricional dos alimentos e a importância de consumir alimentos saudáveis para incentivar hábitos alimentares saudáveis (46). Pais que ensinam seus filhos sobre alimentação 
saudável também incentivam equilíbrio e variedade de alimentos, modelam bons hábitos alimentares e tentam fornecer um ambiente alimentar saudável. (115).

Existem evidências de que menos ensinamentos sobre nutrição, está relacionado com maior IMC de crianças. Mães com maior IMC também relataram usar menos essa prática (116). Lauzon-Guillain e colaboradores (117) mostraram que a maior percepção dos pais sobre sua responsabilidade em relação à alimentação de seus filhos tendem a utilizar mais a prática de ensinálos sobre nutrição.

\subsubsection{Monitoramento}

Monitoramento é a prática em que os pais ficam atentos ao consumo de alimentos menos saudáveis, como doces, refrigerantes e "salgadinhos de pacote". Esta prática está correlacionada positivamente com a criação de ambientes alimentares saudáveis, modelagem e incentivo do equilíbrio e variedade, e negativamente ao uso do alimento para regulação emocional, alimento como recompensa e controle da criança (46).

Faith e colaboradores (51) mostram uma relação negativa entre o monitoramento da ingestão de alimentos ricos em gordura e o IMC das crianças, indicando baixo risco de ganho de peso. No entanto, outros estudos não encontraram relação significativa entre essa prática e a ingestão de alimentos pela mãe (118) e o IMC das crianças $(63,116,118)$.

De acordo com Blisset e Haycraft (119), um nível moderado de controle parental, como o uso de monitoramento do consumo de alimentos não saudáveis, é uma estratégia adequada para controlar o consumo alimentar de crianças. Em contraponto, segundo Johnson e Birch (49) e DiSantis e colaboradores (120), o monitoramento excessivo, assim como a restrição e a pressão para comer, práticas parentais centradas nos pais, podem ser considerados controles não responsivos da alimentação infantil, limitando a autonomia alimentar das crianças e prejudicando a resposta adequada de estímulos internos de saciedade e fome da criança, o que pode contribuir para o ganho de peso infantil. 
Pais que se sentem mais responsáveis pelos hábitos alimentares de seus filhos relatam mais monitoramento da ingestão alimentar das crianças (46). Em resumo, após a apresentação das 12 práticas parentais propostas por Musher (46), pesquisas mostram que práticas centradas nos pais e coercitivas (35) não são recomendadas. O uso em excesso de práticas de controle evidente dos pais, como a restrição e pressão para comer, assim como o uso da comida como recompensa e o uso da comida para controle de emoções podem influenciar negativamente os comportamentos alimentares das crianças, aumentando, assim, o risco de sobrepeso e obesidade infantil.

Assim, conhecer as abordagens de alimentação infantil dos pais e seus impactos na formação dos hábitos alimentares, no consumo de alimentos, no peso da criança e na regulação energética fornecem informações importantes para o desenvolvimento de intervenções de educação alimentar e nutricional para a prevenção da obesidade infantil.

\subsubsection{Compartilhamento de refeições em família}

Refeições em família tem sido mostradas como promotoras de alimentação saudável (30), protetoras do excesso de peso infantil (121) e de desordens alimentares (122). Em uma metanálise com crianças e adolescentes observou-se a redução de $12 \%$ de chance do excesso de peso com frequência de refeições em família de 3 ou mais refeições juntas por semana (123).

Estudos mostram que refeições em família estão relacionadas ao aumento da ingestão de grupos alimentares básicos (124) e maior consumo de frutas, hortaliças $(74,125)$, produtos lácteos e aumento da ingestão de nutrientes (8).

Isso pode ser explicado essencialmente pelo fato de que refeições compartilhadas são momentos oportunos para que os pais exerçam a modelagem de hábitos alimentares saudáveis (74).

A seguir, serão trabalhados os aspectos situacionais que influenciam a alimentação infantil. 


\subsection{Determinantes situacionais}

A escola, os restaurantes e os "fast foods" podem ter um grande impacto nas escolhas alimentares e qualidade da dieta de crianças e adolescentes (26). De acordo com Story (26), o ambiente influencia o comportamento alimentar principalmente pelo acesso e a disponibilidade dos alimentos. $O$ local onde as refeições são realizadas e o hábitos de assistir televisão durante as refeições também têm forte relação com os hábitos alimentares infantis.

Assistir TV durante a refeição é um forte preditor do consumo de alimentos não saudáveis, primariamente mediado pelo hábito de assistir TV da mãe e como isso afeta seu próprio consumo de alimentos, que, por sua vez, influencia o padrão de consumo alimentar de crianças na primeira infância (30).

Em um estudo realizado com 250 crianças com idade entre 8 a 12 anos de uma escola privada do Distrito Federal, verificou-se que $81,7 \%$ dos participantes tinham o comportamento frequente de assistir televisão durante as refeições, sendo que 20,6\% apresentavam sempre esse tipo de comportamento. O hábito de assistir televisão comendo esteve associado positivamente com 0 consumo de alimentos não saudáveis e negativamente com o consumo de alimentos saudáveis. Neste mesmo estudo ressalta-se ainda que pedir os alimentos apresentados na propaganda também prediz o consumo de alimentos não saudáveis a nível situacional (126).

\subsection{Determinantes societais}

Os determinantes societais apresentam influências substanciais em crianças e adolescentes, suas famílias, pares e a comunidade na qual eles vivem, apesar de apresentarem causas mais amplas e distais que os demais determinantes. As influências societais incluem a mídia em massa e propaganda, normas sociais e culturais relacionadas à alimentação, produção alimentar e sistemas de distribuição de alimentos, os quais influenciam a sua disponibilidade, além de políticas públicas e regulamentações relacionadas à alimentação (26). 


\section{Mídia televisiva}

No Brasil, em 2014 o tempo médio de exposição de crianças e adolescentes à televisão foi de 5 horas e 35 minutos por dia, segundo levantamento do Instituto Brasileiro de Opinião Pública e Estatística (Ibope Media), que registra a evolução do tempo dedicado à TV por crianças e adolescentes de 4 a 17 anos de todas as classes sociais e em 15 regiões metropolitanas do Brasil (127).

O consenso da American Academy Pediatrics sobre a Prevenção e tratamento da obesidade infantil recomenda que as crianças menores de 2 anos deveriam não ser expostas à televisão e que crianças com mais de 2 anos deveriam ter um limite diário de exposição de apenas 1 a 2 horas de programas de TV de qualidade ou de uso de tela (128). Em contraste a essas recomendações, uma pesquisa mostrou que aos 3 meses de idade, aproximadamente $40 \%$ das crianças regularmente assistem vídeos, DVDs ou televisão e 90\% das crianças com mais de 2 anos assiste TV diariamente (129)

O aumento do tempo que a criança passa em frente à televisão tem sido associado com o excesso de peso na primeira infância e em crianças em idade pré-escolar. Isso pode ser explicado pelo sedentarismo associado, ao substituir as atividades físicas pelo hábito de assistir televisão e pela quantidade e qualidade de alimentos consumidos ao assistir televisão (30). Entre crianças na primeira infância, assistir TV comendo esteve associado com maiores ingestões de calorias, consumo de bebidas açucaradas, fast food e menor consumo de frutas e hortaliças e grãos integrais, comparativamente a refeições consumidas sem a TV (130).

A mídia, particularmente a televisão, tem um enorme potencial de influência nos hábitos alimentares em crianças, tendo como base a modelagem (131), e em muitos momentos, podem ofuscar as influências da família. Propaganda de alimentos promovem mais frequentemente o consumo de alimentos menos saudáveis, incluindo snacks ricos em gordura e com alta densidade energética, e raramente características de escolhas saudáveis, como frutas e hortaliças. Isso é preocupante, uma vez que as crianças são mais 
propensas a pedir, comprar e consumir alimentos que eles tenham visto na televisão (8). A mídia em massa tem sido identificada com um importante fator de desenvolvimento do sobrepeso e do comportamento alimentar, particularmente em meninas jovens (132). 


\section{Objetivos}

\subsection{Objetivo Geral}

- Determinar as práticas de alimentação maternas e como elas influenciam o comportamento alimentar de crianças de 18 meses a 8 anos.

\subsection{Objetivos Específicos}

- Validar um instrumento de compreensão das práticas parentais de alimentação infantil para a população brasileira;

- Associar as múltiplas práticas alimentares maternas e outros determinantes ao consumo de frutas e hortaliças por crianças de 18 meses a 8 anos. 


\section{Material e Método}

Este é um estudo transversal do tipo Survey, com mães de crianças de 18 meses a oito anos, composto de duas etapas. Inicialmente realizou-se a validação do Comprehensive Feeding Practices Questionnaire (CFPQ) para o Brasil, por meio da análise fatorial. Em seguida, foi realizado um estudo para verificar a associação das múltiplas práticas maternas e outros determinantes ao consumo de frutas e hortaliças por crianças de 18 meses a oito anos.

\subsection{Participantes}

Na primeira etapa do estudo, participaram 844 mães de crianças de 18 meses a oito anos que aceitaram voluntariamente participar da pesquisa. $O$ critério adotado para a escolha da faixa etária e realização da pesquisa apenas com mães foi equivalente a Musher-Eizenman e Holub (46) em seu estudo da validação final do CFPQ.

Como critério de inclusão do estudo, os participantes deveriam ser mães de crianças de 18 meses a 8 anos, residentes no Brasil, alfabetizadas e com acesso à internet.

Foram excluídas as mães que não aceitaram participar da pesquisa, mães de crianças que não possuíam filhos na faixa etária do estudo, residentes em outros países e/ou com filhos que apresentassem condições especiais (exemplo: portadores de enfermidades ou distúrbios específicos relacionados à alimentação).

De acordo com Hair (133) para a validação de instrumentos são necessários de 5 a 10 sujeitos por item do instrumento, dessa forma, considerando os 49 itens do CFPQ deveriam ser selecionadas pelo menos 490 mães. Para esta amostra, a proporção é de 17 sujeitos por variável.

Para a segunda etapa, foram excluídas 163 participantes por apresentarem mais de $10 \%$ de dados faltosos por itens do instrumento. Dessa forma, participaram 681 mães de crianças de 18 meses a 8 anos que aceitaram voluntariamente participar da pesquisa. 


\subsection{Instrumentos}

Os dados foram coletados a partir de um instrumento auto administrado preenchidos pelas mães, contendo questões relacionadas aos hábitos alimentares infantis, às suas práticas em relação à alimentação de seu filho e outros hábitos de vida relacionados à alimentação, bem como seu consumo alimentar e o consumo alimentar da criança. Os instrumentos de medida serão detalhados a seguir.

\subsubsection{Práticas parentais alimentares}

As práticas parentais relacionadas à alimentação infantil foram obtidas por meio do Comprehensive Feeding Practices Questionnaire (CFPQ), um instrumento proposto por Musher-Eizenman e Holub (46) que se propõe a mensurar as múltiplas práticas parentais em relação à alimentação infantil (Anexo 1).

Este instrumento foi escolhido para o presente estudo por ser uma nova e mais completa instância de mensuração das práticas parentais alimentares, pois até então, as práticas mais comumente estudadas eram aquelas referentes ao controle da alimentação infantil.

O instrumento apresenta duas escalas do tipo Likert de 5 pontos, sendo uma delas de frequência, com respostas de "nunca" a "sempre" (itens 1 a 13) e outra de concordância, com respostas de "discordo totalmente" a "concordo totalmente" (itens 14 a 49). Ele é composto originalmente por 49 itens divididos em doze fatores, sendo eles:

- Controle da Criança: Pais permitem que a criança controle seu comportamento alimentar e as interações de alimentação entre ela e os pais;

- Regulação emocional: Pais usam a comida para regular o estado emocional da criança;

- Incentivo ao equilíbrio e variedade: Pais incentivam o consumo de uma alimentação equilibrada, incluindo alimentos variados e escolhas alimentares saudáveis;

- Ambiente: Pais disponibilizam alimentos saudáveis em casa; 
- Comida como recompensa: Pais usam a comida como recompensa para o bom comportamento da criança;

- Envolvimento: Pais incentivam o envolvimento da criança no planejamento e preparo das refeições;

- Exemplo dos pais: Pais demonstram ativamente alimentação saudável para a criança;

- Monitoramento: Pais monitoram a ingestão de alimentos pouco saudáveis pela criança;

- Pressão: Pais pressionam a criança consumir mais alimentos nas refeições;

- Restrição para Manter a Saúde: Pais controlam a alimentação da criança com o propósito de limitar a ingestão de alimentos menos saudáveis e doces;

- Restrição para controle de peso: Pais controle a alimentação da criança com o propósito de diminuir ou manter seu peso; e

- Ensinando sobre nutrição: Pais usam explícitas técnicas didáticas para incentivar o consumo de alimentos saudáveis.

Em 2013, O CFPQ foi traduzido para a língua portuguesa (Português do Brasil) a partir da metodologia de tradução - retradução proposta por Beaton e colaboradores (134) e Cassep-Borges et al (135) em um Trabalho de Conclusão de Curso do Departamento de Nutrição da Universidade de Brasília (136), ainda não publicado. Este procedimento foi realizado em quatro etapas, sendo elas: tradução, reunião de consenso, tradução reversa e validação de conteúdo pela técnica de juízes. A Figura 4 sintetiza as etapas realizadas.

Em relação à validação de conteúdo pela técnica de juízes, cada item foi avaliado pelos critérios de clareza de linguagem, pertinência prática e relevância teórica por três especialistas. A partir disso, observou-se que a maior parte dos itens apresentaram Coeficiente de Validade de Conteúdo total dos itens $\left(\mathrm{CFC}_{\mathrm{c}}\right)$ satisfatórios, ou seja, maior do que 0,8 . Os itens $1,2,3,4,8,36$ e 47 que apresentaram CFC entre 0,63 a 0,76 no critério clareza de linguagem foram adaptados. Todos os critérios avaliados apresentaram Coeficiente de Validade de Conteúdo total do questionário $\left(\mathrm{CVC}_{\mathrm{t}}\right)$ satisfatório. 

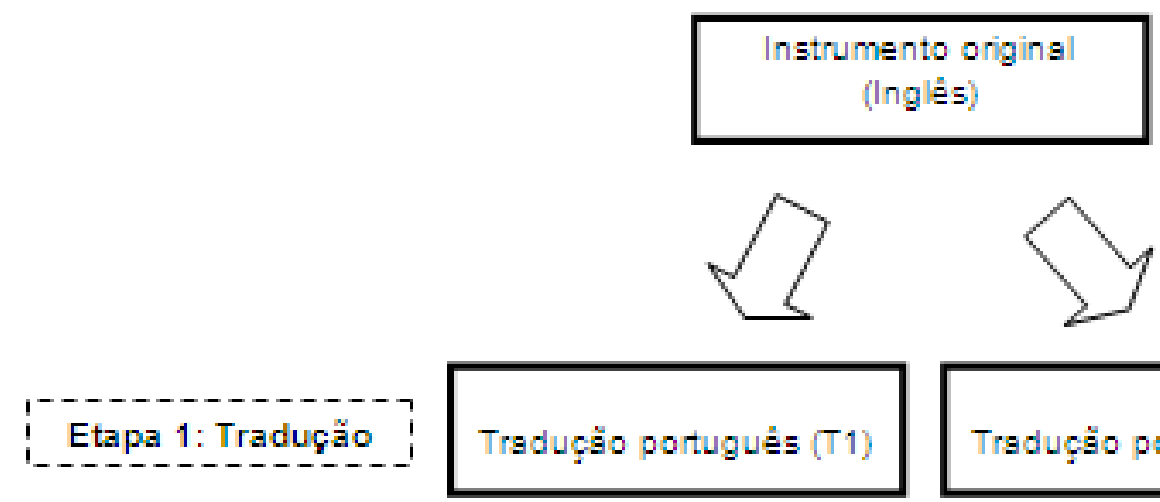

Traduçăo portugués (T2)
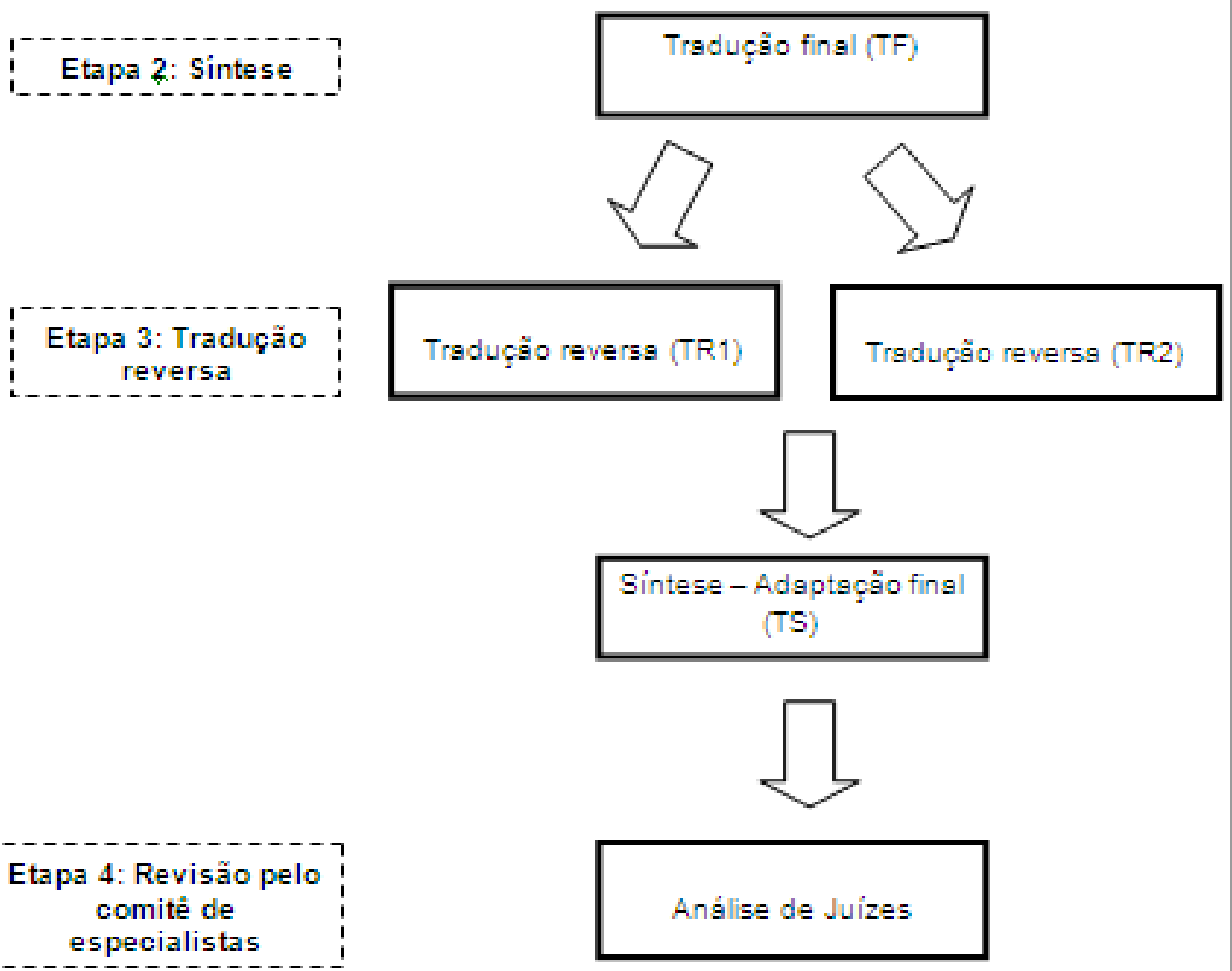

Figura 4 - Etapas de tradução e adaptação cultural de um instrumento, de acordo com Beaton et al (2000).

Quanto à dimensão teórica avaliada pelos juízes, o valor médio do coeficiente kappa foi 0,81, ou seja, satisfatório, de acordo com a classificação de Landis e Koch (137). 
Após a etapa de tradução, o instrumento foi submetido a um estudo piloto de reprodutibilidade do CFPQ para a população brasileira com uma subamostra com trinta e cinco mães de crianças de 2 a 5 anos em um Trabalho de Conclusão de Curso do departamento de Nutrição da Universidade de Brasília (138), ainda não publicado.

Além do CFPQ, como feito por Musher-Eizenman e Holub (46), as mães foram convidadas a responder itens de três escalas de atitudes relacionadas às práticas parentais, sendo elas a escala de preocupação com o excesso de peso da criança (3 itens), retirada do Child Feeding Questionnaire (CFQ) (43) e a Escala de Preocupação com o baixo peso da criança (3 itens) adaptada do CFQ e a Escala de Responsabilidade de alimentação da criança (3 itens).

\subsubsection{Consumo alimentar}

Para avaliação do consumo alimentar das crianças e da mãe foi utilizado - Questionário de Frequência Alimentar (QFA) desenvolvido por Molina et al (139), baseado em estudos realizados no Brasil com crianças (140) e adolescentes (141) e testado em uma subamostra de crianças de sete a dez anos $(n=91)$. Com o objetivo de melhor adequar o instrumento para a população alvo, o QFA foi adaptado, excluindo-se os alimentos peixe, maionese e suco natural do questionário original.

Dessa forma, o questionário em questão tem o objetivo de analisar marcadores de consumo alimentar saudável e não saudável, incluindo 14 alimentos, sendo eles o feijão, salada crua, frutas, leite e legume ou verdura (excluindo batata e aipim), como marcadores de alimentos saudáveis, e batata frita (incluindo a de pacote), salgados fritos, embutidos, biscoito salgado/doce, refrigerante, Petit suisse e macarrão instantâneo, como marcadores de alimentos não saudáveis.

O consumo usual de alimentos foi avaliado por meio do questionamento sobre quantos dias em uma semana comum a criança, em um primeiro momento, e a mãe, em um segundo momento, consome cada alimento. A escala de frequência tipo Likert de 7 pontos, variou de $0=$ "nunca" a $7=$ "7 dias da semana". 


\subsubsection{Hábitos de vida}

Além das práticas parentais e do consumo alimentar da mãe e da criança, o questionário estruturado também abordou hábitos de vida, sendo eles o número de refeições realizadas com a criança, usualmente, de segunda a sexta (variando de "Nenhuma" a "Mais de três"), hábitos de refeição em família (consumo de sentar à mesa com dois ou mais integrantes da família, Sim/Não), hábito de comer assistindo televisão (costumo de comer assistindo televisão, "Não" a "Sim, 7 vezes na semana"; Ontem, comeu assistindo televisão (Sim/Não) e quantas horas por dia criança e/ou mãe assistem televisão ou mexem no celular/ipod/tablet), questões sobre aleitamento materno exclusivo e duração da amamentação, práticas de atividade física, influência da propaganda televisiva de alimentos (Criança costuma pedir os alimentos que vê na Televisão) e o peso e altura maternos referidos.

\subsubsection{Variáveis socioeconômicas}

As mães foram questionadas também sobre sua cidade e estado de moradia, estado civil, número de filhos, idade e sexo da criança sobre quem responderia as questões, sua idade, nível educacional (com sete opções de resposta que variavam de "ensino fundamental (10 Grau) incompleto" a "pós graduação/ mestrado/ doutorado"), renda familiar mensal (em salários mínimos, com sete opções de resposta que variaram de "Até 1 salário mínimo (até $\mathrm{R} \$$ 790,00)" a "Mais de 15 salários mínimos (mais de R\$ 11.850,00)", números de pessoas residentes no lar e ocupação.

Os instrumentos estão disponíveis no Apêndice A.

\subsection{Procedimento de coleta}

A pesquisa foi aplicada via rede mundial de computadores (internet), a partir da ferramenta de pesquisa online Survey Monkey (www.surveymonkey.com) e ficou disponível no período de 19 de janeiro de 2015 a 23 de fevereiro de 2015. Os indivíduos participantes da pesquisa foram selecionados a partir do "efeito bola de neve" no qual o questionário gerado pela ferramenta foi distribuído para listas de endereços eletrônicos, além de ser publicado em redes sociais, como Facebook®. Para garantir maior adesão à 
pesquisa, o link foi reenviado a cada três dias durante o período em que ficou disponível.

O sistema foi programado de forma que cada participante só pudesse responder ao questionário uma única vez. As mães com mais de uma criança foram orientadas a responder sobre a criança mais nova dentro da faixa etária da pesquisa. No caso de filhos gêmeos, dever-se-ia considerar o último a nascer.

\subsection{Procedimentos de análise}

Para as análises estatísticas, foi utilizado o programa Statistical Package fot the Social Sciences (SPSS), versão 21. A amostra inicial total foi de 1418 participantes. Os dados foram submetidos à análise exploratória e tratamento de dados (presença de casos omissos e extremos), além de pressupostos estatísticos, entre eles, os pressupostos de normalidade, assimetria e achatamento, homogeneidade da variância, linearidade e multicolinearidade. Em seguida, foram realizadas as análises relacionais e inferenciais para o teste do modelo.

Na primeira etapa do estudo, 515 (36\%) respostas foram excluídas na fase exploratória por apresentarem mais de $10 \%$ de dados ausentes por sujeito nos itens referentes ao CFPQ. Dez casos extremos multivariados foram excluídos após a análise multivariada evidenciada pela distância de Mahalanobis, com valor de D2/df $(49)=2,5$, de acordo com recomendação de Hair et al (133). Além disso, foram excluídas três participantes residentes em outro país e 46 participantes, as quais seus filhos não preenchiam a idade de 18 meses a oito anos. Dessa forma, a amostra final deste estudo corresponde a 844 casos.

$\mathrm{Na}$ segunda etapa, 638 (45\%) respostas foram excluídas na fase exploratório por apresentarem mais de $10 \%$ de dados ausentes por sujeito, considerando todas as variáveis. A partir da análise de casos extremos na amostra, optou-se por excluir 48 casos extremos multivariados após a análise multivariada evidenciada pela distância de Mahalanobis em valor crítico de $x^{2}$ de $112,311(\mathrm{gl}=70)$ e $\mathrm{p}<0,001$. Além disso, foram excluídas cinco participantes 
residentes em outro país e 46 participantes que não preenchiam a idade de 18 meses a 8 anos. Dessa forma, a amostra final deste estudo corresponde a 681 casos. Mantivera-se os casos extremos univariados, pois estes eram importantes para a caracterização das variáveis e não apresentaram qualquer padrão de diferenciação.

Em ambas as etapas, após avaliação dos dados perdidos, verificou-se que eles eram perdidos ao acaso (MAR). Para que a amostra não apresentasse dados perdidos, optou-se por utilizar a atribuição baseada em modelos (EM) para todas as variáveis que ainda apresentavam 10\% ou menos desses casos, considerado o mais adequado para dados perdidos ao acaso.

A distribuição de normalidade foi testada usando os valores de assimetria e achatamento. Os valores indicaram uma distribuição não normal das variáveis. No entanto, amostras maiores (200 ou mais observações) reduzem o efeito nocivo da não normalidade (133). Em relação à homogeneidade da variância, utilizou-se o Teste $M$ de Box e verificou-se heteroscedasticidade entre as variáveis, provavelmente em função da não normalidade da amostra (133). Os testes de linearidade indicaram relações lineares entre as variáveis. Dessa forma, pode-se avaliar que as exigências conceituais para a realização das análises foram atendidas.

Para que o objetivo primário da primeira etapa do estudo fosse alcançado, realizou-se análise fatorial exploratória, para confirmar ou refutar a estrutura fatorial do instrumento proposto por Musher-Eizenman e Holub (46).

Inicialmente, optou-se por utilizar a análise de componentes principais $(\mathrm{ACP})$, para investigar a fatorabilidade da matriz e o número de componentes que seriam extraídos a partir das 49 variáveis do instrumento original e, assim, saber o número mínimo de fatores necessários para explicar a porção máxima da variância total (142). Para a avaliação do número de componentes para retenção, utilizou-se o critério de autovalor maior do que 1,0 (critério de GuttmanKaiser) e o teste scree.

Para a extração dos fatores, utilizou-se a técnica dos Eixos principais da análise fatorial comum (AFC). Neste caso, optou-se por utilizar AFC com o propósito de investigar e identificar variáveis subjacentes não observáveis, ou 
seja, dimensões ou construtos latentes das variáveis originais $(133,142)$. Depois da extração dos fatores, para simplificar a estrutura fatorial, optou-se por utilizar a rotação fatorial oblíqua (oblimin), por ser mais flexível e mais realista do que a rotação ortogonal, já que existem evidências de que certas práticas de alimentação infantil são correlacionadas entre si $(46,143)$. Além disso, segundo Hair et al (133), este método de rotação fatorial representa o agrupamento de variáveis com maior precisão, pois cada eixo rotacionado aproxima-se do respectivo grupo de variáveis.

Para a decisão sobre a adequação destes testes, os indicadores utilizados foram o índice de adequação Kaiser-Meyer-Olkin (KMO), superior a 0,60 e o teste de Esfericidade de Barlett $(p<0,05)(133,142)$. Considerou-se o critério de cargas fatoriais significativas como sendo maiores do que 0,32 na matriz de correlações. Esse é o valor mínimo para representar a variável, já que representa $10 \%$ da variância explicada (144). Além disso, sugerem-se pelo menos três variáveis para cada fator (145).

A validação da consistência interna de cada fator foi averiguada a partir do valor de alpha de Cronbach. De acordo com a literatura científica o valor esperado do alpha de Cronbach para o estudo de uma escala deve ser superior a 0,7 (142). Os valores de alpha de Cronbach obtidos neste estudo foram comparados com os da estrutura fatorial original proposta por Musher-Eizenman e Holub (46).

Finalmente, foram calculadas as correlações bivariadas (Pearson) entre as subescalas do CFPQ e as escalas de atitude relacionadas para verificar se elas correlacionam de maneira teoricamente esperada, assim como realizado por Musher-Eizenman e Holub (2007). O nível de significância adotado foi $p<$ 0,01 .

Em relação à segunda etapa do estudo, para que os objetivos fossem alcançados, foram realizadas análises relacionais e inferenciais de correlação bivariada de Pearson e regressão linear multivariada, ressaltando que os presentes dados não violam as hipóteses deste teste (133).

A partir das correlações percebeu-se a necessidade de aprofundamento das relações e interações entre as diversas variáveis do modelo. As variáveis 
que mostraram associação significativa $(p<0,05)$ e apresentaram valores superior a 0,20 (determinação de 4\%) foram adicionadas à regressão linear múltipla para determinar contribuições relativas a variância explicada. As análises de regressão foram realizadas para testar o modelo e verificar o impacto de cada uma das variáveis preditoras (práticas e demais determinantes) sobre a variável critério (consumo alimentar de frutas e hortaliças). Para os cálculos, utilizou-se o método por etapas (stepwise) da regressão linear múltipla, pela sua adequação para pesquisas exploratórias. Este método, além da correlação bivariada, leva em consideração as correlações parciais entre as variáveis, determinando assim a sua ordem hierárquica de importância para o modelo (133).

De acordo com Hair et al (133), regressões lineares são efetivas com um tamanho de amostra mínima de 50 e, preferivelmente, 100 observações, com o fim de manter o poder a 0,80. O tamanho da amostra também afeta a generalização dos resultados. Dessa forma, a proporção mínima de observações por variáveis é de $5: 1$, sendo desejável a proporção de $15: 1$ ou 20:1, sendo $50: 1$ quando a estimação stepwise for utilizada, pois essa técnica seleciona apenas as relações mais fortes dentro do conjunto de dados e sofre de uma maior tendência para se tornar especifica da amostra. Para este estudo foi utilizado o critério de 50 observações para uma variável independente. No caso de variáveis preditoras categóricas com mais de duas categorias, utilizou-se a codificação dummy (fictícia), tornando-a dicotômica para fins de análise.

\subsection{Aspectos éticos}

A pesquisa foi aprovada no Comitê de Ética em Pesquisa da Universidade, estando em conformidade com a Resolução 196 do Conselho Nacional de Saúde de 1996 que regulamenta as pesquisas envolvendo seres humanos, de acordo com o parecer número 394.040, de 13 de setembro de 2013, comprometendo-se a estar condizente com as exigentes éticas e científicas de pesquisas envolvendo seres humanos.

Todos os pais participantes deverão estar de acordo com o Termo de Consentimento Livre e Esclarecido, constando que a desistência em participar da pesquisa não trará nenhum tipo de dano ao participante (Apêndice B). 
Ao final do instrumento foi disponibilizado um manual com orientações sobre alimentação saudável para mães de crianças de dois a cinco anos (146), além do Guia Alimentar para Crianças Menores de 2 anos (111) e o Guia Alimentar para a População Brasileira (110).

\subsection{Caracterização da casuística}

\section{Estudo 1}

Participaram do primeiro estudo 844 mães de crianças de 18 meses a oito anos, residentes no Brasil, que aceitaram voluntariamente participar da pesquisa. $O$ estudo foi realizado apenas com mães seguindo o critério adotado por Musher-Eizenman \& Holub (46) em seu estudo da validação final do instrumento.

Verifica-se que a média de idade das respondentes foi de 32,4 anos $(n=721$, DP $=5,307)$. As participantes eram oriundas de 25 unidades federativas do Brasil, exceto Roraima e Amapá, sendo a maioria do Distrito Federal (49,1\%, n = 405) (Tabela 1). Em relação ao estado civil, a maioria das mães é casada $(69,1 \%, n=580)$, com média de dois filhos por família $(n=842$, DP $=0,77) . A$ maioria dos casos apresenta elevada escolaridade (pós-graduação, 38,8\%, $n=$ 729) e elevada renda familiar (mais de 15 salários mínimos, 22,5\%, $n=160$ ). Em relação à idade das crianças estudadas, a média foi de 3,5 anos $(n=825, D P=$ 3) e maioria de crianças do sexo masculino $(56,6 \%, n=470)$. A tabela 2 abaixo apresenta as características sociodemográficas da população do estudo.

Tabela 1 - Participação da amostra por região do Brasil.

\begin{tabular}{ccc}
\hline Região do Brasil & N & $\%$ \\
\hline Centro oeste & 455 & 55,2 \\
Nordeste & 47 & 5,7 \\
Norte & 23 & 2,8 \\
Sudeste & 215 & 26,1 \\
Sul & 85 & 10,2 \\
Total & 825 & $100 \%$ \\
\hline
\end{tabular}


A partir dos resultados das questões socioeconômicas feitas às participantes foi possível avaliar as características da amostra do estudo. Ressalta-se que, apesar da amostra final ser de 844 respondentes, nem todas responderam a todas as variáveis socioeconômicas.

Tabela 2 - Características sociodemográficas da população do estudo "Validação do instrumento Comprehensive Feeding Practices Questionnaire (CFPQ) com mães brasileiras".

\begin{tabular}{|c|c|c|c|}
\hline Variável & Categoria & $\mathbf{N}$ & (\%) \\
\hline \multirow[t]{2}{*}{ Sexo da criança $(n=829)$} & Masculino & 470 & 43,3 \\
\hline & Feminino & 359 & 43,3 \\
\hline \multirow[t]{6}{*}{ Estado civil da mãe $(\mathrm{n}=839)$} & Solteira & 74 & 8,8 \\
\hline & Casada & 580 & 69,1 \\
\hline & Separada & 13 & 1,5 \\
\hline & Divorciada & 15 & 1,8 \\
\hline & Viúva & 1 & 0,1 \\
\hline & União estável & 156 & 18,5 \\
\hline \multirow[t]{7}{*}{ Escolaridade $(\mathrm{n}=729)$} & Ensino fundamental incompleto & 4 & 0,5 \\
\hline & Ensino fundamental completo & 7 & 1 \\
\hline & Ensino médio incompleto & 17 & 2,33 \\
\hline & Ensino médio completo & 87 & 11,9 \\
\hline & Ensino superior incompleto & 99 & 13,6 \\
\hline & Ensino superior completo & 232 & 31,8 \\
\hline & Pós-graduação & 283 & 38,8 \\
\hline
\end{tabular}




\begin{tabular}{|c|c|c|c|}
\hline Variável & Categoria & $\mathbf{N}$ & (\%) \\
\hline \multirow[t]{7}{*}{ Renda familiar $(\mathrm{n}=711)$} & $\begin{array}{l}\text { Até } 1 \text { salário mínimo } \\
(\mathrm{R} \$ 790,00)\end{array}$ & 20 & 2,8 \\
\hline & $\begin{array}{l}1 \text { a } 3 \text { salários mínimos } \\
\text { (de } R \$ 790,01 \text { até } R \$ 2.370,00 \text { ) }\end{array}$ & 92 & 12,9 \\
\hline & $\begin{array}{l}3 \text { a } 6 \text { salários mínimos } \\
\text { (de } R \$ 2.370,01 \text { até } R \$ 4.740,00 \text { ). }\end{array}$ & 135 & 19 \\
\hline & $\begin{array}{l}6 \text { a } 9 \text { salários mínimos } \\
\text { (de } R \$ 4.740,01 \text { até } R \$ 7.110,00 \text { ) }\end{array}$ & 150 & 21,1 \\
\hline & $\begin{array}{l}9 \text { a } 12 \text { salário mínimos } \\
\text { (de } R \$ 7.110,01 \text { até } R \$ 9.490,00 \text { ). }\end{array}$ & 94 & 13,2 \\
\hline & $\begin{array}{l}12 \text { a } 15 \text { salários mínimos } \\
\text { (de } R \$ 9.490,01 \text { até } R \$ 11.850,00 \text { ). }\end{array}$ & 60 & 8,4 \\
\hline & $\begin{array}{l}\text { Mais de } 15 \text { salários mínimos } \\
\text { (mais de } \mathrm{R} \$ 11.850,00 \text { ). }\end{array}$ & 160 & 22,5 \\
\hline
\end{tabular}

\section{Estudo 2}

Participaram do segundo estudo 681 mães de crianças de 18 meses a 8 anos, residentes no Brasil, que aceitaram voluntariamente participar da pesquisa.

A média de idade das respondentes foi de 32,4 anos ( $D P=5,2$ ). As participantes eram oriundas de 24 unidades federativas do Brasil, exceto Alagoas, Roraima e Amapá, sendo a maioria do Distrito Federal $(49,1 \%, n=825)$ (Tabela 3).

Tabela 3 - Participação da amostra por unidade federativa do Brasil.

\begin{tabular}{ccc}
\hline Unidades federativas & Frequência & $\%$ \\
\hline AC & 1 & 0,1 \\
AL & 3 & 0,4 \\
BA & 8 & 1,2 \\
CE & 4 & 10,6 \\
DF & 329 & 49,1 \\
ES & 4 & 0,6
\end{tabular}




\begin{tabular}{|c|c|c|}
\hline GO & 31 & 4,6 \\
\hline MA & 4 & 0,6 \\
\hline MT & 2 & 0,3 \\
\hline MS & 5 & 0,7 \\
\hline$M G$ & 24 & 3,6 \\
\hline PA & 10 & 1,5 \\
\hline PB & 4 & 0,6 \\
\hline PR & 30 & 4,5 \\
\hline PE & 7 & 1,0 \\
\hline PI & 1 & 0,1 \\
\hline RJ & 27 & 4 \\
\hline $\mathrm{RN}$ & 3 & 0,4 \\
\hline $\mathrm{RS}$ & 26 & 3,9 \\
\hline RO & 2 & 0,3 \\
\hline SC & 16 & 2,4 \\
\hline SP & 121 & 18,1 \\
\hline SE & 6 & 0,9 \\
\hline TO & 2 & 0,3 \\
\hline Total & 682 & 100,0 \\
\hline
\end{tabular}

Em relação ao estado civil, a maioria das mães é casada $(70,6 \%, n=482)$, com média de 1,55 filhos por família ( $D P=0,70$, $\min =1$, máx $=5$ ). A maioria dos casos apresenta elevada escolaridade (pós-graduação, 41,1\%, n = 280) e elevada renda familiar (mais de 15 salários mínimos, 23,2\%, $n=158$ ). Em relação à idade das crianças estudadas, a média foi de 3,9 anos (DP $=1,99$ ) e maioria de crianças do sexo masculino $(56,9 \%, n=387)$. A maioria das crianças foi amamentada exclusivamente por até 6 meses $(56,9 \%, n=367)$, com duração de amamentação por 13,03 meses ( $D P=9,2$, mín $=0$, máx $=40)$. A tabela 4 abaixo apresenta as características sociodemográficas e comportamentais da população do estudo.

Tabela 4 - Características sociodemográficas da população do estudo "Práticas maternas e outros determinantes relacionados ao consumo de frutas e hortaliças por crianças de 18 meses a 8 anos".

\begin{tabular}{cccc}
\hline Variável & Categoria & $\mathrm{N}$ & (\%) \\
\hline Sexo da criança & Masculino & 387 & 56,9 \\
& Feminino & 294 & 43,1
\end{tabular}




$$
\begin{aligned}
& \text { Solteira } \\
& \text { Casada }
\end{aligned}
$$$$
\text { Separada }
$$

Divorciada

$$
\text { Viúva }
$$

União estável

Escolaridade $(\mathrm{n}=729)$

Renda familiar $(n=711)$

A criança costuma comer quando está assistindo à TV, mexendo no celular/ ipod/ tablet?

$(\mathrm{R} \$ 790,00)$

$$
\begin{array}{cc}
54 & 7,9 \\
482 & 70,6 \\
11 & 1,6 \\
12 & 1,8 \\
2 & 0,3 \\
120 & 17,7 \\
3 & 0,4 \\
6 & 0,9 \\
10 & 1,5 \\
71 & 10,6 \\
\hline 93 & 13,6 \\
\hline 218 & 32 \\
\hline 280 & 41,1
\end{array}
$$

Ensino fundamental incompleto

Ensino fundamental completo

Ensino médio incompleto

Ensino médio completo

Ensino superior incompleto

Ensino superior completo

Pós-graduação

Até 1 salário mínimo

$13 \quad 1,9$

1 a 3 salários mínimos

(De $R \$ 790,01$ até $R \$ 2.370,00$ )

$82 \quad 12,2$

3 a 6 salários mínimos

(De $R \$ 2.370,01$ até $R \$ 4.740,00$ ).

13019,1

6 a 9 salários mínimos

(De $\mathrm{R} \$ 4.740,01$ até $\mathrm{R} \$ 7.110,00$ )

14421,1

9 a 12 salário mínimos

(De $R \$ 7.110,01$ até $R \$ 9.490,00$ ).

$90 \quad 13,1$

12 a 15 salários mínimos

(De $R \$ 9.490,01$ até $R \$ 11.850,00$ ).

649,4

Mais de 15 salários mínimos (Mais de $\mathrm{R} \$ 11.850,00$ ).

$158 \quad 23,2$

Uma vez por semana

$67 \quad 9,8$

Duas vezes por semana

$75 \quad 11$

Três vezes por semana

$60 \quad 8,8$

Quatro vezes por semana

$50 \quad 7,3$

Cinco vezes por semana

$74 \quad 10,9$

Seis vezes por semana

334,8 
Sete vezes por semana

Nunca

Ontem, a criança comeu assistindo TV?

Onde a criança fica a maior parte do tempo?

Sim

Não

Em casa
Casa de parente

Quem cuida da criança na maior parte do tempo?

Criança faz atividade física na escola ou brinca na rua?

Família costumar sentar à mesa nas refeições (almoço e/ou jantar?)

Seu filho costuma pedir os alimentos que vê na TV?

Frequência de compra de alimentos não saudáveis que criança pede.
Casa de vizinho

Creche/ escola

Outro

$114 \quad 16,9$

$208 \quad 30,5$

$268 \quad 39,5$

41360,6

$449 \quad 66$

$31 \quad 4,5$

20,3

17826,1

$21 \quad 3,1$

Babá

$56 \quad 8,2$

Avô/avó

$53 \quad 7,8$

Mãe

39257,6

Creche

$119 \quad 17,4$

Pai

$29 \quad 4,3$

Outro

32

Sim

59787,7

Não

$84 \quad 12,3$

Sim

58786,2

Não

$94 \quad 12,3$

Nunca

$239 \quad 35,2$

Raramente

$197 \quad 28,9$

Às vezes

$198 \quad 29$

Quase sempre

$33 \quad 4,8$

Sempre

$14 \quad 2,1$

Nunca

$85 \quad 12,5$ 
Às vezes

Quase Sempre

Sempre

Sim, baixo peso

pediatra/ nutricionista

diagnosticou seu filho com

baixo pesou ou obesidade?

Sim, excesso de peso

Não

IMC da mãe

Baixo peso

$19 \quad 2,8$

Eutrofia

$377 \quad 55,4$

Sobrepeso

$186 \quad 27,3$

Obesidade 


\section{Resultados}

\section{ARTIGO 1}

\section{VALIDAÇÃO DO INSTRUMENTO COMPREHENSIVE FEEDING PRACTICES QUESTIONNAIRE (CFPQ) COM MÃES BRASILEIRAS.}

\section{Resumo}

O comportamento alimentar infantil é fortemente influenciado pelas práticas parentais. Por isso, instrumentos de avaliação dessas práticas são largamente utilizados em vários países. O Comprehensive Feeding Practices Questionnaire (CFPQ) é um instrumento constituído por doze fatores, que se propõe a medir as práticas parentais alimentares de forma abrangente. No Brasil essas práticas são pouco estudadas e existe uma lacuna de instrumentos traduzidos e/ou validados que avaliem sua relação com a alimentação infantil. Dessa forma, este estudo teve como objetivo realizar a validação do CFPQ por meio de validação cultural e análise da estrutura fatorial do instrumento. Mães brasileira de crianças de 18 meses a 8 anos responderam uma versão traduzida-retraduzida e validada culturalmente do instrumento $(\mathrm{N}=844)$. A Análise fatorial exploratória revelou solução fatorial final caracterizada por 9 fatores e 39 itens (KMO = 0,830 e 56,5\% de variância), sendo que cinco fatores se mantiveram iguais ao original. Os fatores Restrição para controle de peso e Restrição para manter a saúde se combinaram em um único fator e os itens do fator Ensino sobre Nutrição foram realocados. Excluiu-se um item do fator Incentivo ao balanço e variedade, um do fator Pressão para comer e todos os itens do fator Ambiente Saudável. Assim, considera-se que o CFPQ foi aprimorado, resultando em um instrumento que contribui para o entendimento do ambiente alimentar infantil e suas práticas parentais relacionadas, sendo um bom início de uso no Brasil.

Palavras-chave: Práticas parentais, alimentação infantil, análise fatorial, comportamento alimentar, crianças. 


\section{Abstract}

The children's eating behaviour is strongly influenced by parenting feeding practices. Therefore, assessment tools such practices are widely used in several countries. The Comprehensive Feeding Practices Questionnaire (CFPQ) is an instrument composed of twelve factors, which aims to measure the feeding practices comprehensively. In Brazil there are few studies and a lack of translated instruments and/or validated to assess its relation to infant feeding. Thus, this study aimed to carry out CFPQ validation through cultural validation and analysis of the factor structure. Brazilian mothers of children 18 months to 8 years responded with a translated-back-translated and culturally validated instrument $(N=844)$. Exploratory factor analysis revealed the final factor solution characterized by 9 factors and 39 items (KMO $=0,830$ and $56,5 \%$ of variance), and five factors remained equal to the original. The Restriction factors for weight control and Restriction for health combined into a single factor and the factor of items Teaching about Nutrition were relocated. It was excluded from an item Factor Encourage balance and variety, a Factor Pressure to eat and all items of the Factor Healthy Environment. Finally, it is considered that the CFPQ has been enhanced, resulting in an instrument that contributes to the understanding of children's food environment and its related parenting practices, being a good start in its use in Brazil. Considerable improvements of the contents and reliability coefficients are also supporting the new model.

Keywords: feeding practices, child eating, factor analysis, food beahviour, child. 


\section{Introdução}

A alimentação nos primeiros anos de vida é considerada determinante para o estabelecimento de práticas e hábitos alimentares adequados ao longo da vida (1). Ao mesmo tempo em que está associada à saúde do adulto, podendo representar um dos principais fatores de prevenção de doenças a longo prazo (3-5) Além disso, evidências indicam que os hábitos aprendidos na infância persistem na vida adulta $(41,147)$. Portanto, a educação e os cuidados alimentares devem começar desde as primeiras práticas alimentares do indivíduo (7).

Estudos têm mostrado que o comportamento alimentar infantil é fortemente influenciado pelo ambiente familiar, que inclui o comportamento alimentar dos pais e práticas de alimentação de crianças (41). As práticas parentais, por sua vez, se não são a causa, são fortemente associadas com o estado nutricional e escolhas saudáveis ao longo da infância (148).

As mães são as primeiras responsáveis pela transmissão dos padrões alimentares saudáveis para os filhos (149), além da interação direta que possuem, principalmente por meio da amamentação. Assim, representam a influência mais marcante na formação de hábitos na primeira infância (7).

De acordo com Musher-Eizenman (46), existem algumas formas de abordagem para estudar as práticas parentais e sua relação com consumo alimentar infantil. Entre elas, sugere-se que a utilização de questionários de autorrelato seja uma alternativa rápida e prática de coleta e pode ser considerado recurso fundamental para o entendimento das práticas alimentares. Vários estudos internacionais são realizados com o objetivo de avaliar as práticas parentais e sua influência sobre o comportamento alimentar infantil, no entanto, no Brasil elas são pouco estudadas.

Os dois instrumentos mais utilizados na literatura para a avaliação das práticas parentais são o Child Feeding Questionnaire (CFQ; (43)) e o Preschooler Feeding Questionnaire (PFQ; (47)). No entanto, eles não captam 
toda a abrangência dos comportamentos relativos às práticas de alimentação das crianças. A partir disso, Musher-Eizenmann e Holub (46) elaboraram o Comprehensive Feeding Practices Questionnaire, um instrumento que se propõe a avaliar as práticas de alimentação relacionadas ao comportamento alimentar infantil de forma mais abrangente, o que justifica a sua escolha para este estudo. Este novo instrumento têm sido utilizado em pesquisas recentes $(81,150,151) \mathrm{e}$ adaptado para vários países, tais como Noruega (143), Malásia (152) e Nova Zelândia (153)

Dessa forma, este estudo tem o objetivo de realizar a validação do Comprehensive Feeding Practices Questionnaire (CFPQ) com mães brasileira, por meio de validação cultural e análise da estrutura fatorial do instrumento.

\section{Métodos}

\section{Delineamento do Estudo}

Para diminuir os vieses da cultural original da qual do instrumento provem (135), em um estudo anterior feito pelos pesquisadores deste estudos o instrumento foi adaptado para o Brasil, por meio da tradução-retradução e sua validação cultural.

Em 2013, O CFPQ foi traduzido para a língua portuguesa (Português do Brasil) a partir da metodologia de tradução - retradução proposta por et al Beaton et al. (134) e Cassep-Borges et al (135) em um Trabalho de Conclusão de Curso do Departamento de Nutrição da Universidade de Brasília (136). Este procedimento foi realizado em quatro etapas, sendo elas: tradução, reunião de consenso, tradução reversa e validação de conteúdo pela técnica de juízes.

A etapa de tradução consistiu na realização de duas traduções do instrumento original (em inglês) para a língua portuguesa por tradutores bilíngues, de forma independente ( $\mathrm{O}$ instrumento original encontra-se no anexo 1). Em seguida, foi realizada reunião de consenso com especialistas em nutrição bilíngues e submetida a um dos tradutores da etapa 1 para aprovação. $O$ documento resultante foi submetido a dois novos tradutores, não participantes 
da primeira etapa e independentes entre si, para a tradução reversa para a língua inglesa.

Considerando que apenas a tradução não seja suficiente para garantir a aplicabilidade do instrumento (135), na última etapa, os documentos finais foram enviados para revisão de três especialistas peritos no tema, sendo nutricionista, psicólogo e pediatra, para que fosse realizada a análise de conteúdo. Para essa etapa, a metodologia utilizada para verificar a concordância entre os juízes foi a de Coeficiente de Validade de Conteúdo (CVC), proposta por Hernández-Nieto (154). Cada item foi avaliado pelos critérios de clareza de linguagem, pertinência prática e relevância teórica pelos especialistas.

Após a Tradução, retradução e validação semântica, o instrumento foi submetido a um estudo piloto com trinta e cinco mães de crianças de 2 a 5 anos respondentes do CFPQ traduzido, em um Trabalho de Conclusão de Curso do departamento de Nutrição da Universidade de Brasília (138), ainda não publicado. Dessa forma, foi considerado como instrumento para esse trabalho o resultado final do estudo piloto previamente realizado. O instrumento traduzido e adaptado foi submetido a validação estatística por meio de um estudo transversal proposto para este fim.

\section{Participantes}

Participaram do presente estudo 844 mães de crianças de 18 meses a oito anos, residentes no Brasil, que aceitaram voluntariamente participar da pesquisa. $\mathrm{O}$ estudo foi realizado apenas com mães seguindo o critério adotado por Musher-Eizenman e Holub (46) em seu estudo da validação final do instrumento. De acordo com Hair (133) para a validade de instrumentos são necessários de 5 a 10 sujeitos por item do instrumento, dessa forma, considerando os 49 itens do Comprehensive Feeding Practices Questionnaire deveriam ser selecionadas pelo menos 490 mães. A amostra referente a este estudo representou a proporção de 17 sujeitos por variável.

Verifica-se que a média de idade das respondentes foi de 32,4 anos ( $n=$ 721 , DP $=5,307)$. As participantes eram oriundas de 25 unidades federativas do Brasil, exceto Roraima e Amapá, sendo a maioria do Distrito Federal (49,1\%, n 
= 405). Em relação ao estado civil, a maioria das mães é casada $(69,1 \%, n=$ 580 ), com média de dois filhos por família $(n=842$, $D P=0,77)$. A maioria dos casos apresenta elevada escolaridade (pós-graduação, 38,8\%, $n=729$ ) e elevada renda familiar (mais de 15 salários mínimos, 22,5\%, $n=160$ ). Em relação à idade das crianças estudadas, a média foi de 3,5 anos $(n=825$, DP $=$ 3) e maioria de crianças do sexo masculino $(56,6 \%, n=470)$.

A partir dos resultados das questões socioeconômicas feitas às participantes foi possível avaliar as características da amostra do estudo. Ressalta-se que, apesar da amostra final ser de 844 respondentes, nem todas responderam a todas as variáveis socioeconômicas.

\section{Instrumento}

O Comprehensive Feeding Practices Questionnaire (CFPQ) é um instrumento proposto por Musher-Eizenman \& Holub (46) que se propõe a mensurar as múltiplas práticas de alimentação adotadas por pais e/ou mães com seus filhos. O instrumento original possui 49 itens, divididos em doze fatores e apresenta duas escalas do tipo Likert de resposta, sendo elas de frequência, com respostas de "nunca" a "sempre" (itens 1 a 13) e concordância, com respostas de "discordo totalmente" a "concordo totalmente" (itens 14 a 49). $O$ instrumento encontra-se no apêndice A.

Segundo os autores, os pais podem utilizar doze práticas de alimentação infantil, sendo elas:

1 - Controle da alimentação pela criança ( 5 itens, exemplo "Você deixa seu filho comer o que ele quer?");

2 - Regulação emocional (3 itens, exemplo "Você dá a seu filho algo para comer ou beber caso ele esteja sem nada para fazer, mesmo achando que ele está sem fome?");

3 - Incentivo ao equilíbrio e variedade (4 itens, exemplo "Você Incentiva essa criança a comer alimentos saudáveis antes dos não saudáveis?");

4 - Ambiente saudável (4 itens, exemplo "A maioria dos alimentos disponíveis na minha casa são saudáveis."); 
5 - Alimento como recompensa: pais utilizam a comida como recompensa ao bom comportamento do seu filho (3 itens, exemplo "Eu ofereço doces (balas, sorvete, bolo, docinhas e outros) para o meu filho como recompensa por um bom comportamento.");

6 - Envolvimento (3 itens, exemplo "Eu envolvo meu filho no planejamento das refeições.");

7 - Modelo (4 itens, exemplo "Eu como de forma saudável para servir de exemplo para meu filho.");

8 - Monitoramento (4 itens, exemplo "O quanto você controla os salgadinhos de pacote (Ruffles $\AA^{\circledR}$, Doritos $\AA$, Cheetos ${ }^{\circledR}$ ) que seu filho come?");

9 - Pressão (4 itens, exemplo "Meu filho deve sempre comer toda a comida que está em seu prato.");

10 - Restrição por saúde (4 itens, exemplo "Eu controlo a alimentação do meu filho para que ele não coma uma quantidade excessiva de seus alimentos favoritos.");

11 - Restrição para controle do peso (8 itens, exemplo "Incentivo meu filho a comer menos para que ele não fique gordo"); e

12 - Ensino sobre nutrição ( 3 itens, exemplo "Eu converso com meu filho sobre o valor nutricional dos alimentos.").

Além disso, como feito por Musher-Eizenman e Holub (46), além do CFPQ, as mães foram convidadas a responder itens de três escalas de atitudes relacionadas às práticas parentais, sendo elas a escala de preocupação com o excesso de peso da criança (três itens), retirada do Child Feeding Questionnaire (CFQ) (43), a Escala de Preocupação com o baixo peso da criança (três itens) adaptada também do CFQ e a Escala de Responsabilidade de alimentação da criança (três itens), além de um item sobre a percepção das mães sobre o peso da criança. 


\section{Procedimento de coleta}

A pesquisa foi aplicada via rede mundial de computadores (internet), a partir da ferramenta de pesquisa online Survey Monkey (www.surveymonkey.com). Este método, também adotado por MusherEizenman e Holub (2007) foi considerado mais adequado, pois permite o alcance de uma amostra mais diversa geograficamente, além de tender a ser considerável mais representativa do que os métodos convencionais (155).

Os indivíduos participantes da pesquisa foram selecionados a partir do "efeito bola de neve", uma vez que o link do questionário gerado pela ferramenta foi distribuído para listas de endereços eletrônicos, além de ser publicado em redes sociais (Facebook®). O link de acesso à pesquisa ficou disponível dos dias 19 de janeiro a 23 de fevereiro de 2015 (35 dias). O sistema foi programado de forma que cada participante só pudesse responder ao questionário uma única vez.

As mães com mais de um (a) filho (a) foram orientadas a responder sobre a criança mais nova dentro da faixa etária. No caso de filhos gêmeos, deveria ser considerar o último a nascer.

\section{Análise estatística}

Para as análises estatísticas, foi utilizado o programa Statistical Package fot the Social Sciences (SPSS), versão 21. A n total foi de 1418 participantes, das quais $515(36 \%)$ respostas foram excluídas na fase exploratória por apresentarem mais de $10 \%$ de dados ausentes por sujeito no instrumento submetido à validação. Após avaliação dos dados perdidos, verificou-se que eles eram perdidos ao acaso (MAR), ou seja, requer métodos especiais para acomodar componentes não aleatórios. Para que a amostra não apresentasse dados perdidos, optou-se por utilizar a atribuição baseada em modelos (EM), considerada a mais adequado para dados perdidos ao acaso. Dez casos extremos multivariados foram excluídos após a análise multivariada evidenciada pela distância de Mahalanobis, com valor de $D^{2} /$ df $(49)=2,5$, de acordo com recomendação de HAIR et al. (133). Além disso, foram excluídas três participantes residentes em outro país e 46 participantes, as quais seus filhos 
não preenchiam a idade de 18 meses a oito anos. Dessa forma, a amostra final deste estudo corresponde a 844 casos.

Os dados foram submetidos à análise exploratória e de pressupostos estatísticos. Dessa forma, pode-se avaliar que as exigências conceituais para a realização da análise fatorial foram atendidas.

Para que o objetivo primário deste estudo fosse alcançado, realizou-se análise fatorial exploratória, para confirmar ou refutar a estrutura fatorial do instrumento proposto por Musher-Eizenman e Holub (46). Inicialmente, optou-se por utilizar a análise de componentes principais (ACP), para investigar a fatorabilidade da matriz e o número de componentes que seriam extraídos a partir das 49 variáveis do instrumento original, ou seja, para saber o número mínimo de fatores necessários para explicar a porção máxima da variância total (142). Para a avaliação do número de componentes para retenção, utilizou-se o critério de autovalor maior do que 1,0 (critério de Guttman-Kaiser) e o teste scree.

Para a extração dos fatores, utilizou-se a técnica dos Eixos Principais da Análise Fatorial Comum (AFC). Neste caso, optou-se por utilizar AFC com o propósito de investigar e identificar variáveis subjacentes não observáveis, ou seja, dimensões ou construtos latentes das variáveis originais $(133,142)$. Depois da extração dos fatores, para simplificar a estrutura fatorial, optou-se por utilizar a rotação fatorial oblíqua (oblimin), por ser mais flexível e mais realista do que a rotação ortogonal, já que existem evidências de que certas práticas de alimentação infantil são correlacionadas entre si $(46,143)$. Além disso, segundo Hair et al (133), este método de rotação fatorial representa o agrupamento de variáveis com maior precisão, pois cada eixo rotacionado aproxima-se do respectivo grupo de variáveis.

Para a decisão sobre a adequação destes testes, os indicadores utilizados foram o índice de adequação Kaiser-Meyer-Olkin (KMO), superior a 0,60 e o teste de Esfericidade de Barlett $(p<0,05)(133,142)$. Considerou-se o critério de cargas fatoriais significativas como sendo maiores do que 0,32 na matriz de correlações. Esse é o valor mínimo para representar a variável, já que representa $10 \%$ da variância explicada (144). Além disso, sugerem-se pelo menos três variáveis para cada fator (145). 
A validação da consistência interna de cada fator foi averiguada a partir do valor de alpha de Cronbach. De acordo com a literatura científica o valor esperado do alpha de Cronbach para o estudo de uma escala deve ser superior a 0,8. (142). Os valores de alpha de Cronbach obtidos neste estudo foram comparados com os da estrutura fatorial original proposta por Musher-Eizenman \& Holub (46).

Finalmente, foram calculadas as correlações bivariadas entre as subescalas do CFPQ e as escalas de atitude relacionadas para verificar se elas correlacionam de maneira teoricamente esperada, assim como realizado por Musher-Eizenman \& Holub (46). O nível de significância adotado foi $p<0,01$.

\section{Aspectos éticos}

A pesquisa foi aprovada no Comitê de Ética em Pesquisa da Universidade, estando em conformidade com a Resolução 196 do Conselho Nacional de Saúde de 1996 que regulamenta as pesquisas envolvendo seres humanos, de acordo com o parecer número 394.040 (13 de setembro de 2013), comprometendo-se a estar condizente com as exigências éticas e científicas de pesquisas envolvendo seres humanos. Todas as participantes estavam de acordo com o Termo de Consentimento Livre e Esclarecido, constando que a desistência em participar da pesquisa não traria nenhum tipo de dano ao participante (Apêndice B).

\section{Resultados}

Tradução, retradução e validação semântica com juízes

Para a elaboração da versão final traduzida, analisou-se, principalmente, se as duas traduções eram correspondentes e se traziam a ideia original do item. $\mathrm{Na}$ maioria das questões, as traduções foram iguais ou semelhantes. Dessa forma, ela foi construída a partir da tradução proposta que melhor correspondesse a ideia original ou pela combinação delas. Em casos específicos, foram realizadas alterações de palavras que melhor se adaptam a realidade brasileira e termos de nutrição mais comumente utilizados, de forma a manter a pertinência e clareza do item, adaptado ao construto do questionário avaliado. 
Em relação à validação semântica, a tabela 3 apresenta os resultados do Coeficiente de Validade de Conteúdo calculados em relação aos três critérios avaliados, sendo eles clareza de linguagem, pertinência prática e referencial teórico. Observa-se também o julgamento de cada juiz com relação a qual dimensão estaria mais apropriada para o item correspondente.

Tabela 5 - Cálculo do Coeficiente de Variedade de Conteúdo de cada item $\left(\mathrm{CVC}_{c}\right)$ e do questionário $\left(\mathrm{CVC}_{\mathrm{t}}\right)$ e apresentação da classificação das dimensões teóricas pelos juízes.

\begin{tabular}{|c|c|c|c|c|c|c|c|c|}
\hline $\mathrm{N}^{0}$ & Itens & & $\mathrm{CVC}_{\mathrm{c}}$ & & Din & tens & o teó & ica \\
\hline \multirow[b]{2}{*}{1} & \multirow[b]{2}{*}{$\begin{array}{l}\text { Quanto você monitora os doces (bala, } \\
\text { sorvete, bolo, tortas, docinhos) que seu } \\
\text { filho come? }\end{array}$} & CL & PP & RT & J1 & J2 & J3 & 0 \\
\hline & & 0,70 & 0,83 & 0,90 & VIII & VIII & VIII & VIII \\
\hline 2 & $\begin{array}{l}\text { Quanto você monitora os salgadinhos de } \\
\text { pacote (Ruffles } \AA \text {, Doritos } \AA \text {, Cheetos } \AA \text { ) } \\
\text { que seu filho come? }\end{array}$ & 0,70 & 0,83 & 0,90 & VIII & VIII & VIII & VIII \\
\hline 3 & $\begin{array}{l}\text { Quanto você monitora os alimentos ricos } \\
\text { em gordura que seu filho come? }\end{array}$ & 0,76 & 0,83 & 0,96 & VIII & VIII & VIII & VIII \\
\hline 4 & $\begin{array}{l}\text { Quanto você monitora a quantidade de } \\
\text { bebidas açucaradas (refrigerantes, suco } \\
\text { em pó) que seu filho bebe? }\end{array}$ & 0,70 & 0,83 & 0,96 & VIII & VIII & VIII & VIII \\
\hline 5 & $\begin{array}{l}\text { Você deixa seu filho comer o que ele } \\
\text { quer? }\end{array}$ & 0,96 & 0,96 & 0,96 & 1 & I & I & 1 \\
\hline 6 & $\begin{array}{l}\text { No jantar, você deixa seu filho escolher os } \\
\text { alimentos que ele quer daquilo que foi } \\
\text { servido? }\end{array}$ & 0,83 & 0,90 & 0,90 & 1 & 1 & I & 1 \\
\hline 7 & $\begin{array}{l}\text { Quando seu filho fica agitado, a primeira } \\
\text { coisa que você faz é dar-lhe algo para } \\
\text { comer ou beber? }\end{array}$ & 0,83 & 0,90 & 0,90 & II & II & II & II \\
\hline 8 & $\begin{array}{l}\text { Você dá a seu filho algo para comer ou } \\
\text { beber caso ele esteja entediado, mesmo } \\
\text { achando que ele está sem fome? }\end{array}$ & 0,76 & 0,90 & 0,90 & II & II & II & II \\
\hline 9 & $\begin{array}{l}\text { Você dá a seu filho algo para comer ou } \\
\text { beber caso ele esteja chateado, mesmo } \\
\text { achando que ele está sem fome? }\end{array}$ & 0,90 & 0,90 & 0,90 & II & II & II & II \\
\hline 10 & $\begin{array}{l}\text { Se seu filho não gostar do que está sendo } \\
\text { servido, você prepara outra coisa? }\end{array}$ & 0,96 & 0,96 & 0,96 & 1 & I & I & 1 \\
\hline 11 & $\begin{array}{l}\text { Você deixa seu filho fazer lanches sempre } \\
\text { que quer? }\end{array}$ & 0,83 & 0,96 & 0,96 & 1 & I & I & 1 \\
\hline 12 & $\begin{array}{l}\text { Você permite que seu filho deixe a mesa } \\
\text { quando está satisfeito, mesmo que sua } \\
\text { família não tenha terminado de comer? }\end{array}$ & 0,96 & 0,96 & 0,96 & 1 & 1 & I & 1 \\
\hline
\end{tabular}




\begin{tabular}{|c|c|c|c|c|c|c|c|c|}
\hline \multirow[t]{2}{*}{$\mathrm{N}^{0}$} & \multirow[t]{2}{*}{ Itens } & \multicolumn{3}{|c|}{$\mathrm{CVC}_{\mathrm{c}}$} & \multicolumn{4}{|c|}{ Dimensão teórica } \\
\hline & & CL & PP & CL & PP & CL & PP & \\
\hline 13 & $\begin{array}{l}\text { Você incentiva essa criança a comer } \\
\text { alimentos saudáveis antes dos não } \\
\text { saudáveis? }\end{array}$ & 0,83 & 0,90 & 0,90 & IV & III & III & III \\
\hline 14 & $\begin{array}{l}\text { A maioria dos alimentos que tenho em casa } \\
\text { é saudável. }\end{array}$ & 0,83 & 0,96 & 0,96 & IV & IV & IV & IV \\
\hline 15 & $\begin{array}{l}\text { Eu envolvo meu filho no planejamento das } \\
\text { refeições da família. }\end{array}$ & 0,90 & 0,83 & 0,83 & VI & VI & VI & VI \\
\hline 16 & $\begin{array}{l}\text { Mantenho muitos salgadinhos de pacote } \\
\text { (Ruffles } \AA \text {, Doritos } \AA \text {, Cheetos } \AA \text { ) na minha } \\
\text { casa. }\end{array}$ & 0,90 & 0,83 & 0,83 & IV & IV & IV & IV \\
\hline 17 & $\begin{array}{l}\text { Meu filho deve sempre comer toda comida } \\
\text { que estiver no seu prato. }\end{array}$ & 0,90 & 0,96 & 0,96 & IX & $X I$ & IX & IX \\
\hline 18 & $\begin{array}{l}\text { Preciso garantir que meu filho não coma } \\
\text { muitos alimentos ricos em gordura. }\end{array}$ & 0,76 & 0,90 & 0,90 & $x$ & $x$ & $x$ & $X I$ \\
\hline 19 & $\begin{array}{l}\text { Eu ofereço a meu filho seus alimentos } \\
\text { preferidos em troca de um bom } \\
\text { comportamento. }\end{array}$ & 0,90 & 0,96 & 0,96 & II & II & V & V \\
\hline 20 & $\begin{array}{l}\text { Eu deixo meu filho ajudar a preparar as } \\
\text { refeições da família. }\end{array}$ & 0,90 & 0,83 & 0,83 & VI & VI & VI & VI \\
\hline 21 & $\begin{array}{l}\text { Se eu não orientasse ou regulasse a } \\
\text { alimentação do meu filho, ele comeria uma } \\
\text { quantidade excessiva de seus alimentos } \\
\text { favoritos. }\end{array}$ & 0,90 & 0,90 & 0,90 & VIII & $x$ & $x$ & $x$ \\
\hline 22 & $\begin{array}{l}\text { Uma variedade de alimentos saudáveis está } \\
\text { disponível para o meu filho em cada } \\
\text { refeição servida em casa. }\end{array}$ & 0,90 & 0,96 & 0,96 & IV & IV & IV & IV \\
\hline 23 & $\begin{array}{l}\text { Eu ofereço doces (balas, sorvete, bolo, } \\
\text { docinhos) para o meu filho como } \\
\text { recompensa por bom comportamento. }\end{array}$ & 0,83 & 0,90 & 0,90 & V & II & V & $\mathrm{V}$ \\
\hline 24 & $\begin{array}{l}\text { Eu incentivo meu filho a experimentar novos } \\
\text { alimentos. }\end{array}$ & 0,96 & 0,96 & 0,96 & III & III & III & III \\
\hline 25 & $\begin{array}{l}\text { Eu converso com meu filho sobre a } \\
\text { importância de se comer alimentos } \\
\text { saudáveis. }\end{array}$ & 0,90 & 0,96 & 0,96 & III & XII & XII & XII \\
\hline 26 & $\begin{array}{l}\text { Digo a meu filho que alimentos saudáveis } \\
\text { são gostosos. }\end{array}$ & 0,90 & 0,83 & 0,83 & III & XII & XII & III \\
\hline
\end{tabular}




\begin{tabular}{|c|c|c|c|c|c|c|c|c|}
\hline \multirow[t]{2}{*}{$\mathbf{N}^{0}$} & \multirow[t]{2}{*}{ Itens } & \multicolumn{3}{|c|}{$\mathrm{CVC}_{\mathrm{c}}$} & \multicolumn{4}{|c|}{ Dimensão teórica } \\
\hline & & CL & PP & RT & J1 & J2 & J3 & 0 \\
\hline 27 & $\begin{array}{l}\text { Incentivo meu filho a comer menos para que } \\
\text { não engorde (ou para que não fique } \\
\text { gordo?). }\end{array}$ & 0,90 & 0,96 & 0,96 & $X I$ & $X I$ & $X I$ & $X I$ \\
\hline 28 & $\begin{array}{l}\text { Se eu não orientasse ou regulasse a } \\
\text { alimentação do meu filho, ele comeria muita } \\
\text { "besteira" (junk food). }\end{array}$ & 0,90 & 0,90 & 0,90 & VIII & $x$ & $\mathrm{X}$ & $x$ \\
\hline 29 & $\begin{array}{l}\text { Eu dou a meu filho porções pequenas nas } \\
\text { refeições para controlar seu peso. }\end{array}$ & 0,83 & 0,90 & 0,90 & $X I$ & $X I$ & $X I$ & $X I$ \\
\hline 30 & $\begin{array}{l}\text { Se meu filho diz: "Não estou com fome", } \\
\text { tento fazer com que coma mesmo assim. }\end{array}$ & 0,96 & 0,90 & 0,96 & IX & IX & IX & IX \\
\hline 31 & $\begin{array}{l}\text { Eu converso com meu filho sobre o valor } \\
\text { nutricional dos alimentos. }\end{array}$ & 0,83 & 0,90 & 0,90 & XII & XII & XII & XII \\
\hline 32 & $\begin{array}{l}\text { Eu incentivo meu filho a participar das } \\
\text { compras de supermercado. }\end{array}$ & 0,83 & 0,83 & 0,96 & VI & VI & VI & VI \\
\hline 33 & $\begin{array}{l}\text { Se meu filho come mais do que o normal } \\
\text { em uma refeição, tento restringir o que ele } \\
\text { come na refeição seguinte. }\end{array}$ & 0,96 & 0,96 & 0,96 & $X I$ & $X I$ & $X I$ & $X I$ \\
\hline 34 & $\begin{array}{l}\text { Restrinjo os alimentos que meu filho come e } \\
\text { que podem fazê-lo engordar. }\end{array}$ & 0,83 & 0,90 & 0,83 & $X I$ & $X I$ & $X I$ & $X I$ \\
\hline 35 & $\begin{array}{l}\text { Há certos alimentos que meu filho não deve } \\
\text { comer, pois o deixarão gordo. }\end{array}$ & 0,83 & 0,83 & 0,90 & $X I$ & $X I$ & $X I$ & $X I$ \\
\hline 36 & $\begin{array}{l}\text { Ou eu proíbo doces/sobremesa a meu filho } \\
\text { em resposta ao mau comportamento. }\end{array}$ & 0,70 & 0,90 & 0,96 & V & V & V & $\mathrm{V}$ \\
\hline 37 & $\begin{array}{l}\text { Mantenho muitos doces (bala, sorvete, bolo, } \\
\text { torta, docinhos) na minha casa. }\end{array}$ & 0,83 & 0,90 & 0,90 & IV & IV & IV & IV \\
\hline 38 & $\begin{array}{l}\text { Incentivo meu filho a comer alimentos } \\
\text { variados. }\end{array}$ & 0,83 & 0,90 & 0,83 & III & III & III & III \\
\hline 39 & $\begin{array}{l}\text { Se meu filho come apenas uma pequena } \\
\text { porção, tento fazer com que ele coma mais }\end{array}$ & 0,90 & 0,90 & 0,96 & IX & IX & IX & IX \\
\hline 40 & $\begin{array}{l}\text { Preciso garantir que meu filho não coma } \\
\text { uma quantidade excessiva de seus } \\
\text { alimentos favoritos. }\end{array}$ & 0,90 & 0,90 & 0,90 & VIII & VIII & $x$ & $x$ \\
\hline 41 & $\begin{array}{l}\text { Não deixo meu filho beliscar* entre as } \\
\text { refeições porque não quero que ele } \\
\text { engorde. }\end{array}$ & 0,90 & 0,90 & 0,90 & VIII & XI & $X I$ & XI \\
\hline 42 & $\begin{array}{l}\text { Eu digo a meu filho o que comer e o que } \\
\text { não comer sem dar explicação. }\end{array}$ & 0,90 & 0,90 & 0,96 & VIII & $x$ & $x$ & XII \\
\hline 43 & $\begin{array}{l}\text { Preciso garantir que meu filho não coma } \\
\text { muitos doces (balas, sorvete, bolo ou } \\
\text { docinhos). }\end{array}$ & 0,83 & 0,90 & 0,90 & VIII & $X$ & $x$ & $x$ \\
\hline
\end{tabular}


(Continuação)

\begin{tabular}{|c|c|c|c|c|c|c|c|c|}
\hline \multirow[t]{2}{*}{$\mathrm{N}^{0}$} & \multirow[t]{2}{*}{ Itens } & \multicolumn{3}{|c|}{$\mathrm{CVC}_{\mathrm{c}}$} & \multicolumn{4}{|c|}{ Dimensão teórica } \\
\hline & & CL & PP & RT & J1 & J2 & J3 & 0 \\
\hline 44 & $\begin{array}{l}\text { Eu dou exemplo de alimentação } \\
\text { saudável para meu filho me alimentando } \\
\text { de forma saudável. }\end{array}$ & 0,90 & 0,96 & 0,96 & VII & VII & VII & VII \\
\hline 45 & $\begin{array}{l}\text { Frequentemente coloco meu filho em } \\
\text { uma dieta para controlar seu peso. }\end{array}$ & 0,90 & 0,96 & 0,96 & $X I$ & $X I$ & $X I$ & $X I$ \\
\hline 46 & $\begin{array}{l}\text { Eu tento comer alimentos saudáveis na } \\
\text { frente do meu filho, mesmo que não } \\
\text { sejam os meus favoritos. }\end{array}$ & 0,90 & 0,96 & 0,96 & VII & VII & VII & VII \\
\hline 47 & $\begin{array}{l}\text { Eu tento demonstrar entusiasmo em } \\
\text { comer alimentos saudáveis. }\end{array}$ & 0,63 & 0,90 & 0,90 & VII & VII & VII & VII \\
\hline 48 & $\begin{array}{l}\text { Eu mostro a meu filho o quanto eu gosto } \\
\text { de comer alimentos saudáveis. }\end{array}$ & 0,90 & 0,90 & 0,90 & VII & VII & VII & VII \\
\hline \multirow[t]{2}{*}{49} & $\begin{array}{l}\text { Quando meu filho diz que já terminou de } \\
\text { comer, procuro fazer com que ele coma } \\
\text { mais uma (mais duas etc.) colheradas. }\end{array}$ & 0,90 & 0,90 & 0,90 & IX & IX & VII & IX \\
\hline & Total $\left(C^{\prime} C_{t}\right)$ & 0,82 & 0,87 & 0,88 & & & & \\
\hline
\end{tabular}

Onde: $\mathrm{N}^{0}=$ Número do item; $\mathrm{CVC}_{c}$ é o Coeficiente de Validade de Conteúdo total de cada item; $\mathrm{CVC}_{\mathrm{t}}=$ Coeficiente de Validade de Conteúdo total do questionário; $\mathrm{CL}=$ Clareza de Linguagem; $\mathrm{PP}=$ Pertinência Prática; RT = Referencial teórico;J1 = Juiz 1; J2 = Juiz 2; J3 = Juiz 3; O: Ordem original das dimensões propostas por Muscher-Eizenman (2007).

De acordo com a tabela 3, pode-se perceber que a maior parte dos itens apresentaram Coeficiente de Validade de Conteúdo total dos itens ( $\mathrm{CFC}_{\mathrm{c}}$ ) satisfatórios, ou seja, maior do que 0,8 (137). Todos os critérios avaliados apresentaram Coeficiente de Validade do Conteúdo total do questionário $\left(\mathrm{CVC}_{\mathrm{t}}\right)$ satisfatório, assim como os $\mathrm{CFC}_{c}$ dos critérios de Pertinência e Referencial teórico. 
Com relação à clareza de linguagem, os itens 1 , 2, 3, 4, 8, 18, 36 e 47 apresentaram índices insatisfatórios (entre 0,63 e 0,73). Para a próxima etapa, esses itens foram adequados à fim de que se tornassem mais claros, segundo as recomendações de Pasquali (156).

Quanto à dimensão teórica avaliada pelos juízes, o valor médio do coeficiente kappa foi 0,81 , ou seja, adequado, de acordo com a classificação de Landis e Koch (137).

\section{Análise fatorial Exploratória}

$\mathrm{Na}$ análise fatorial, de acordo com o critério de autovalor $\geq 1$, poderiam ser extraídos 12 componentes da Matriz R, com variância explicada de 56,9\%. Já o teste scree indicou de 5 a 12 componentes importantes.

Na primeira hipótese, utilizando todas as 49 variáveis, foi encontrada uma solução de 12 fatores que explicavam 56,9\% da variância e possuía índice de adequação da amostra (KMO) de 0,854. Porém, alguns problemas foram encontrados: 1) Alguns itens não alcançaram o valor mínimo de carga fatorial $(0,32) ; 2)$ Itens tiveram cargas aceitáveis e próximas em mais de um fator (cargas cruzadas); 3) Alguns fatores eram constituídos por apenas um item, sendo assim inviável precisar sua consistência interna, além de não estarem de acordo à recomendação de pelo menos três itens por fator.

Utilizando a técnica dos Eixos Principais da análise fatorial comum (AFC) e a rotação Oblimin, foram testadas e comparadas soluções fatoriais com 12, 11, 10, 9 e 8 fatores. Considerando as análises estatísticas e a base teórica da literatura existente, a estrutura fatorial que melhor se adequou para esta amostra foi a de 9 fatores. Foram excluídos oito itens que apresentaram cargas fatoriais menores do que 0,32 (Itens 13, 16, 17, 18, 21, 22, 42, 43) e dois outros itens foram excluídos por afetarem negativamente a significância do fator, diminuindo, assim, o alpha de Cronbach (itens 37 e 14).

Dessa forma, a solução fatorial final foi caracterizada por 9 fatores, 39 itens, com KMO de $0,830,56,5 \%$ de variância explicada e com explicação de $2 \%$ da covariância da matriz residual. Os itens que compuseram cada fator, suas respectivas cargas fatoriais, a porcentagem de variância por fator e a variância 
total explicada, os respectivos valores de Alpha de Cronbach, assim como as comunalidades dos itens são apresentador na Tabela 4.

Tabela 6 - Matriz fatorial Pattern

\begin{tabular}{|c|c|c|c|}
\hline Variável & $\begin{array}{c}\text { Cargas } \\
\text { fatoriais }\end{array}$ & $\begin{array}{c}\% \text { de } \\
\text { Variância }\end{array}$ & $\begin{array}{l}\text { Precisão } \\
\text { (Alpha) }\end{array}$ \\
\hline Fator 1 & & $10 \%$ & 0,83 \\
\hline $\begin{array}{l}\text { Item } 47 \text { - Eu tento demonstrar empolgação ao comer } \\
\text { alimentos saudáveis. }\end{array}$ & 0,88 & & \\
\hline $\begin{array}{l}\text { Item } 48 \text { - Eu mostro a meu filho o quanto eu gosto de } \\
\text { comer alimentos saudáveis. }\end{array}$ & 0,87 & & \\
\hline $\begin{array}{l}\text { Item } 46 \text { - Eu como alimentos saudáveis na frente do } \\
\text { meu filho, mesmo que não sejam os meus favoritos. }\end{array}$ & 0,67 & & \\
\hline $\begin{array}{l}\text { Item } 44 \text { - Em como de forma saudável para servir de } \\
\text { exemplo para meu filho. }\end{array}$ & 0,52 & & \\
\hline Fator 2 & & $9 \%$ & 0,81 \\
\hline $\begin{array}{l}\text { Item } 29 \text { - Eu dou a meu filho porções pequenas nas } \\
\text { refeições para controlar seu peso. }\end{array}$ & 0,72 & & \\
\hline $\begin{array}{l}\text { Item } 27 \text { - Incentivo meu filho a comer menos para que } \\
\text { não fique gordo. }\end{array}$ & 0,71 & & \\
\hline $\begin{array}{l}\text { Item } 35 \text { - Proíbo meu filho de comer certos alimentos, } \\
\text { pois o deixarão gordo. }\end{array}$ & 0,68 & & \\
\hline $\begin{array}{l}\text { Item } 34 \text { - Limito os alimentos que meu filho come e que } \\
\text { podem fazê-lo engordar. }\end{array}$ & 0,66 & & \\
\hline $\begin{array}{l}\text { Item } 33 \text { - Se meu filho come mais do que o normal em } \\
\text { uma refeição, tento restringir o que ele come na } \\
\text { refeição seguinte. }\end{array}$ & 0,64 & & \\
\hline $\begin{array}{l}\text { Item } 41 \text { - Não deixo meu filho beliscar entre as refeições } \\
\text { porque não quero que ele engorde. }\end{array}$ & 0,58 & & \\
\hline $\begin{array}{l}\text { Item } 45 \text { - Coloco meu filho de dieta com frequência para } \\
\text { controlar seu peso. }\end{array}$ & 0,48 & & \\
\hline $\begin{array}{l}\text { Item } 28 \text { - Se eu não regulasse a alimentação do meu } \\
\text { filho, ele comeria muita "besteira" (junk food). }\end{array}$ & 0,33 & & \\
\hline $\begin{array}{l}\text { Item } 40 \text { - Tento garantir que meu filho não coma uma } \\
\text { quantidade excessiva de seus alimentos favoritos. }\end{array}$ & 0,32 & & \\
\hline Fator 3 & & $9 \%$ & 0,87 \\
\hline $\begin{array}{l}\text { Item } 2 \text { - Controlo os salgadinhos de pacote que meu } \\
\text { filho come. }\end{array}$ & $-0,87$ & & \\
\hline Item 1 - Controle os doces que meu filho come. & $-0,79$ & & \\
\hline $\begin{array}{l}\text { Item } 3 \text { - Controlo os alimentos com excesso de gordura } \\
\text { que meu filho come. }\end{array}$ & $-0,79$ & & \\
\hline $\begin{array}{l}\text { Item } 4 \text { - Controlo a quantidade de bebidas açucaradas } \\
\text { que meu filho bebe. }\end{array}$ & $-0,72$ & & \\
\hline
\end{tabular}


(Continuação)

\begin{tabular}{|c|c|c|c|}
\hline Variável & $\begin{array}{l}\text { Cargas } \\
\text { fatoriai }\end{array}$ & \% de Variância & $\begin{array}{l}\text { Precisão } \\
\text { (Alpha) }\end{array}$ \\
\hline Fator 4 & & $5 \%$ & 0,76 \\
\hline $\begin{array}{l}\text { Item } 9 \text { - Dou a meu filho algo para comer ou beber caso ele } \\
\text { esteja triste, mesmo achando que ele está sem fome. }\end{array}$ & 0,85 & & \\
\hline $\begin{array}{l}\text { Item } 8 \text { - Dou a meu filho algo para comer ou beber caso ele } \\
\text { esteja sem nada para fazer, mesmo achando que ele está } \\
\text { sem fome. }\end{array}$ & 0,73 & & \\
\hline $\begin{array}{l}\text { Item } 7 \text { - Quando meu filho fica agitado, procuro dar-Ihe algo } \\
\text { para comer. }\end{array}$ & 0,59 & & \\
\hline Fator 5 & & $4 \%$ & 0,66 \\
\hline $\begin{array}{l}\text { Item } 49 \text { - Quando meu filho fiz que já terminou de comer, } \\
\text { procuro fazer com que ele coma mais colheradas de seu } \\
\text { prato }\end{array}$ & $-0,69$ & & \\
\hline $\begin{array}{l}\text { Item } 39 \text { - Se meu filho come apenas uma pequena porção, } \\
\text { tento fazer com que ele coma mais. }\end{array}$ & $-0,62$ & & \\
\hline $\begin{array}{l}\text { Item } 30 \text { - Se meu filho diz: "Não estou com fome", tento } \\
\text { fazer com que coma mesmo assim. }\end{array}$ & $-0,56$ & & \\
\hline Fator 6 & & $6 \%$ & 0,65 \\
\hline $\begin{array}{l}\text { Item } 20 \text { - Eu deixo meu filho ajudar a preparar as refeições } \\
\text { da família. }\end{array}$ & 0,60 & & \\
\hline $\begin{array}{l}\text { Item } 32 \text { - Eu estimulo meio filho a participar das compras } \\
\text { de supermercado. }\end{array}$ & 0,57 & & \\
\hline $\begin{array}{l}\text { Item } 31 \text { - Eu converso com meu filho sobre o valor } \\
\text { nutricional dos alimentos. }\end{array}$ & 0,51 & & \\
\hline $\begin{array}{l}\text { Item } 15 \text { - Eu envolvo meu filho no planejamento das } \\
\text { refeições da família. }\end{array}$ & 0,42 & & \\
\hline Fator 7 & & $5 \%$ & 0,66 \\
\hline $\begin{array}{l}\text { Item } 19 \text { - Eu ofereço a meu filho seus alimentos preferidos } \\
\text { em troca de um bom comportamento. }\end{array}$ & $-0,77$ & & \\
\hline $\begin{array}{l}\text { Item } 23 \text { - Eu ofereço doces para o meu filho como } \\
\text { recompensa de um bom comportamento. }\end{array}$ & $-0,75$ & & \\
\hline $\begin{array}{l}\text { Item } 36 \text { - Eu proíbo que meu filho coma doces ou seus } \\
\text { alimentos preferidos em resposta a um mau } \\
\text { comportamento }\end{array}$ & $-0,40$ & & \\
\hline Fator 8 & & $4 \%$ & 0,58 \\
\hline $\begin{array}{l}\text { Item } 6 \text { - Nas refeições, eu deixo meu filho escolher o que } \\
\text { eles quer dentro daquilo que foi preparado. }\end{array}$ & 0,57 & & \\
\hline Item 5 - Deixo meu filho comer o que ele quer. & 0,51 & & \\
\hline Item 11 - Deixo meu filho fazer lanches sempre que quer. & 0,46 & & \\
\hline $\begin{array}{l}\text { Item } 12 \text { - Permito que meu filho deixe a mesa quando está } \\
\text { satisfeito, mesmo que sua família ainda esteja comendo. }\end{array}$ & 0,36 & & \\
\hline $\begin{array}{l}\text { Item } 10 \text { - Se meu filho não gostar do que está sendo } \\
\text { servido, preparo outra coisa. }\end{array}$ & 0,35 & & \\
\hline
\end{tabular}


(Continuação)

\begin{tabular}{l|ccc}
\hline Variável & $\begin{array}{c}\text { Cargas } \\
\text { fatoriais }\end{array}$ & $\%$ de Variância & $\begin{array}{c}\text { Precisão } \\
\text { (Alpha) }\end{array}$ \\
\hline Fator 9 & & $6 \%$ & 0,74 \\
\hline $\begin{array}{l}\text { Item } 24 \text { - Eu incentivo meu filho a experimentar novos } \\
\text { alimentos. }\end{array}$ & 0,68 & & \\
$\begin{array}{l}\text { Item } 25 \text { - Eu converso com meu filho sobre a } \\
\text { importância de se comer alimentos saudáveis. }\end{array}$ & 0,58 & & \\
$\begin{array}{l}\text { Item } 26 \text { - Digo a meu filho que alimentos saudáveis são } \\
\text { gostosos. } \\
\text { Item } 38 \text { - Estimulo meu filho a comer uma variedade de } \\
\text { alimentos saudáveis. }\end{array}$ & 0,49 & \\
\hline
\end{tabular}

Os fatores da nova escala fatorial são:

- Modelagem parental (4 itens) - Esse fator descreve o quanto os pais relatam servir de modelo à criança em relação ao consumo de alimentos saudáveis;

- Restrição de escolha quantitativa e qualitativa de alimentos (9 itens) - Esse fator descreve o quanto os pais relatam restringir ou controlar a alimentação de seus filhos, para manter a saúde e o peso;

- Controle ao acesso de alimentos não saudáveis (4 itens) - Esse fator descreve o quanto os pais relatam controlar a ingestão de alimentos não saudáveis pelas crianças;

- Controle emocional pela comida (3 itens) - Esse fator descreve o quanto os pais relatam usar a comida para regular o estado emocional da criança;

- Pressão para comer (3 itens) - Esse fator descreve o quanto os pais relatam pressionar a criança a consumir mais alimentos nas refeições;

- Envolvimento da criança com a refeição da família (4 itens) - Esse fator descreve o quanto os pais relatam incentivar o envolvimento da criança no planejamento e preparo das refeições;

- Uso da comida como recompensa (3 itens) - Esse fator descreve o quanto os pais relatam usar a comida como recompensa para o comportamento da criança; 
- Permissividade e controle infantil (5 itens) - Esse fator descreve o quanto os pais permitem que a criança controle seu comportamento alimentar e as interaçãoes de alimentação entre ela e os pais; e

- Incentivo à experimentação e consumo saudável (4 itens) - Esse fator descreve o quanto os pais relatam incentivar a experimentação de novos alimentos e promover o consumo de uma alimentação equilibrada, variada e saudável.

As médias, desvios padrão, assimetria e curtose da solução fatorial final de 9 fatores e as escalas de atitudes relacionadas são apresentados na tabela 5 .

Tabela 7 - Média, desvio padrão, assimetria e curtose (achatamento) dos 9 fatores do CFPQ e das 3 escalas de atitude relacionadas.

\begin{tabular}{lccc}
\hline & $\begin{array}{c}\text { Média } \\
\text { (DP) }\end{array}$ & Assimetria & Curtose \\
\hline Escala adaptada CFPQ & & & \\
& & & \\
Modelagem Parental (4) & $4,24(0,9)$ & $-1,45$ & 1,85 \\
Restrição de escolha quantitativa e qualitativa de & $2,42(0,8)$ & 0,47 & $-0,22$ \\
alimentos (9) & $4,13(0,9)$ & $-1,23$ & 1,28 \\
Controle ao acesso de alimentos não saudáveis (4) & $1,50(0,7)$ & 2,19 & 6,48 \\
Controle emocional pela comida (3) & $3,09(1,0)$ & $-0,25$ & $-0,66$ \\
Pressão para comer (3) & $3,52(1,0)$ & $-0,46$ & $-0,44$ \\
Envolvimento da criança com a refeição da família (4) & $1,87(0,9)$ & 1,04 & 0,45 \\
Uso da comida como recompensa (3) & $2,67(0,7)$ & 0,32 & $-0,06$ \\
Permissividade e controle infantil (5) & $4,64(0,6)$ & $-2,19$ & 5,67 \\
Incentivo à experimentação e consumo saudável (4) & & & \\
Escala de atitudes relacionadas & & & $-1,34$ \\
\hline Responsabilidade com a alimentação da criança (3) & $4,64(0,5)$ & $-1,65$ & 2,89 \\
Percepção do peso (1) & $2,87(0,5)$ & $-0,68$ & 3,43 \\
Preocupação com excesso de peso (3) & $2,59(1,2)$ & 0,372 & $-0,99$ \\
Preocupação com baixo peso (2) & $2,85(0,5)$ & 0,13 & - \\
\hline
\end{tabular}

Os resultados da correlação bivariada mostraram que 0 fator 1 (Modelagem parental) se relaciona positivamente com o fator 3 (Controle ao 
acesso de alimentos não saudáveis) $r(844)=0,34, p<0,001$; fator 6 (Envolvimento da criança com a refeição da família) $r(844)=0,35, p<0,001$; e fator 9 (Incentivo à experimentação e consumo saudável) $r(844)=0,47, p<$ 0,001 . Tais relações podem ser consideradas moderadas (157). Ou seja, as mães que servem de modelo à criança em relação ao consumo de alimentos saudáveis também tendem a apresentar maior controle ao acesso de alimentos não saudáveis pelas crianças, maior incentivo ao envolvimento das crianças no planejamento e preparo das refeições, além do maior incentivo à experimentação de novos alimentos e promoção do consumo de uma alimentação equilibrada, variada e saudável. $O$ fator 9 (Incentivo à experimentação e consumo saudável) e o fator 6 (Envolvimento da criança com a refeição da família) também apresentaram correlação entre si positiva moderada $r(844)=0,45, p<0,001$ As demais correlações entre os fatores são consideradas fracas, conforme pode ser visto na tabela 6 .

Tabela 8 - Correlações (Pearson) entre os nove fatores.

\begin{tabular}{|c|c|c|c|c|c|c|c|c|c|}
\hline \multirow[b]{2}{*}{ Variáveis } & \multicolumn{9}{|c|}{ Correlações } \\
\hline & $\begin{array}{c}\text { Fator } \\
1\end{array}$ & $\begin{array}{l}\text { Fator } \\
2\end{array}$ & $\begin{array}{c}\text { Fator } \\
3\end{array}$ & $\begin{array}{c}\text { Fator } \\
4\end{array}$ & $\begin{array}{c}\text { Fator } \\
5\end{array}$ & $\begin{array}{l}\text { Fator } \\
6\end{array}$ & $\begin{array}{c}\text { Fator } \\
7\end{array}$ & $\begin{array}{c}\text { Fator } \\
8\end{array}$ & $\begin{array}{c}\text { Fator } \\
9\end{array}$ \\
\hline $\begin{array}{c}1 \text { - Modelagem } \\
\text { Parental }\end{array}$ & 1,00 & & & & & & & & \\
\hline $\begin{array}{c}2 \text { - Restrição de } \\
\text { escolha } \\
\text { quantitativa e } \\
\text { qualitativa de } \\
\text { alimentos }\end{array}$ & $0,17^{\star \star}$ & 1,00 & & & & & & & \\
\hline $\begin{array}{l}3 \text { - Controle ao } \\
\text { acesso de } \\
\text { alimentos não } \\
\text { saudáveis }\end{array}$ & $0,34^{\star *}$ & $0,12^{* *}$ & 1,00 & & & & & & \\
\hline $\begin{array}{c}4 \text { - Controle } \\
\text { emocional pela } \\
\text { comida }\end{array}$ & $-0,13^{* *}$ & $0,07^{*}$ & $-0,15^{* *}$ & 1,00 & & & & & \\
\hline $\begin{array}{l}5 \text { - Pressão } \\
\text { para comer }\end{array}$ & 0,05 & 0,02 & $-0,02$ & $0,06^{*}$ & 1,00 & & & & \\
\hline $\begin{array}{c}6 \text { - } \\
\text { Envolvimento } \\
\text { da criança com } \\
\text { a refeição da } \\
\text { família }\end{array}$ & $0,35^{\star \star}$ & $0,14^{* \star}$ & $0,18^{* *}$ & $-0,09^{\star *}$ & $-0,04$ & 1,00 & & & \\
\hline
\end{tabular}




\begin{tabular}{|c|c|c|c|c|c|c|c|c|c|}
\hline $\begin{array}{l}7 \text { - Uso da } \\
\text { comida como } \\
\text { recompensa }\end{array}$ & $-0,04^{*}$ & $0,14^{* *}$ & $-0,18^{* *}$ & $0,20^{\star *}$ & $0,21^{* *}$ & $-0,02$ & 1,00 & & \\
\hline $\begin{array}{c}8 \text { - } \\
\text { Permissividade } \\
\text { e controle } \\
\text { infantil }\end{array}$ & $-0,24^{* *}$ & $-0,11^{* *}$ & $-0,19^{* *}$ & $0,22^{\star \star}$ & $-0,01$ & $-0,06$ & 0,07 & 1,00 & \\
\hline $\begin{array}{l}9 \text { - Incentivo à } \\
\text { experimentação } \\
\text { e consumo } \\
\text { saudável }\end{array}$ & $0, \mathbf{4 7} 7^{\star \star}$ & $0,11^{*}$ & $0,27^{\star *}$ & $-0,15^{\star *}$ & 0,03 & $0,45^{* *}$ &,- 09 & $-0,19^{* *}$ & 1,00 \\
\hline
\end{tabular}

*. A correlação é significativa no nível 0,05.

**. A correlação é significativa no nível 0,01.

Comparando o modelo fatorial encontrado neste estudo e o original, proposto por Musher-Eizenman e Holub (46), observa-se que cinco fatores são iguais, sendo eles Monitoramento (denominado como "Controle ao acesso de alimentos não saudáveis" para esta versão), Regulação emocional (denominado "controle emocional pela comida"), Comida como recompensa (denominado "uso da comida como recompensa".), Controle da Criança ("Permissividade e controle infantil") e Exemplo dos pais ("Modelagem parental"). Os demais fatores sofreram algum tipo de modificação, a saber: as variáveis que compunham os fatores Restrição para controle do peso e Restrição para manter a saúde se apresentaram pertencendo a um único fator, denominado neste estudo por "Restrição de escolha quantitativa e qualitativa de alimentos" e os itens 18, 21 e 43 foram excluídos. Um item foi excluído do fator Incentivo ao balanço e variedade (item 13), e esse fator recebeu o nome de "Incentivo à experimentação e consumo saudável". O item 17 foi excluído do fator Pressão para comer e optou-se por manter esta denominação. O fator antes denominado Envolvimento recebeu um novo item (31) e passou a ser chamado por "Envolvimento da criança com a refeição da família".

Com essa nova conformação, todos os itens do fator "Ambiente saudável" foram excluídos. Um item do fator Ensino sobre nutrição foi excluído e os demais itens foram realocados (item 25 como "Incentivo à experimentação e consumo saudável" e item 31 como "Envolvimento da criança com a refeição da família"). O Apêndice $C$ apresenta o modelo fatorial final. 
O último passo foi verificar a validade externa das subescalas. A correlação bivariada (Pearson) foi realizada entre os nove fatores e os itens de atitudes relacionadas. $O$ fator 2 (Restrição de escolha quantitativa e qualitativa de alimentos) e a percepção do peso da criança também apresentaram correlação positiva moderada $r(781)=0,29, p<0,001$. Isso significa que as mães que mais restringem ou controlam a alimentação de seus filhos, para manter a saúde e o peso, também apresentaram maior avaliação do peso de seus filhos, em comparação com outras que são mães de crianças da mesma idade e sexo. As demais correlações entre os fatores são consideradas fracas, conforme pode ser visto na Tabela 7.

Tabela 9 - Correlações (Pearson) entre os fatores do CFPQ e escalas de atitudes relacionadas.

\begin{tabular}{ccccccccccc}
\hline \multicolumn{10}{c}{ Correlações } \\
\hline Variáveis & Fator 1 & Fator 2 & Fator 3 & Fator 4 & Fator 5 & Fator 6 & Fator 7 & Fator 8 & Fator 9 \\
\hline Responsabilidade & $\mathbf{0 , 3 1 ^ { * * }}$ & $\mathbf{0 , 2 3 ^ { * * }}$ & $\mathbf{0 , 2 1 ^ { * * }}$ & $-0,05$ & $0,12^{* *}$ & $0,09^{* *}$ & 0,004 & $-0,16^{* *}$ & $\mathbf{0 , 2 4 ^ { * * }}$ \\
$\begin{array}{c}\text { Percepção do } \\
\text { peso das } \\
\text { crianças }\end{array}$ & $-0,06$ & $\mathbf{0 , 2 0 * *}$ & 0,03 & 0,03 & $-0,17^{* *}$ & 0,04 & $-0,07^{*}$ & $-0,01^{* *}$ & $-0,02$ \\
$\begin{array}{c}\text { Preocupação } \\
\text { com excesso de } \\
\text { peso }\end{array}$ & $0,10^{* *}$ & $\mathbf{0 , 4 2 *}$ & 0,07 & 0,02 & 0,03 & $0,08^{*}$ & 0,01 & $-0,13^{* *}$ & 0,05 \\
$\begin{array}{c}\text { Preocupação } \\
\text { com baixo peso }\end{array}$ & $-0,01$ & 0,06 & $-0,06$ & 0,01 & $\mathbf{0 , 2 3 * *}$ & 0,04 & 0,06 & $-0,06$ & $-0,02$ \\
\hline
\end{tabular}

*. A correlação é significativa no nível 0,05

**. A correlação é significativa no nível 0,01

Este é o primeiro estudo de validação e avaliação do CFPQ no Brasil, no entanto, este instrumento já foi adaptado para vários países. A tabela 8 apresenta a comparação da estrutura fatorial de estudos realizados conduzindo a análise fatorial. 
Tabela 10 - Comparação da estrutura fatorial de estudos realizados conduzindo a análise fatorial no CFPQ.

\begin{tabular}{|c|c|c|c|c|c|}
\hline & $\begin{array}{c}\text { Estado } \\
\text { Unidos } \\
\text { MUSHER- } \\
\text { EIZENMAN; } \\
\text { HOLUB, 2007 } \\
\text { (46) }\end{array}$ & $\begin{array}{c}\text { Noruega } \\
\text { (crianças de } \\
10 \text { a } 12 \text { anos) } \\
\text { MELBYE; } \\
\text { ØGAARD; } \\
\text { ØVERBY, } \\
2011 \text { (143) }\end{array}$ & $\begin{array}{c}\text { Malásia } \\
\text { SHOHAIMI; } \\
\text { WEI; SHARIFF, } \\
2014(152)\end{array}$ & $\begin{array}{c}\text { Nova } \\
\text { Zelândia } \\
\text { HASZARD et } \\
\text { al., 2013 } \\
\text { (153) }\end{array}$ & Brasil \\
\hline Monitoramento* & $\alpha=0,81$ & $\alpha=0,84$ & $\alpha=0,9$ & $\alpha=0,9$ & $\alpha=0,87$ \\
\hline Itens & $1,2,3,4$ & $1,2,3,4$ & $1,2,3,4$ & $1,2,3,4$ & $1,2,3,4$ \\
\hline $\begin{array}{l}\text { Regulação } \\
\text { emcoional }{ }^{\star}\end{array}$ & $\alpha=0,74$ & - & $\alpha=0,61$ & - & $\alpha=0,76$ \\
\hline Itens & $7,8,9$ & - & $7,8,9$ & - & $7,8,9$ \\
\hline $\begin{array}{l}\text { Comida como } \\
\text { recompensa* }\end{array}$ & $\alpha=0,69$ & - & $\alpha=0,76$ & - & $\alpha=0,66$ \\
\hline Itens & $19,23,36$ & - & 19,23 & - & $19,23,36$ \\
\hline $\begin{array}{c}\text { Controle da } \\
\text { criança }^{*}\end{array}$ & $\alpha=0,64$ & $\alpha=0,55$ & $\alpha=0,45$ & $\alpha=0,63$ & $\alpha=0,58$ \\
\hline Itens & $5,6,10,11,12$ & $5,6,10,11,12$ & $5,6,10,11$ & $5,6,10,11$ & $\begin{array}{c}5,6,10,11 \\
12\end{array}$ \\
\hline $\begin{array}{l}\text { Exemplo dos } \\
\text { pais }^{\star}\end{array}$ & $\alpha=0,8$ & $\alpha=0,66$ & $\alpha=0,64$ & - & $\alpha=0,83$ \\
\hline Itens & $44,46,47,48$ & $44,46,47,48$ & $44,46,47,48$ & - & $\begin{array}{c}44,46,47 \\
48\end{array}$ \\
\hline $\begin{array}{l}\text { Restrição para } \\
\text { controle do } \\
\text { peso* }\end{array}$ & $\alpha=0,7$ & $\alpha=0,83$ & $\alpha=0,55$ & - & $\alpha=0,81$ \\
\hline Itens & $\begin{array}{l}18,27,29,33 \\
34,35,41,45\end{array}$ & $\begin{array}{l}18,27,29,33 \\
34,35,41,45\end{array}$ & $\begin{array}{c}27,29,33,34,35 \\
, 45,41\end{array}$ & - & $\begin{array}{l}27,28,29, \\
33,34,35, \\
40,41,45\end{array}$ \\
\hline $\begin{array}{l}\text { Restrição para } \\
\text { manter a saúde* }\end{array}$ & $\alpha=0,81$ & $\alpha=0,73$ & $\alpha=0,57$ & - & - \\
\hline Itens & $21,28,40,43$ & $21,28,40,43$ & 21,28 & - & - \\
\hline $\begin{array}{c}\text { Ensino sobre } \\
\text { nutrição** }\end{array}$ & 0,68 & 0,44 & 0,83 & - & - \\
\hline Itens & $25,31,42$ & $25,31,42$ & 25,31 & - & - \\
\hline
\end{tabular}




\begin{tabular}{|c|c|c|c|c|c|}
\hline & $\begin{array}{c}\text { Estado } \\
\text { Unidos } \\
\text { MUSHER- } \\
\text { EIZENMAN; } \\
\text { HOLUB, 2007 } \\
\text { (46) }\end{array}$ & $\begin{array}{c}\text { Noruega } \\
\text { (crianças de } \\
10 \text { a } 12 \text { anos) } \\
\text { MELBYE; } \\
\text { ØGAARD; } \\
\text { ØVERBY, } \\
2011 \text { (143) }\end{array}$ & $\begin{array}{c}\text { Malásia } \\
\text { SHOHAIMI; } \\
\text { WEI; SHARIFF, } \\
2014(152)\end{array}$ & $\begin{array}{c}\text { Nova Zelândia } \\
\text { HASZARD et } \\
\text { al., } 2013(153)\end{array}$ & Brasil \\
\hline $\begin{array}{l}\text { Incentivo ao } \\
\text { balanço e } \\
\text { variedade* }^{*}\end{array}$ & $\alpha=0,58$ & $\alpha=0,66$ & $\alpha=0,59$ & - & $\alpha=0,74$ \\
\hline Itens & $13,24,26,38$ & $13,24,26,38$ & $13,24,26$ & - & $\begin{array}{c}24,25,26 \\
38\end{array}$ \\
\hline $\begin{array}{l}\text { Pressão para } \\
\text { comer }^{\star}\end{array}$ & $\alpha=0,79$ & $\alpha=0,61$ & $\alpha=0,73$ & $\alpha=0,72$ & $\alpha=0,66$ \\
\hline Itens & $17,30,39,49$ & $17,30,39$ & $30,39,49$ & $\begin{array}{c}9,19,23,30,36 \\
, 39,49\end{array}$ & $30,39,49$ \\
\hline $\begin{array}{l}\text { Ambiente } \\
\text { saudável }^{*}\end{array}$ & $\alpha=0,75$ & $\alpha=0,57$ & $\alpha=0,69$ & - & - \\
\hline Itens & $14,16,22,37$ & $14,16,22,37$ & 14,22 & - & - \\
\hline Envolvimento* & $\alpha=0,77$ & $\alpha=0,67$ & $\alpha=0,67$ & - & $\alpha=0,65$ \\
\hline Itens & $15,20,32$ & $15,20,32$ & $15,20,32$ & - & $\begin{array}{c}15,20,31 \\
32\end{array}$ \\
\hline Restrição** & - & - & - & $\alpha=0,75$ & - \\
\hline Itens & - & - & - & $\begin{array}{c}27,29,33,34,3 \\
5,40,41,45\end{array}$ & - \\
\hline $\begin{array}{l}\text { Orientação de } \\
\text { alimentação } \\
\text { saudável }^{\star *}\end{array}$ & - & - & - & $\alpha=0,82$ & - \\
\hline Itens & - & - & - & $\begin{array}{l}14,24,25,26,3 \\
1,38,44,47,48\end{array}$ & - \\
\hline Total de itens & 49 itens & 42 itens & 39 itens & 32 itens & 39 itens \\
\hline $\begin{array}{l}\text { \# Itens } \\
\text { Excluídos }\end{array}$ & & $\begin{array}{l}7,8,9,19 \\
23,36,49\end{array}$ & $\begin{array}{c}12,16,17,18 \\
36,37,38,40 \\
42,43\end{array}$ & $\begin{array}{c}7,13,15,16 \\
17,18,20 \\
21,32,37 \\
42,43,22 \\
46,8,28,12\end{array}$ & $\begin{array}{c}13,16,17 \\
18,21 \\
22,42 \\
43,37,14\end{array}$ \\
\hline
\end{tabular}

Na Tabela 4 foram apresentados também os valores de comunalidade de cada uma das variáveis do instrumento, considerando a solução fatorial de nove 
fatores e 39 itens. O tamanho da comunalidade (variância comum) define a qualidade da representação comportamental do traço latente pelas variáveis observáveis (itens) (142). De acordo com Hair et al (133), as variáveis em geral deveriam ter comunalidades maiores do que 0,5 para serem mantidas na análise. Por questões teóricas e conceituais, optou-se por manter as variáveis com comunalidades menores do que 0,5. Tabachnick \& Fidell (144) ressalta que, em relação às comunalidades, amostras maiores que 500 são necessárias em casos de condições de baixa comunalidades e fatores determinados fracamente, de forma que este estudo atende tal critério.

\section{Discussão}

$\mathrm{Na}$ elaboração da tradução final deste trabalho, a adaptação cultural foi levada em conta desde a primeira etapa. No momento da tradução, exemplos utilizados no questionário original como "pastries", comum na cultura americana, foi substituído por "docinhos", largamente consumidos no Brasil. Outro exemplo disso são os "soda/pop" e "kool-aid", que foram substituídos por refrigerantes e sucos em pó. O termo "junk food", foi mantido na tradução final, por ser uma expressão já conhecida no português. No entanto, optou-se por associá-lo ao termo "besteira", considerado seu equivalente na cultura brasileira.

Além disso, o questionário original utiliza os dois gêneros ( $\mathrm{He} / \mathrm{she}$ ) quando se refere à criança. Porém verifica-se que essa tradução para o português tornaria o texto das questões extenso, dificultando sua leitura ("o/a seu/sua filho/a"), por isso, optou-se por utilizar apenas a expressão "seu filho", no genérico masculino.

Outro termo que gerou confusão foi o "snack", pois pode assumir dois significados, sendo o primeiro como lanches entre as grandes refeições e o segundo como sinônimo de comer besteira, petiscar. Essa ambiguidade também foi observada por Musher-Eizenman e Holub (46), durante a validação do questionário original. No Brasil, esses termos são distintos, gerando a dificuldade no momento da tradução. Lanches podem ser feitos com alimentos saudáveis ou não saudáveis, sendo o significado oposto utilizado como sinônimo de má alimentação e prejudicial à saúde das crianças. Dessa forma, assumiu-se que nas questões 2 e 16, em "How much do you keep track of the snack food" e "I 
keep a lot of snack food" como sendo o sentido de alimento não saudável, pois o comportamento que deve ser observado está ligado ao monitoramento dos pais e a investigação de um ambiente saudável ou não em casa; e na questão 11 "Do you allow this child to eat snacks whenever s/He wants" como lanches de forma geral, pois não ter horário para refeições e comer em qualquer momento demonstra um comportamento em que a criança assume o controle alimentar perante aos pais, o que de certo modo, não é desejável.

Outro ponto relevante é o papel dos juízes em relação à validade de conteúdo de um questionário traduzido. Mesmo com a realização de todas as etapas da tradução revers. Importantes contribuições foram feitas para melhorar a compreensão das questões e garantir a sua aplicabilidade. Em relação às dimensões teóricas, verificou-se que o coeficiente kappa ( $k$ ), que se refere à concordância das questões, mostrou-se adequado. No entanto, a discordância entre os itens pode ser gerada pela multidimensionalidade atribuída a este questionário, além das dimensões se relacionarem em muitos momentos.

No que se refere à análise fatorial, uma estrutura fatorial de 39 itens e nove fatores tem um melhor ajuste do que o de doze fatores, pois menos fatores oferecem uma solução mais parcimoniosa, considerando o objetivo principal da análise fatorial sendo a redução da ordem de uma matriz de intercorrelações e sua simplificação, tornando os resultados mais interpretáveis $(142,144)$.

Ressalta-se que, em nenhuma das soluções fatoriais testadas, os fatores excluídos apresentaram-se com a mesma conformação da escala original. Além disso, possuíam cargas significantes baixas, evidenciando que esses itens apresentavam baixa variância de explicação do fator e estas por sua vez não são correlacionadas a um nível aceitável. Além disso, optou-se por utilizar nova denominação à maioria dos fatores com base no conteúdo semântico dos itens que o compõem, além de adaptá-los à realidade brasileira, de forma que o rótulo utilizado representasse cada fator determinado da melhor forma possível.

Nesta amostra, a maioria das correlações encontradas entre os 9 fatores mostraram-se estatisticamente significantes, no entanto são consideradas fracos $(r<0,3)$. Correlações positivas moderadas entre a modelagem parental, Incentivo à experimentação e consumo saudável e o Envolvimento da criança 
com a refeição da família também foram encontrados no modelo de 12 fatores proposto por Musher-Eizenman e Holub (46).

Em relação à média de respostas de cada fator, observou-se que os fatores que apresentaram maior média foram a modelagem parental $(M=4,24$, $\mathrm{DP}=0,9)$, Controle ao acesso de alimentos não saudáveis $(M=4,13, \mathrm{DP}=0,9)$ e Incentivo à experimentação e consumo saudável $(M=4,64, D P=0,6)$. Já o Controle emocional pela comida $(\mathrm{M}=1,50, \mathrm{DP}=0,7)$ e o Uso da comida como recompensa $(M=1,87, D P=0,9)$ apresentaram as menores média.

É desejável que práticas como a modelagem parental, envolvimento da criança com a refeição da família e incentivo a experimentação e consumo saudável tenham médias maiores, e que aquelas coercitivas e centradas no pais, como Pressão para comer, Uso da comida como recompensa, Restrição de escolha quantitativa e qualitativa de alimentos, Controle ao acesso de alimentos não saudáveis e Controle emocional pela comida apresentem menor média. Observa-se ainda que, apesar da literatura mostrar que o controle ao acesso de alimentos não saudáveis pode ter um efeito negativo sobre o estado nutricional da criança $(50,51)$ e aumento do desejo por alimentos restringidos $(158)$, os itens pertencentes ao fator não deixam claro qual a estratégia de restrição utilizada. Sabe-se que estratégias de restrição menos evidentes de controle da alimentação infantil podem ser efetivas para a redução do consumo de alimentos não saudáveis, evitando os prejuízos de formas de controle mais evidentes. Deve-se considerar ainda a influência da desejabilidade social nessas questões.

Os resultados da caracterização da amostra indicam que, em média as participantes do estudo têm maior renda familiar e educação do que o Brasil como um todo. De acordo com os indicadores da Pesquisa Nacional por Amostra de Domicílios Contínua do IBGE (159), no primeiro trimestre de 2015, a maioria dos brasileiros possuía Ensino fundamental incompleto ou equivalente $(30,1 \%)$, seguido de Ensino médio completo ou equivalente (26\%). Além disso, o rendimento médio real de todos os trabalhos, habitualmente recebido por mês, pelas pessoas de 14 anos ou mais de idade, ocupadas na semana de referência, foi estimado em $\mathrm{R} \$ 1.840,00$ (2,3 salários mínimos). Dessa forma, apesar da larga amostra obtida, os dados deste estudo não podem ser generalizáveis a toda a população brasileira. Mais estudo de validação são necessários, com 
outros extratos socioeconômicos da população Essa também é uma fragilidade do estudo original da Musher-Eiznman e Holub (46).

Outra questão que deve ser levada em consideração é o fato de que resultados obtidos por meio de instrumentos autopreenchidos podem estar sujeitos a esquecimentos, desejabilidade social e falha de interpretação dos itens.

\section{Considerações finais}

Em conclusão, com as modificações sugeridas por essa análise, o CFPQ foi aprimorado, resultando em um instrumento adaptado para o Brasil que contribui para o entendimento do ambiente alimentar infantil e suas práticas parentais relacionadas, sendo um bom início de uso no Brasil. Consideráveis melhorias na modificação dos índices e coeficientes de confiabilidade também suporta o novo modelo.

Sugere-se que estudos futuros avaliem as práticas comportamentais parentais e sua influência na alimentação infantil também na perspectiva dos pais, a fim de verificar se os padrões são semelhantes. Fortalece-se a necessidade de replicação da estrutura fatorial estudada com uma amostra mais diversa e assim, sendo possível definir as práticas parentais de forma mais generalizável.

Ademais, sugere-se que sejam realizadas pesquisas qualitativas buscando investigar a interpretação e desenvolvimento conceitual dos itens, além da busca de questões adicionais na literatura que não estejam contempladas no CFPQ.

O melhor entendimento das práticas parentais se faz necessário para possibilitar mais pesquisas ou intervenções na identificação de problemas cada vez mais presentes no Brasil, tais como a obesidade infantil. 


\section{PRÁTICAS MATERNAS E OUTROS DETERMINANTES RELACIONADOS AO CONSUMO DE FRUTAS E HORTALIÇAS POR CRIANÇAS DE 18 MESES A 8 ANOS DE IDADE}

\section{RESUMO}

O consumo de frutas e hortaliças exerce um importante papel no estabelecimento de uma dieta diversificada e saudável na infância, sendo importante na promoção da saúde e prevenção de doenças. No entanto, frente ao baixo consumo desses alimentos pela população brasileira, faz-se necessário o entendimento da complexidade de fatores que influenciam o consumo e o comportamento alimentar das crianças. Dessa forma, o estudo em questão teve o objetivo de associar as múltiplas práticas maternas e outros determinantes ao consumo de frutas e hortaliças por crianças de 18 meses a 8 anos. Foi realizado um estudo transversal do tipo survey, no qual 681 mães preencheram um instrumento autoadministrado, contendo questões relacionadas aos hábitos alimentares infantis, práticas parentais e outros hábitos de vida relacionados à alimentação, bem como consumo alimentar da mãe e da criança. Os resultados mostram que o consumo materno é um forte preditor do consumo de alimentos saudáveis pela criança. A frequência de compra de alimentos não saudáveis e a idade também apareceram como preditores do consumo, apresentando associação inversa. Não houveram correlações significativas entre as práticas parentais e o consumo de frutas e hortaliças. Assim, para intervenções efetivas, sugere-se 0 incentivo do consumo de alimentos saudáveis pelos pais, ressaltando a importância da disponibilidade, acesso e exposição de alimentos saudáveis em casa.

Palavras-chave: Consumo alimentar; práticas parentais; Influência materna; Promoção de alimentação saudável; Frutas e hortaliças. 


\section{Summary}

Consumption of fruits and vegetables plays an important role in establishing a diverse and healthy diet in childhood is important in health promotion and disease prevention. However, compared to the low consumption of such foods by the Brazilian population, it is necessary to understand the complexity of factors that influence consumption and eating behaviour of children. Thus, the present study aimed to associate multiple maternal feeding practices and other determinants of consumption of fruits and vegetables by children 18 months to 8 years. It was conducted a cross-sectional study of the survey type, in which 681 children whose mothers completed a self-administered instrument, containing issues related to children's eating habits, parenting and other life habits related to food, as well as mother and child food consumption. The results show that the maternal consumption is a strong predictor of the consumption of healthy food for the child. The frequency purchase of unhealthy food and age also appeared as predictors of consumption, an inverse association. There were no significant correlations between parenting practices and consumption of fruits and vegetables. So for effective interventions, it is suggested encouraging the consumption of healthy foods by parents, emphasizing the importance of availability, access and display of healthy foods at home.

Keywords: food consumption, feeding practices, maternal influence, healthy eating promotion, fruits and vegetables. 


\section{Introdução}

O consumo de frutas e hortaliças exerce um importante papel no estabelecimento de uma dieta diversificada e saudável, sendo importante na promoção da saúde e prevenção de doenças (160). Na infância, o consumo adequado de frutas e hortaliças está associado ao crescimento e desenvolvimento intelectual e menores índices de gordura corporal (161). Estudos têm mostrado ainda que o consumo diário desses alimentos pode contribuir para a prevenção de doenças crônicas não transmissíveis, como doenças cardiovasculares, Diabetes Mellitus tipo $2(160,162,163)$ e certos tipos de câncer (164). Além disso, frutas e hortaliças podem exercer o papel de substitutos do consumo de alimentos ricos em gordura saturada, açúcar e sal (160).

No entanto, para se obter os benefícios de proteção e promoção desses alimentos, a Organização Mundial da Saúde (OMS) e a Organização das Nações Unidas para Alimentação e Agricultura (FAO) preconizam ingestão de no mínimo $400 \mathrm{~g}$ de frutas e hortaliças por dia (160), sendo recomendado três porções ou mais de frutas e três de hortaliças (salada crua e verdura) diariamente para pessoas maiores de 2 anos de idade (11).

No Brasil, menos de $10 \%$ da população atinge essas recomendações (10). Em um estudo realizado com 4957 crianças de 6 a 59 meses observou-se que $44,6 \%$ das crianças consumiram diariamente frutas, $12,7 \%$, salada crua e $21,8 \%$, verduras (165). Em relação aos jovens, uma pesquisa nacional realizada com estudantes de 13 a 15 anos mostrou que o consumo de hortaliças foi de $31,3 \%$, enquanto $31,5 \%$ dos escolares apresentou o consumo de frutas frescas em cinco dias ou mais (166). Ou seja, o consumo desses alimentos está muito aquém da recomendação, considerando diversas faixas etárias, inclusive a infância, período crítico de formação de hábitos alimentares e crescimento e desenvolvimento da criança (167).

Por isso, promover hábitos alimentares saudáveis na infância, incluindo o incentivo ao consumo de frutas e hortaliças, exerce um papel fundamental. Evidências sugerem que o padrão de consumo nessa fase tem efeitos a longo prazo e permanecem na fase adulta $(168,169)$. Além disso, os hábitos 
alimentares em crianças podem ser mais flexíveis a mudanças do que os hábitos alimentares em adolescentes e adultos (170).

Diversos fatores influenciam os hábitos alimentares infantis, e consequentemente o seu consumo de frutas e hortaliças, incluindo fatores individuais, como o sexo, a idade, as preferências alimentares e conhecimentos e atitudes de nutrição; os fatores interpessoais, que envolvem a relação com os pais e familiares e os seus pares; fatores ambientais, ou seja, acessibilidade e disponibilidade de alimentos, o tamanho das porções e ambiente escolares; e fatores societais, que envolve a mídia e a publicidade, as políticas públicas, a regulação e as normas sociais $(8,171)$.

O comportamento alimentar das crianças é fortemente influenciado pelo ambiente familiar. Os pais são os responsáveis pelas escolhas alimentares da família, servem de modelo para escolhas e padrões alimentares e usam práticas de alimentação para reforçar o desenvolvimento de padrões e comportamentos alimentares que consideram adequados para seus filhos (167). Essas práticas, por sua vez, estão associadas ao comportamento alimentar da criança, incluindo os estilos específicos de alimentação, as escolhas e preferências de alimentos e a sua regulação da ingestão energética (41).

Certas práticas parentais relacionadas ao consumo de frutas e hortaliças têm sido amplamente estudadas. Entre elas, destaca-se o controle parental, que envolve práticas restritivas de alimentos não saudáveis e a pressão para comer. No entanto, os resultados sobre como essas práticas estão associadas ao comportamento ainda são inconsistentes. De forma geral, estudos mostram uma associação negativa entre crianças que são pressionadas a comer e o consumo de frutas e hortaliças $(13,65)$, assim como a restrição materna esteve relacionadas a um menor consumo desses alimentos (57).

Assim, maiores entendimentos de quais e como as práticas parentais de alimentação promovem o consumo de frutas e hortaliças são necessários. Além disso, para que sejam realizadas intervenções efetivas, o entendimento da complexidade de fatores que influenciam o comportamento alimentar das crianças é necessário. Por isso, o estudo em questão tem o objetivo de associar 
as múltiplas práticas maternas e outros determinantes ao consumo de frutas e hortaliças por crianças de 18 meses a 8 anos. Essa faixa etária foi escolhida de acordo com proposto por por Musher-Eizenman e Holub (2007) em seu estudo de validação de um novo instrumento de práticas parentais, adotado neste trabalho.

\section{Métodos}

\section{Tipo de estudo e participantes}

Foi realizada uma pesquisa transversal, do tipo survey. A variável critério investigada foi o consumo de marcadores de alimentos saudáveis (frutas, verdura e salada crua). As variáveis preditoras utilizadas foram as práticas parentais e demais hábitos de vida associados à alimentação e variáveis sociodemográficas. Este estudo faz parte de uma pesquisa maior intitulada Práticas Parentais e a Alimentação Infantil. A pesquisa foi aprovada no Comitê de Ética em Pesquisa da Universidade, estando em conformidade com a Resolução 196 do Conselho Nacional de Saúde de 1996 que regulamenta as pesquisas envolvendo seres humanos, de acordo com o parecer número 394.040, de 13 de setembro de 2013, comprometendo-se a estar condizente com as exigentes éticas e científicas de pesquisas envolvendo seres humanos. Todas as participantes estavam de acordo com o Termo de Consentimento Livre e Esclarecido, constando que a desistência em participar da pesquisa não traria nenhum tipo de dano ao participante.

Participaram do presente estudo 681 mães de crianças de 18 meses a 8 anos, residentes no Brasil, que aceitaram voluntariamente participar da pesquisa.

A média de idade das respondentes foi de 32,4 anos (DP $=5,2$ ). As participantes eram oriundas de 24 unidades federativas do Brasil, exceto Alagoas, Roraima e Amapá, sendo a maioria do Distrito Federal (49,1\%, $n=825)$.

Em relação ao estado civil, a maioria das mães é casada $(70,6 \%, n=482)$, com média de 1,55 filhos por família ( $D P=0,70, \min =1$, máx $=5$ ). A maioria dos casos apresenta elevada escolaridade (pós-graduação, 41,1\%, $n=280$ ) e elevada renda familiar (mais de 15 salários mínimos, 23,2\%, $n=158$ ). Em 
relação à idade das crianças estudadas, a média foi de 3,9 anos ( $\mathrm{DP}=1,99$ ), sendo a maioria do sexo masculino $(56,9 \%, n=387)$. A maioria das crianças foi amamentada exclusivamente por até 6 meses $(56,9 \%, n=367)$, com duração de amamentação por 13,03 meses ( $D P=9,2$, mín $=0$, máx $=40$ ).

\section{Instrumento e procedimento de coleta}

A pesquisa foi aplicada via internet, a partir da ferramenta de pesquisa online Survey Monkey (www.surveymonkey.com) e ficou disponível no período de 19 de janeiro de 2015 a 23 de fevereiro de 2015. Os indivíduos participantes da pesquisa foram selecionados a partir do "efeito bola de neve" no qual o questionário gerado pela ferramenta foi distribuído para listas de endereços eletrônicos, além de ser publicado em redes sociais, como Facebook® $\mathrm{O}$ sistema foi programado de forma que cada participante só pudesse responder ao questionário uma única vez.

As mães com mais de uma criança foram orientadas a responder sobre a criança mais nova dentro da faixa etária da pesquisa. No caso de filhos gêmeos, dever-se-ia considerar o último a nascer.

Os dados socioeconônimos e demográficos e os hábitos de vida foram obtidos a partir de um instrumento autoadministrado preenchidos por mães, contendo questões relacionadas aos hábitos alimentares infantis, às suas práticas em relação a alimentação de seu filho e outros hábitos de vida relacionados à alimentação, bem como seu consumo alimentar e o consumo alimentar da criança. Os instrumentos de medida serão detalhados a seguir.

As práticas parentais relacionadas à alimentação infantil foram obtidas por

meio do Comprehensive Feeding Practices Questionnaire (CFPQ), um instrumento proposto por Musher-Eizenman e Holub (46) que se propõe a mensurar as múltiplas práticas parentais em relação à alimentação infantil.

Este instrumento foi traduzido para o português por meio do métodos de tradução-retradução e passou por uma validação de conteúdo pela técnica de juízes. (134). Em seguida, realizou-se um estudo piloto de reprodutibilidade do CFPQ para a população brasileira com uma subamostra de mães de crianças de 2 a 5 anos $(n=35)$. Por fim, o instrumento foi validado para a população brasileira 
de mães de crianças de 18 meses a 8 anos em um estudo anterior, por meio de análise fatorial (136), de sorte que a solução fatorial final foi caracterizada por 9 fatores, 39 itens, $\mathrm{KMO}=0,830,56,5 \%$ de variância explicada e com explicação de $2 \%$ da covariância da matriz residual.

Os fatores da escala adaptada pra o Brasil são:

- Modelagem parental (4 itens) - Esse fator descreve o quanto os pais relatam servir de modelo à criança em relação ao consumo de alimentos saudáveis;

- Restrição de escolha quantitativa e qualitativa de alimentos (9 itens) - Esse fator descreve o quanto os pais relatam restringir ou controlar a alimentação de seus filhos, para manter a saúde e o peso;

- Controle ao acesso de alimentos não saudáveis (4 itens) - Esse fator descreve o quanto os pais relatam controlar a ingestão de alimentos não saudáveis pelas crianças;

- Controle emocional pela comida ( 3 itens) - Esse fator descreve o quanto os pais relatam usar a comida para regular o estado emocional da criança;

- Pressão para comer (3 itens) - Esse fator descreve o quanto os pais relatam pressionar a criança a consumir mais alimentos nas refeições;

- Envolvimento da criança com a refeição da família (4 itens) - Esse fator descreve o quanto os pais relatam incentivar o envolvimento da criança no planejamento e preparo das refeições;

- Uso da comida como recompensa (3 itens) - Esse fator descreve o quanto os pais relatam usar a comida como recompensa para o comportamento da criança;

- Permissividade e controle infantil (5 itens) - Esse fator descreve o quanto os pais permitem que a criança controle seu comportamento alimentar e as interações de alimentação entre ela e os pais; e

- Incentivo à experimentação e consumo saudável (4 itens) - Esse fator descreve o quanto os pais relatam incentivar a experimentação de novos 
alimentos e promover o consumo de uma alimentação equilibrada, variada e saudável.

O instrumento apresenta duas escalas com amplitude de 5 pontos, sendo uma delas de frequência, com respostas de "nunca" a "sempre" (itens 1 a 13) e outra de concordância, com respostas de "discordo totalmente" a "concordo totalmente" (itens 14 a 49).

Além disso, como feito por Musher-Eizenman e Holub (46), as mães foram convidadas a responder itens de três escalas de atitudes relacionadas às práticas parentais, sendo elas a escala de preocupação com o excesso de peso da criança (3 itens), retirada do Child Feeding Questionnaire (CFQ) (43), a Escala de Preocupação com o baixo peso da criança (3 itens) adaptada do CFQ e a Escala de Responsabilidade de alimentação da criança (3 itens).

Para avaliação do consumo alimentar das crianças e da mãe foi utilizado o Questionário de Frequência Alimentar desenvolvido por Molina et al (139), baseado em estudos realizados no Brasil com crianças (140) e adolescentes (141) e testado em uma subamostra de crianças de sete a dez anos $(n=91)$.

Com o objetivo de melhor adequar o instrumento para a população alvo, o QFA foi adaptado, excluindo-se os alimentos peixe, maionese e suco natural do questionário original. Dessa forma, o questionário em questão tem o objetivo de analisar marcadores de consumo alimentar saudável e não saudável, incluindo 14 alimentos, sendo eles o feijão, salada crua, frutas, leite e legume ou verdura (excluindo batata e aipim), como marcadores de alimentos saudáveis, e batata frita (incluindo a de pacote), salgados fritos, embutidos, biscoito salgado/doce, refrigerante, Petit suisse e macarrão instantâneo, como marcadores de alimentos não saudáveis.

O consumo usual de alimentos foi avaliado por meio do questionamento sobre quantos dias em uma semana comum a criança, em um primeiro momento, e a mãe, em um segundo momento, consome cada alimento. A escala de frequência tipo Likert de 7 pontos, variou de $0=$ "nunca" a 7 = "7 dias da semana". 
Além das práticas parentais e do consumo alimentar da mãe e da criança, o questionário estruturado também abordou hábitos de vida, sendo eles 0 número de refeições realizadas com a criança, usualmente, de segunda a sexta (variando de "Nenhuma" a "Mais de três"), hábitos de refeição em família (consumo de sentar à mesa com dois ou mais integrantes da família, Sim/Não), hábito de comer assistindo televisão (costumo de comer assistindo televisão, "Não" a "Sim, 7 vezes na semana"; Ontem, comeu assistindo televisão (Sim/Não) e quantas horas por dias criança e/ou mãe assistem televisão ou mexem no celular/ipod/tablet), questões sobre aleitamento materno exclusivo e duração da amamentação, práticas de atividade física, influência da propaganda televisiva de alimentos (Criança costuma pedir os alimentos que vê na televisão) e o peso e altura maternos referidos. Neste estudo o peso da criança não foi obtido, pois, por se tratar de um instrumento online, o valor referido pela mãe poderia estar enviesado, considerando o período de desenvolvimento e crescimento da criança, além do viés de memória e a falta de padronização na sua mensuração.

As mães foram questionadas também sobre sua cidade e estado de moradia, estado civil, número de filhos, idade e sexo da criança sobre quem responderia as questões, sua idade, nível educacional (com sete opções de resposta que variavam de "ensino fundamental (1ํ Grau) incompleto" a "pós graduação/ mestrado/ doutorado"), renda familiar mensal (em salários mínimos, com sete opções de resposta que variaram de "Até 1 salário mínimo (até $R \$$ 790,00)" a "Mais de 15 salários mínimos (mais de $\mathrm{R} \$ 11.850,00$ )", números de pessoas residentes no lar e ocupação.

\section{Procedimentos de análise}

Para as análises estatísticas, foi utilizado o programa Statistical Package fot the Social Sciences (SPSS), versão 21. A amostra inicial total foi de 1418 participantes, das quais $638(45 \%)$ respostas foram excluídas na fase exploratório por apresentarem mais de $10 \%$ de dados ausentes por sujeito, considerando todas as variáveis. Após avaliação dos dados perdidos, verificouse que eles eram perdidos ao acaso (MAR). Para que a amostra não apresentasse dados perdidos, optou-se por utilizar a atribuição baseada em modelos $(E M)$ para todas as variáveis que ainda apresentavam $10 \%$ ou menos 
desses casos, considerado o mais adequado para dados perdidos ao acaso (133).

Os dados foram submetidos à análise exploratória e tratamento de dados (presença de casos omissos e extremos), além de pressupostos estatísticos. Em seguida, foram realizadas as análises relacionais e inferenciais para o teste do modelo. Para testar a diferença entre o consumo de verduras cozidas e salada, foi realizado o teste dos sinais de Wilcoxon.

A partir das correlações percebeu-se a necessidade de aprofundamento das relações e interações entre as diversas variáveis do modelo. As variáveis que mostraram associação significante $(p<0,05)$ e apresentaram valores superior a 0,20 foram adicionadas à regressão linear múltipla para determinar contribuições relativas a variância explicada. As análises de regressão foram realizadas para testar o modelo e verificar o impacto de cada uma das variáveis preditoras (práticas e demais determinantes) sobre a variável critério (consumo alimentar de frutas e hortaliças). Para os cálculos, utilizou-se o método por etapas (stepwise) da regressão linear múltipla, pela sua adequação para pesquisas exploratórias. Este método, além da correlação bivariada, leva em consideração as correlações parciais entre as variáveis, determinando assim a sua ordem hierárquica de importância para o modelo (133).

\section{Resultados}

\section{Consumo de frutas e hortaliças pelas mães e crianças}

Observa-se que $45,1 \%(n=307)$ das crianças e $37,7 \%(n=257)$ das mães consumiram frutas diariamente, sendo que 7,6\% ( $n=52)$ e 5,4\% $(n=37)$ de crianças e mães, respectivamente, não consumiu nenhum tipo de fruta na semana. Em relação às hortaliças, verifica-se o consumo de 15,5\% ( $n=106)$ diários pelas crianças e $33,9 \%(n=231)$ pelas mães.

O consumo de verduras cozidas e salada crua também foi avaliado separadamente, de forma que 38,3\% $(n=261)$ das crianças e 46,6\% $(n=317)$ das mães consomem verduras diariamente e em relação a salada crua, 23,9\% ( $n=163)$ das crianças e 44,6\% $(n=304)$ das mães têm o consumo diário e $22,3 \%(n=152)$ das crianças não consumiram salada crua em nenhum dia da 
semana. As figuras 4 e 5 mostram a frequência do consumo de frutas, verduras cozidas, salada crua e hortaliças pelas crianças e mães.

Para as crianças, o consumo de verdura $(M=4,86)$ foi significativamente mais alto que o de salada $(M=3,69, Z=-10,04, p<0,001)$. Não houve diferença, porém, entre as médias de consumo de verdura e salada pelas mães. Sendo que o consumo de verdura da mãe $(M=5,44)$ é igual ao consumo de salada ( $M$ $=5,30) . Z=-2,07, p<0,05, r=0,08$.

Frente à variação no consumo de verduras cozidas e salada crua, optouse por trabalhar esses dois tipos de alimento separadamente.

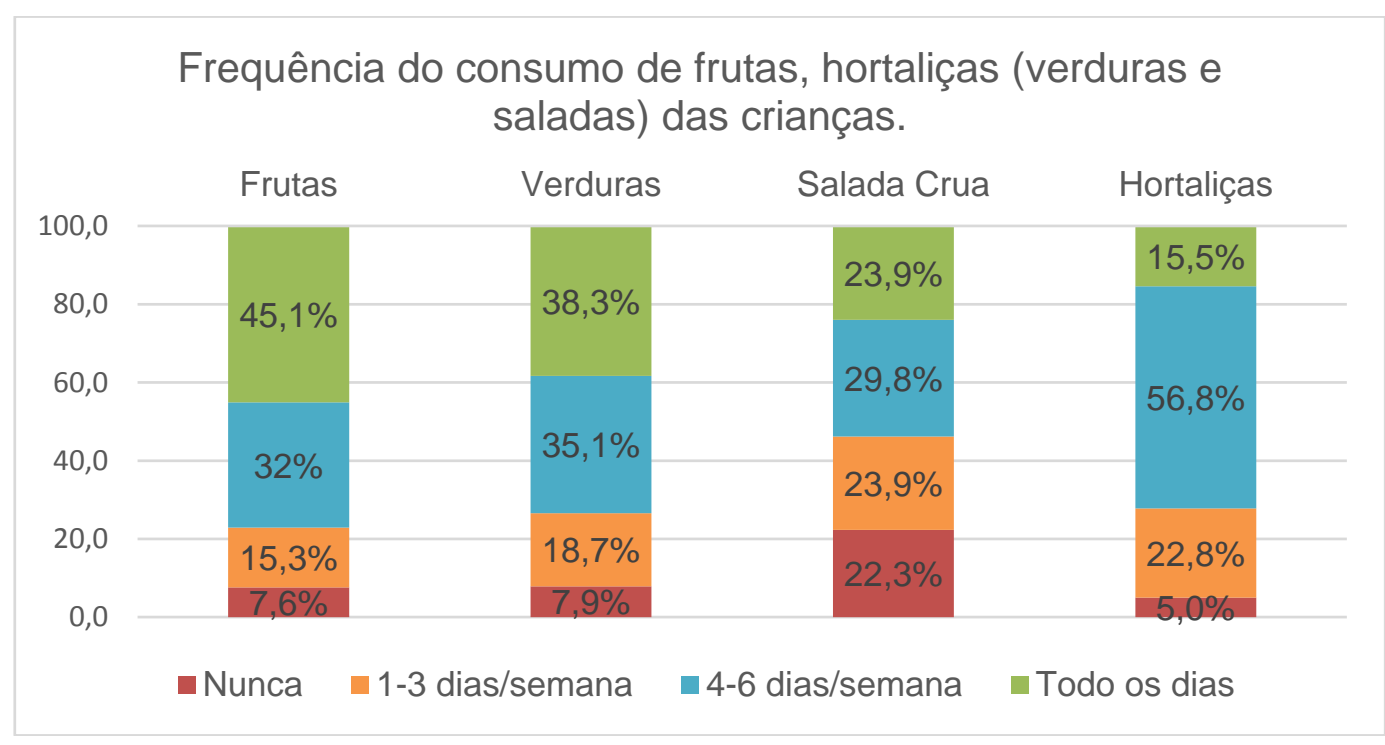

Figura 5 - Perfil de consumo de frutas, verduras cozidas, salada e a média de hortaliças por crianças de 18 meses a 8 anos.

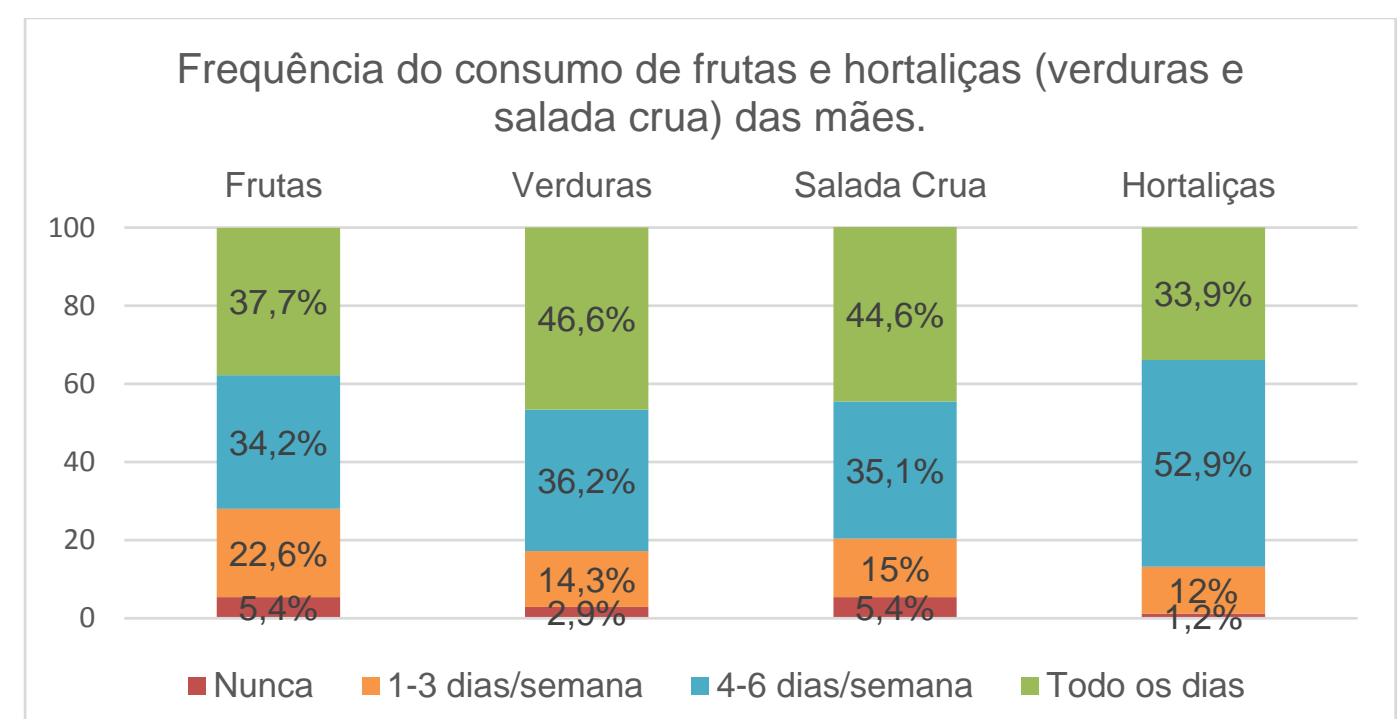

Figura 6 - Perfil de consumo de frutas, verduras cozidas, salada crua e a média de hortaliças pelas mães. 
O Consumo de frutas, verduras cozidas e salada crua foram correlacionados às variáveis de práticas maternas e demais hábitos de vida. $\mathrm{O}$ consumo de verdura pela criança teve uma associação positiva moderada (157) com o consumo de salada crua $r(681)=0,34, p<0,001$, e frutas $r(681)=0,38, p$ $<0,001$ pelas crianças, assim como o consumo de de verduras $r(681)=0,50, p$ $<0,001$ pela mãe.

Já o consumo de salada esteve associado ao consumo de verdura r (681) $=0,35, p<0,001$ e frutas pelas crianças $r(681)=0,31, p<0,001$ e ao consumo de salada crua pelas mães $r(681)=0,37, p<0,001$. Seguindo o mesmo padrão, o consumo de frutas tem correlação positiva com verdura $r(681)=0,39, p<$ 0,001 , salada $r(681)=0,31, p<0,001$ e com consumo de frutas pela mãe $r(681)$ $=0,42, p<0,001)$.

As demais correlações entre os fatores são consideradas fracas, conforme pode ser visto na Tabela 11. A tabela completa de correlações entre as variáveis está disponível no Apêndice $\mathrm{D}$. As demais variáveis testadas não apresentam correlações significativas ou apresentam associações fracas, menores que 0,20 . Destaca-se ainda que nenhuma das práticas parentais esteve correlacionada significativamente com as variáveis critério deste estudo.

Tabela 11 - Correlação de Pearson entre o consumo de verduras cozidas, salada crua, frutas e os determinantes relacionados à alimentação infantil.

\begin{tabular}{cccc}
\hline Variáveis independentes & $\begin{array}{c}\text { Verdura } \\
\text { cozida }\end{array}$ & Salada crua & Frutas \\
\hline Idade da criança & $-0,21^{* *}$ & & $-0,20^{* *}$ \\
Feijão (criança) & $0,20^{* *}$ & & $0,13^{* *}$ \\
Embutidos (criança) & $-0,16^{* *}$ & & $-0,18^{* *}$ \\
Verdura (criança) & & $0,36^{* *}$ & $0,39^{* *}$ \\
Saladacrua (criança) & 1 & $0,33^{* *}$ \\
Frutas (criança) & $0,36^{* *}$ & $0,33^{* *}$ & 1 \\
$\quad$ Refri (criança) & $0,39^{* *}$ & & $-0,19^{* *}$ \\
(Qual frequência de compra de alimentos \\
não saudáveis para o filho?
\end{tabular}


(Continuação)

\begin{tabular}{cccc}
\hline Variáveis independentes & Verdura & Salada crua & Frutas \\
\hline Verdura (mãe) & $0,47^{* *}$ & $0,20^{\star *}$ & $0,24^{\star *}$ \\
Saladacrua (mãe) & $0,20^{\star *}$ & $0,46^{\star *}$ & $0,19^{\star *}$ \\
Frutas (mãe) & 0,16 & $0,23^{\star *}$ & $0,40^{\star *}$ \\
\hline
\end{tabular}

Apresentados apenas os valores de correlação $>0,20$.

** A correlação é significativa no nível 0,01 (2 extremidades).

* A correlação é significativa no nível 0,05 (2 extremidades).

$\mathrm{n}=681$

As Tabelas 12, 13 e 14 apresentam os resultados das análises inferenciais da regressão stepwise, predizendo o consumo infantil de frutas, verduras cozida e salada crua.

A Tabela 12 mostra os resultados da análise do consumo de frutas $\left(\mathrm{F}_{7,680}\right.$ $=50,960, p<0,001)$. Observa-se que o maior preditor do aumento de consumo de frutas pela criança é o consumo de frutas pela mãe $(\beta=0,35, p<0,001)$, representando $16 \%$ de variância explicada, seguido pelo consumo de verdura ( $\beta$ $=0,22, p<0,001)$ e salada pela criança $(\beta=0,24, p<0,001)$. Além disso, observa-se que quanto maior a idade da criança $(\beta=-0,13, p<0,001)$, menor $o$ consumo de frutas. Essa relação inversa também está presente com o consumo de embutidos pela criança $(\beta=-0,08, p<0,05)$, assim como o aumento da frequência de compra de alimentos não saudáveis pela mãe $(\beta=-0,09, p<0,05)$ e pelo consumo de salada crua pela mãe $(\beta=-0,12, p<0,05)$.

Tabela 12 - Etapas do método stepwise da RM para predição do consumo de Frutas e determinantes da alimentação infantil.

\begin{tabular}{|c|c|c|c|c|c|}
\hline & \multirow{2}{*}{ Modelo } & \multicolumn{2}{|c|}{$\begin{array}{l}\text { Coeficientes não } \\
\text { padronizados }\end{array}$} & \multirow{2}{*}{$\begin{array}{c}\begin{array}{c}\text { Coeficientes } \\
\text { padronizados }\end{array} \\
\beta\end{array}$} & \multirow{2}{*}{$t$} \\
\hline & & B & Modelo padrão & & \\
\hline \multirow{2}{*}{1} & (Constante) & 3,128 & 0,191 & & 16,393 \\
\hline & Frutas_QFA2 & 0,408 & 0,036 & 0,401 & 11,412 \\
\hline \multirow{4}{*}{7} & (Constante) & 3,623 & 0,363 & & $9,993^{*}$ \\
\hline & Frutas (mãe) & 0,357 & 0,036 & 0,351 & $9,912^{*}$ \\
\hline & Verdura (criança) & 0,214 & 0,035 & 0,217 & $6,184^{*}$ \\
\hline & Saladacrua (criança) & 0,206 & 0,032 & 0,243 & $6,469^{*}$ \\
\hline
\end{tabular}




\begin{tabular}{ccccc}
\hline Modelo & \multicolumn{1}{c}{$\begin{array}{c}\text { Coeficientes não } \\
\text { padronizados }\end{array}$} & $\begin{array}{c}\text { Coeficientes } \\
\text { padronizados }\end{array}$ & \multirow{2}{*}{ t } \\
\cline { 2 - 4 } 7 & B & Modelo padrão & $\boldsymbol{\beta}$ & \\
\hline $\begin{array}{c}\text { Idade da criança } \\
\text { Iual frequência de compra }\end{array}$ & $-0,012$ & 0,003 & $-0,130$ & $-3,854^{*}$ \\
$\begin{array}{c}\text { de alimentos não saudáveis } \\
\text { para o filho }\end{array}$ & $-0,256$ & 0,091 & $-0,094$ & \\
$\begin{array}{c}\text { Saladacrua (mãe) } \\
\text { Embutidos (criança) }\end{array}$ & $-0,136$ & 0,042 & $-2,812^{* *}$ \\
\hline
\end{tabular}

Variável dependente: Frutas. Nota: $R^{2}=0,162$ (Passo 1). $D^{2}{ }^{2}=0,271$ (Passo 2), 0,292 (Passo 3), 0,318 (Passo 4), 0,330 (Passo 5), 0,340 (Passo 6), 0,346 (Passo7). * $p<0,001 ;{ }^{* *} p<0,05$.

O consumo de salada crua pela mãe chama atenção pela sua relação inversa (traduzida pelo sinal negativo), o que difere do seu coeficiente calculado na correlação bivariada. Análises inferenciais da colinearidade foram realizada e não se encontrou valores excessivos de multicolinearidade.

No entanto, segundo Ryan (172), "sinais errados" são comuns quando dois preditores (o consumo de frutas e salada pela mãe) são altamente correlacionados com a variável $Y$ (consumo de fruta pela criança) e também correlacionados entre si. Dessa forma, o preditor mais fraco (no caso, o consumo de salada pela mãe) pode ter um sinal na equação de regressão diferente do sinal do coeficiente de correlação com $Y$ quando o seu coeficiente de correlação é menor do que a correlação entre o outro regressor (consumo de frutas pela mãe) e $Y$ (consumo de fruta pela criança). $O$ autor ainda completa que este fato pode ocorrer até quando quando as três correlações não são tão grandes, de forma que o determinante é a relação entre as correlações.

Em relação ao consumo de verdura (tabela 13), são variáveis preditoras o consumo de verduras cozidas pela mãe, contribuindo com $22 \%$ da variância explicada $(\beta=0,49, p<0,001)$, o consumo de frutas $(\beta=0,20, p<0,001)$, salada crua $(\beta=0,32, p<0,001)$, feijão $(\beta=0,08, p<0,05)$ e embutidos pela criança ( $\beta$ $=-0,07, p<0,05)$ e o consumo de salada crua $(\beta=-0,20, p<0,001)$ e frutas pela mãe $(\beta=-0,12, p<0,001)$, além da idade da criança $(\beta=-0,16, p<0,001)$. Ressalta-se a relação inversa das três últimas variáveis. 
Tabela 13 - Etapas do método stepwise da RM para predição do consumo de verdura e determinantes da alimentação infantil.

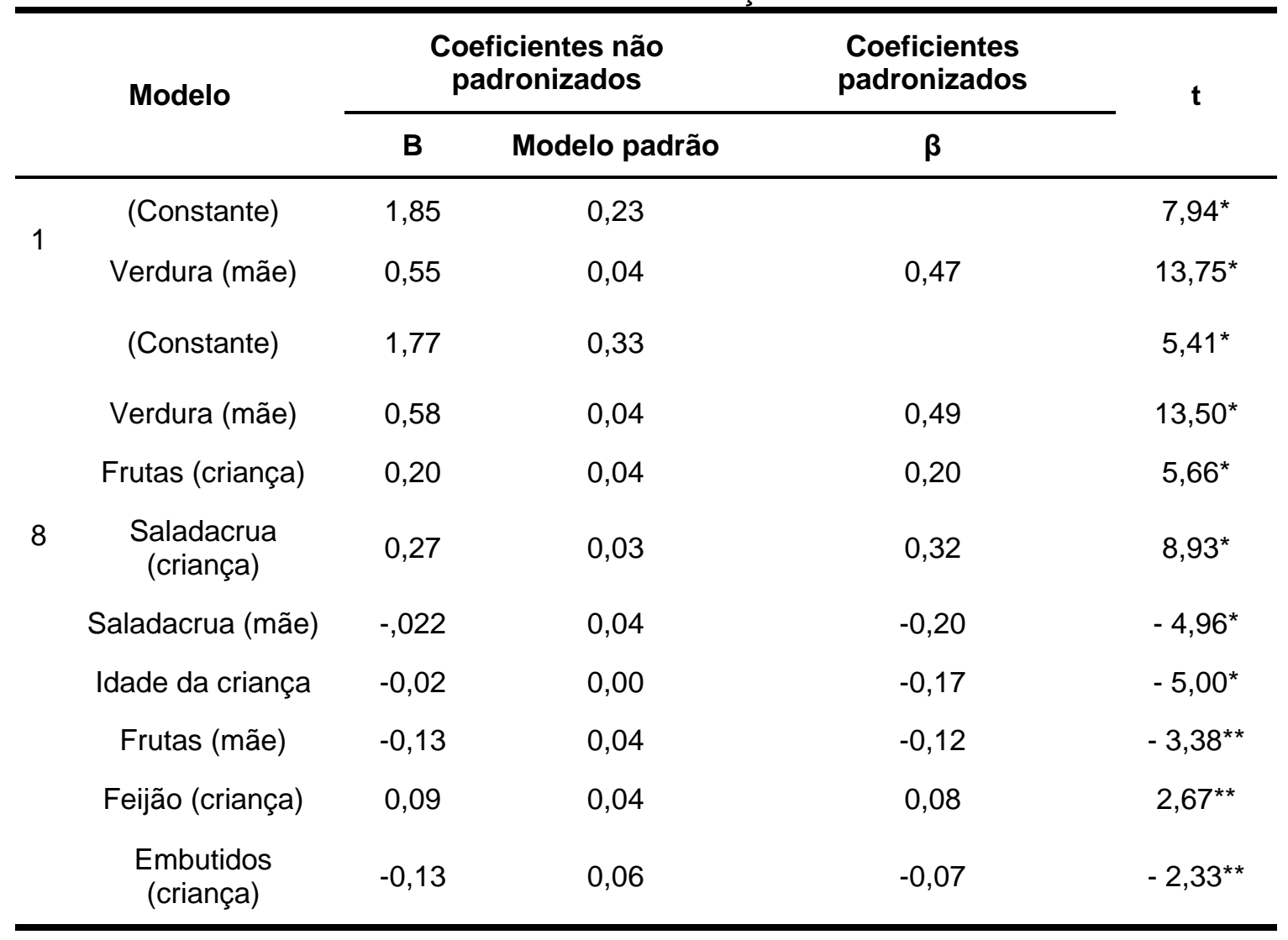

Variável dependente: Verdura. Nota: $R^{2}=0,218$ (Passo1). $D R^{2}=0,300$ (Passo 2), 0,337 (Passo 3), 0,368 (Passo 4), 0,398 (Passo 5), 0,408 (Passo 6), 0,415 (Passo7), 0,420 (Passo 8) . ${ }^{*} p<0,001{ }^{* \star} p<0,05$.

Novamente, no que diz respeito ao consumo de salada crua e frutas, a associação inversa difere do estimado pela correlação bivariada, sendo assim o sinal negativo considerado um "sinal errado". O mesmo acontece com o consumo de salada crua e o consumo de verdura pela mãe.

O consumo de salada crua pelas mães $(\beta=0,50, p<0,001)$, assim como o consumo de verdura $(\beta=0,30, p<0,001)$, e frutas pela criança $(\beta=0,18, p$ $<0,001)$, e o consumo de verdura pela mãe $(\beta=-0,24, p<0,001)$, são variáveis preditoras do consumo de salada crua pela criança. $O$ consumo de salada pela mãe explica $21 \%$ da variância 
Tabela 14 - Etapas do método stepwise da RM para predição do consumo de salada crua e determinantes da alimentação infantil.

\begin{tabular}{|c|c|c|c|c|c|}
\hline & \multirow{2}{*}{ Modelo } & \multicolumn{2}{|c|}{$\begin{array}{l}\text { Coeficientes não } \\
\text { padronizados }\end{array}$} & \multirow{2}{*}{$\begin{array}{c}\begin{array}{c}\text { Coeficientes } \\
\text { padronizados }\end{array} \\
\beta\end{array}$} & \multirow{2}{*}{$\mathbf{t}$} \\
\hline & & B & Modelo padrão & & \\
\hline \multirow{2}{*}{1} & (Constante) & 0,581 & 0,247 & & 2,353 \\
\hline & Saladacrua_QFA2 & 0,587 & 0,043 & 0,461 & $13,545^{\star}$ \\
\hline \multirow{3}{*}{2} & (Constante) & $-0,614$ & 0,275 & & $-2,229$ \\
\hline & Saladacrua_QFA2 & 0,517 & 0,042 & 0,406 & $12,275^{\star}$ \\
\hline & Verdura_QFA1 & 0,322 & 0,039 & 0,276 & $8,348^{*}$ \\
\hline \multirow{4}{*}{3} & (Constante) & $-0,046$ & 0,286 & &,- 161 \\
\hline & Saladacrua_QFA2 & 0,657 & 0,048 & 0,516 & $13,823^{\star}$ \\
\hline & Verdura_QFA1 & 0,428 & 0,042 & 0,368 & $10,253^{\star}$ \\
\hline & Verdura_QFA2 & $-0,336$ & 0,057 & $-0,243$ & $-5,870^{*}$ \\
\hline \multirow{5}{*}{4} & (Constante) & $-0,595$ & 0,299 & & $-1,987$ \\
\hline & Saladacrua_QFA2 & 0,631 & 0,047 & 0,496 & $13,469^{*}$ \\
\hline & Verdura_QFA1 & 0,354 & 0,043 & 0,304 & $8,140^{*}$ \\
\hline & Verdura_QFA2 & $-0,339$ & 0,056 & $-0,245$ & $-6,041^{*}$ \\
\hline & Frutas_QFA1 & 0,209 & 0,040 & 0,177 & $5,209^{*}$ \\
\hline
\end{tabular}

Variável dependente: Salada crua. Nota: $R^{2}=0,213$ (Passo1). $\mathrm{DR}^{2}=$ 0,286 (Passo 2), 0,321 (Passo 3), 0,347 (Passo 4). ${ }^{*} p<0,001{ }^{* *} p<0,05$.

\section{Discussão}

Este estudo buscou identificar as múltiplas práticas parentais, especificamente as maternas, e os determinantes relacionados ao consumo de frutas e hortaliças por crianças de 18 meses a 8 anos. Os resultados mostram que o consumo materno saudável é um forte preditor do consumo de alimentos saudáveis. Esses achados corroboram com diversas pesquisas $(13,17,39,147,173)$.

Wardle, Carnell e Cooke (147) em estudo com 564 pais de crianças de 2 a 6 anos mostraram que o consumo de frutas e hortaliças pelos adultos representou uma variância explicada de $23 \%$ em relação ao consumo de frutas e hortaliças pelas crianças. Fisher e colaboradores (13) também apresentaram 
o consumo pelos pais como forte preditor, explicando $21,5 \%$ do consumo de frutas e hortaliças.

Diversos fatores podem estar relacionados à variável consumo dos pais como preditor do consumo das crianças, entre eles a modelagem, a similaridade genética e a disponibilidade e o acesso desses alimentos em casa, considerando que pais que apresentam maior consumo de frutas e hortaliças tendem a comprar e manter em casa esses alimentos. Assim, a maior exposição resultaria no maior consumo pela crianças (39), além da maior oportunidade de experimentação e familiaridade com frutas e hortaliças. A familiaridade, por sua vez, exerce um papel importante na aceitação de alimentos pela criança (33).

No mesmo sentido, em um estudo que tinha o objetivo de comparar as preferência alimentares de crianças a longo prazo e identificar fatores relacionados a tal preferência, Skinner e colaboradores (40) mostraram que as mães pareciam não introduzir às suas crianças alimentos que elas mesmo não gostavam. As preferências das crianças e das mães estiveram correlacionadas para alimentos que relataram gostar, desgostar e nunca ter provado, indicando também a forte influência da mãe na preferência alimentar das criança e, consequentemente, no seu consumo. Existem fortes evidências de que a preferência alimentar sejam um preditor de padrões de consumo $(27,28)$.

Estudos têm mostrado que a modelagem é um fator importante no comportamento alimentar $(13,68,74)$, sendo a modelagem de alimentos saudáveis positivamente associados com a ingestão alimentar de crianças e a preferência por frutas e hortaliças (74). No entanto, no presente estudo, apesar da associação entre o consumo materno e o consumo da criança, a modelagem parental, avaliada pelo CFPQ, não apresentou correlação significativa com o consumo infantil. Outros estudos reforçam esses achados. Matheson, Robinson, Varady e Killen (60) também encontraram que o papel da modelagem parental de alimentos saudáveis não esteve associado significativamente com o consumo de alimentos saudáveis pelas crianças. Além do consumo das mães, são também variáveis preditoras do consumo de frutas a frequência de compra de alimentos não saudáveis e a idade, que também apareceu como preditora do consumo de hortaliças. 
A frequência de compra de alimentos não saudáveis apareceu como variável preditora do consumo de frutas, apresentando uma associação inversa. Isso pode ser explicado, pois a compra desses alimentos aumenta o seu acesso e disponibilidade, evidenciando o fato de que a disponibilidade, o acesso e a exposição de alimentos pode determinar tanto o consumo saudável de crianças quanto o não saudável, dependendo da oferta de alimentos disponíveis.

Outra possível explicação, combinada à anterior, envolve o contexto no qual geralmente se consome as frutas, ou seja, em lanches entre as grandes refeições. No entanto, nesses momentos o consumo de frutas concorre de forma direta com lanches não saudáveis, como doces, refrigerante ou salgadinhos de pacote, alimentos mais desejáveis e palatáveis. Por serem, geralmente, alimentos ricos em açúcares, gordura, sal e aditivos, são formulados para que sejam extremamente saborosos, com o objetivo de induzir o hábito ou até mesmo criar dependência (110). Isso, aliado à predisposição da criança a preferir alimentos com sabores doces ou salgados, torna pouco provável que frutas ganhem essa competição, dada, geralmente, a sua baixa densidade energética e seu sabor menos doce.

Em relação à idade, os resultados ainda são pouco consistentes. Estudos mostram que os hábitos alimentares são relativamente estáveis com o passar do tempo $(40,168)$, enquanto outros apresentam que o consumo de frutas e hortaliças diminui à medida que a criança vai ficando mais velha $(8,74)$, reforçando os nossos achados para frutas e verduras. Em outro estudo, ainda, encontrou-se que crianças mais velhas comiam vegetais significativamente mais do que as mais novas, mas não houve associação entre a idade e o consumo de frutas (39).

Os achados em relação a idade podem ser explicados, por exemplo, pois a alimentação de crianças mais novas são mais limitadas aos alimentos que os pais disponibilizam a elas, possibilitando o aumento da oferta e do consumo de alimentos saudáveis, coma as frutas e hortaliças. Com o passar do tempo, observa-se menor determinação dos pais e outros determinantes estão envolvido com os hábitos e práticas alimentares, como a escola e os pares, que 
podem estar relacionados a comportamentos alimentares não saudáveis e menor ingestão de frutas e verduras.

O Guia Alimentar para crianças menores de dois anos (111) recomenda que, desde o início da introdução alimentar, os pais estimulem o consumo de frutas e hortaliças. No entanto, a introdução de salada crua é tardia, o que pode explicar o seu menor consumo. Este fato também pode estar relacionado à variável idade não ter apresentado correlação significativa com o consumo de salada crua, indicando que, provavelmente, o consumo desses alimentos não sofre determinação da idade da criança nesta faixa etária.

Além disso, o maior consumo de frutas, em relação ao consumo de verduras cozidas e salada crua se justifica pela evidência da predisposições inatas para alimentos com gosto adocicado, ao invés daqueles com sabor azedo ou amargo (33).

Verificou-se ainda que o próprio consumo de alimentos saudáveis pela criança são preditores positivos do consumo de frutas e hortaliças. Assim como os alimentos não saudáveis, representados por embutidos, apresentaram associação negativa com o consumo de frutas. Esses resultados são importantes pois reafirmam, por exemplo, que ambientes alimentares saudáveis são promotores de saúde e hábitos alimentares saudáveis. Isso deve ser levando em consideração na realizações de intervenções, a partir do momento que é importante que haja o incentivo de uma alimentação saudável de forma geral para que ocorra o aumento do consumo de alimentos específicos como frutas e/ou hortaliças.

No presente estudo, as práticas parentais não apresentaram correlações significativa com o consumo de frutas e hortaliças.

Os estudos têm encontrado uma associação negativa entre o controle dos pais, principalmente a pressão para comer, e o consumo de frutas e hortaliças $(13,57)$. As evidências sugerem que pressionar a criança a comer pode diminuir a sua habilidade de auto regulação da ingestão. Além disso, pesquisas sugerem que as crianças que são forçadas a consumir certos alimentos os associam a 
experiências negativas de alimentação, desenvolvendo, assim, uma "aversão" a eles $(71,72)$.

No entanto, a associação entre as práticas parentais e o consumo de frutas e hortaliças ainda são inconsistentes. O'Connor e colaboradores (88) não encontraram associação entre as categorias de práticas parentais e o consumo de frutas e hortaliças. O mesmo aconteceu com Melbye, Øverby e Øgaard, (81). Este estudo, que também utilizou o CFPQ para avaliação das práticas parentais, identificou que algumas práticas estavam correlacionadas fracamente com 0 comportamento de comer frutas e algumas variáveis correlacionadas também fracamente com a intenção e o consumo de vegetais pelas crianças. A variável ambiente esteve positivamente associada com o consumo de vegetais pelas crianças, mas a variância explicada para essa prática foi pequena. Esta variável não faz parte do instrumento adaptado da versão brasileira, pois todos itens desse fator apresentaram baixas cargas fatoriais na análise fatorial exploratória. Dessa forma, o presente estudo não avaliou questões relativas ao ambiente alimentar, como a disponibilidade de variedade de alimentos saudáveis e não saudáveis em casa.

Estudos também encontraram associação positiva entre a pressão para comer e o consumo de frutas e hortaliças. Gregory e colaboradores (68), por exemplo, encontram que a pressão em crianças mais novas foi positivamente correlacionada com a frequência de consumo de frutas por crianças em uma análise transversal e então encontraram uma associação negativa um ano depois. Isso porque a forma que os pais pressionam crianças maiores a comer provavelmente é diferente do que a pressão com crianças de um ano, que precisam de assistência para se alimentar, além disso, as crianças podem perceber a pressão de formas diferentes.

Para explicar a falta de associação entre as práticas maternas e 0 consumo de frutas e hortaliças pelas crianças, várias hipóteses podem ser citadas. A primeira delas é que pode existir uma diferença entre o que os pais relatam de suas próprias práticas e como é o comportamento de fato, principalmente em relação à percepção das crianças. 
As práticas parentais, ao contrário dos estilos parentais, são mais flexíveis, a partir do momento que são motivados por determinados fatores, como o peso das crianças e sua ingestão alimentar, podendo variar entre as crianças e as situações e estando sensível ao contexto em que a família está inserida (12).

Outra explicação, referida por Melbye e colaboradores (81) e adequada também ao presente estudo, é o fato de que o CFPQ avalia os construtos relacionados, de forma geral, a comportamentos não saudáveis, o que pode causar uma diferença na especificidade em relação ao consumo de alimentos saudáveis.

A mãe exerce um importante papel na alimentação infantil, sendo que essa influência pode começar desde a gravidez. Mennella, Jagnow e Beauchamp (16) sugerem que os sabores da alimentação da mãe são transmitidos desde a gestação, pelo líquido amniótico, e depois pelo leite materno. Isso explica porque bebês amamentados são mais exposto a sabores variados do que as crianças que foram amamentadas com fórmulas lácteas, característica que que pode facilitar a aceitação dos alimentos na alimentação complementar, por conta da familiaridade com os gostos dos alimentos $(20,39)$. Além disso, as mães têm um particular interesse no comportamento alimentar de seus filhos, pois como tem sido demonstrado, passam mais tempo em interação direta com suas crianças por várias situações familiares, incluindo as refeições, do que o pai ou outros familiares (174). O presente estudo sugere que a influência materna está relaciona com o consumo de frutas e hortaliças através dos hábitos alimentares maternos e, provavelmente, pela disponibilidade de alimentos, não por estratégias comportamentais de alimentação empregadas às crianças.

O tamanho da amostra é um ponto positivos do presente estudo, permitindo aplicação de análises estatísticas sofisticadas e aumentando o poder estatístico dos resultados. Além disso, destaca-se a ampla abordagem do questionário preenchido pelas mães, contendo diversos determinantes relacionados à alimentação. $O$ controle parental tem sido bastante estudado, no entanto, observa-se que existem poucos estudos que relacionam as práticas 
parentais ao consumo alimentar de crianças, principalmente tratando-se das múltiplas práticas.

As limitações do estudo também precisam ser discutidas. Primeiramente, destaca-se o fato deste estudo ser transversal, não sendo possível avaliar os resultados a médio ou longo prazo. Além disso, a amostra foi caracterizada, predominantemente, por mães de alta escolaridade e alta renda, dessa forma, os resultados não podem ser generalizáveis para populações com baixa renda ou menores níveis de educação. Outro ponto importante é que a avaliação do consumo e dos determinantes da alimentação basearam-se apenas no relato materno por meio de questionários auto preenchidos. Deve ser levado em consideração que outros fatores podem ter influenciado no preenchido do instrumento, como percepção das mães em relação a comportamentos corretos e a desejabilidade social. Ademais, $O$ fato da avaliação do consumo ter sido realizada por meio do Questionário de Frequência Alimentar (QFA) pode superestimado a ingestão alimentar das crianças (175). Outra limitação em relação à avaliação do consumo é o fato das mães terem respondido as questões relativas ao seu consumo e ao consumo das crianças, o que pode implicar em um viés de aferição, assim como viés de memória.

Outra característica do estudo é o amplo escopo da faixa etária trabalhada. Estudos posteriores devem ser realizados levando em consideração características etárias com base no desenvolvimento da criança, a partir do momento que os determinantes da alimentação, assim como o consumo de frutas e hortaliças podem ser diferentes de acordo com a idade da criança e o contexto em que ela está inseridas

Para futuras pesquisas, sugere-se que sejam realizados estudos qualitativas com o objetivo de avaliar os determinantes e as práticas relacionadas ao consumo de frutas e hortaliças para crianças. Considerando os escassos trabalhos relativos a esse tema no Brasil, recomenda-se que outros estudos que trabalhem as práticas parentais sejam realizados com amostras mais diversas em relação a classes sociais e regiões brasileiras, além de limitar a amplitude da idade, considerando por exemplo pré-escolares e escolares. Outra sugestão para estudos futuros incluem avaliação da associação entre o consumo materno 
e outras características da mãe e as práticas parentais de alimentação infantil, por exemplo, a fim de verificar se essas estratégias de alimentação são moduladas por características e hábitos maternos.

Outros estudos que avaliem a modelagem parental e a percepção da criança frente à essa e a outras práticas são necessários, assim como a avaliação da disponibilidade de alimentos em casa e a sua relação com o consumo de frutas e hortaliças pelas crianças.

\section{Considerações finais}

A partir das questões apresentadas no estudo, sugere-se que o hábito alimentar materno influencia a alimentação das crianças, sendo que o consumo de frutas e hortaliças pelas mães é o maior preditor do consumo infantil desses alimentos. Além disso, as estratégias de alimentação infantil parecem não ser determinantes para o aumento do consumo de frutas e hortaliças pelas crianças.

Frente ao baixo consumo de frutas e hortaliças pela população brasileira, medidas voltadas ao aumento do consumo desses alimentos são necessárias. Para isso, sugere-se que o alvo seja primordialmente o consumo de alimentos saudáveis pelos pais, ressaltando a importância da disponibilidade, acesso e exposição de alimentos saudáveis em casa. Os pais devem ser encorajados a ter uma alimentação mais saudável para promover uma melhor alimentação dos seus filhos. O guia alimentar para a população brasileira (110) recomenda que os alimentos in natura ou minimamente processados, ou seja, aqueles obtidos diretamente de plantas ou animais, adquiridos diretamente da natureza, sejam a base da alimentação nutricionalmente balanceada e saudável. 


\section{Considerações finais}

O objetivo geral do presente trabalho foi determinar as práticas maternas e como elas influenciam o comportamento alimentar de crianças de 18 meses a 8 anos. Os objetivos específicos foram (1) Validar um instrumento de compreensão das práticas parentais de alimentação infantil para a população brasileira; e (2) Associar as múltiplas práticas maternas e outros determinantes ao consumo de frutas e hortaliças por crianças de 18 meses a 8 anos.

Frente a isso, conclui-se que:

O CFPQ validado para a população brasileira apresenta 9 fatores, 39 itens, com KMO de 0,83 e 56,5\% de variância explicada, sendo os critérios considerados adequados. O menor número de itens é favorável, à medida que 0 instrumento se torna cansativo com uma quantidade de itens muito extensa. $O$ menor número de fatores, por sua vez, justifica-se pelo critério da parcimônia da análise fatorial. Para estudos futuros, sugere-se que testes sejam realizados com o objetivo de avaliar se menos itens podem medir os fatores em questão em uma escala simplificada, aprimorando a sua aplicabilidade e praticidade. Outra proposta é realizar análise fatorial confirmatória, com o objetivo de confirmar ou refutar o modelo fatorial obtido neste estudo.

Os fatores da escala adaptada pra o Brasil são: Modelagem parental (4 itens, $\alpha$ de Cronbach = 0,81); Restrição de escolha quantitativa e qualitativa de alimentos ( 9 itens, $\alpha=0,806$ ); Controle ao acesso de alimentos não saudáveis (4 itens, $\alpha$ de Cronbach $=0,875$ ); Controle emocional pela comida ( 3 itens, $\alpha$ de Cronbach $=0,756$ ); Pressão para comer ( 3 itens, $\alpha$ de Cronbach $=0,66$ ); Envolvimento da criança com a refeição da família (4 itens, $\alpha$ de Cronbach = 0,65 ); Uso da comida como recompensa (3 itens, $\alpha$ de Cronbach $=0,66$ ); Permissividade e controle infantil ( 5 itens, $\alpha$ de Cronbach $=0,58$ ) Incentivo à experimentação e consumo saudável ( 4 itens, $\alpha$ de Cronbach $=0,743$ ).

A presença de alfas de Cronbach baixos pode ser uma limitação da escala, pois esse índice mede a consistência do fator. Alfas de Cronbach baixos podem significar relações pobres entre as variáveis. No entanto, esses valores 
são esperados, já que todas as subescaladas do CFPQ apresentam poucos itens e baixos valores foram observáveis também na escala original.

Comparando o modelo fatorial encontrado neste estudo com o instrumento original, observa-se que, dos nove fatores, cinco são iguais ao original. Os demais fatores sofreram algum tipo de modificação (exclusão de itens ou inclusão de novos itens de fatores diferentes) e apenas o fator "Ambiente saudável" não foi incluído ao instrumento adaptado. No CFPQ este fator é composto por quatro itens que abordam questões como disponibilidade de alimentos saudáveis em casa, assim como snack foods e doces, no entanto, na versão brasileira esses itens não foram consistentes.

Frente a isso, sugere-se que novos estudos qualitativos sejam realizados com o objetivo de identificar questões relevantes sobre a disponibilidade e o acesso de alimentos em casa que influenciam a alimentação infantil, assim como outras possíveis práticas parentais para a população brasileira que não estejam contempladas no CFPQ.

Dessa forma, conclui-se que o objetivo específico de validar um instrumento de compreensão das práticas parentais de alimentação infantil para a população brasileira foi atingido. Considera-se que o CFPQ adaptado seja adequado para a população brasileira, resultando em um instrumento que contribui para o entendimento abrangente das práticas alimentares infantis, podendo ser aplicado no Brasil.

Em relação ao objetivo específico de associar as múltiplas práticas maternas e outros determinantes ao consumo de frutas e hortaliças por crianças de 18 meses a 8 anos, observa-se que ele foi atingido com o segundo artigo deste trabalho.

Apesar do estudo ter sido realizado apenas com mães, incentiva-se que novos estudos com pais também sejam realizados, sendo um campo ainda pouco explorado, uma vez que a atribuição do pai na alimentação infantil precisar ser valorizado e incentivado. Nas últimas décadas, os papéis de gênero familiares mudaram e as demandas e a falta de tempo crônica atinge homens, mulheres e jovens. Por isso a divisão das responsabilidades na família, incluindo a alimentação infantil é fundamental. Além disso, pesquisas comparativas entre 
pais e mães são importantes, a partir do momento que podem ser necessárias intervenções diferentes para cada um deles. Pesquisas com pais contribuem para um entendimento mais abrangente sobre o ambiente familiar.

Outra questão importante para discussão é o papel da mãe nos cuidados com a criança, incluindo a alimentação. É comum atribuir a culpa do excesso de peso infantil ou de maus hábitos alimentares aos pais da criança, principalmente às mães. No entanto, deve-se levar em consideração que os pais sempre agem com boas intenções, acreditando fazer o melhor para seu filho. O conhecimento sobre as práticas parentais, assim como suas consequências ainda são pouco abordadas. Porém, não se deve atribuir a culpa a elas. Como é sabido, o comportamento alimentar pode ser influenciado por um complexo conjunto de fatores, sendo que as práticas parentais podem ter alguma parcela de explicação. Esta questão é fortalecida pelos resultados do segundo artigo, no qual as práticas parentais não tiveram correlação significativa com o consumo de frutas e hortaliças pela criança, apesar da influência materna ter sido relevante. Deve-se considerar ainda que as práticas parentais são responsivas ao contexto e que a resposta do comportamento da criança também tem certa influência sobre o comportamento dos pais.

Os profissionais de saúde devem estar atentos a esse conjunto de fatores que envolvem a alimentação. De acordo com os achados do presente estudo, ressalta-se a importância de, em intervenções para o incentivo do consumo de frutas e hortaliças pelas crianças, por exemplo, incentivar os bons hábitos alimentares também do pais, considerando que a alimentação deles representa a maior parte da variância explicada do consumo desses alimentos pela criança. Os pais devem ainda conhecer como os hábitos infantis são formados, como suas práticas afetam a alimentação de seus filhos e como eles podem contribuir para uma alimentação adequada e mais saudável.

De forma mais ampla, esses conhecimentos deveriam ser abordados também em estratégias políticas de promoção da alimentação saudável e prevenção do sobrepeso e obesidade infantil, incluindo orientações em guias alimentares para crianças, por exemplo. Assim, considera-se que o presente estudo forneça uma contribuição importante para a literatura sobre processos psicológicos de práticas parentais e potencial prevenção para obesidade infantil 
e que o objetivo de determinar as práticas maternas no Brasil e como elas influenciam o comportamento alimentar de crianças de 18 meses a 8 anos foi cumprido. 


\section{Referências Bibliográficas}

1. Gibson EL, Kreichauf S, Wildgruber A, Vögele C, Summerbell CD, Nixon $\mathrm{C}$, et al. A narrative review of psychological and educational strategies applied to young children's eating behaviours aimed at reducing obesity risk. Obesity Reviews. 2012. p. 85-95.

2. Kelder SH, Perry CL, Klepp KI, Lytle LL. Longitudinal tracking of adolescent smoking, physical activity, and food choice behaviours. Am J Public Health. $1994 ; 84(7): 1121-6$.

3. Nicklas T, Johnson R. Position of the American Dietetic Association: Dietary guidance for healthy children ages 2 to 11 years. J Am Diet Assoc. 2004;104(4):660-77.

4. Baranowski T, Bar-Or O, Blair S, Corbin C, Dowda M, Freedson P, et al. Guidelines for School and Community Programs to Promote Lifelong Physical Activity Among Young People [Internet]. The Journal of school health. $1997 . \quad$ p. 202-19. Available from: http://www.ncbi.nlm.nih.gov/pubmed/9285866

5. Whincup PH, Gilg JA, Papacosta O, Seymour C, Miller GJ, Alberti KGMM, et al. Early evidence of ethnic differences in cardiovascular risk: cross sectional comparison of British South Asian and white children. BMJ. 2002;324(7338):635.

6. Moller JH, Taubert KA, Allen HD, Clark EB, Lauer RM. Cardiovascular health and disease in children: current status. A Special Writing Group from the Task Force on Children and Youth, American Heart Association. Circulation. 1994;89(2):923-30.

7. Vieira GO, Silva LR, Vieira TDO, Almeida JAG, Cabral V a. Hábitos alimentares de crianças menores de 1 ano amamentadas e nãoamamentadas. J Pediatr (Rio J). 2004;80(5):411-6.

8. Taylor JP, Evers S, McKenna M. Determinants of healthy eating in children and youth. Can J Public Heal. 2005;96(SUPPL. 3):20-6.

9. Lobstein T, Jackson-Leach R, Moodie ML, Hall KD, Gortmaker SL, Swinburn BA, et al. Child and adolescent obesity: part of a bigger picture. Lancet [Internet]. Elsevier; 2015 Feb 18 [cited 2015 Feb 19];385(9986):2510-20. Available from: http://www.thelancet.com/article/S0140673614617463/fulltext

10. IBGE. Pesquisa de Orçamentos Faminliares 2008-2009 [Internet]. Rio de Janeiro; $2011 . \quad$ Available from: http://www.ibge.gov.br/home/estatistica/populacao/condicaodevida/pof/20 08_2009_analise_consumo/pofanalise_2008_2009.pdf 
11. Brasil. Pesquisa Nacional de Demografia e Saúde da Criança e da Mulher [Internet]. Brasília; $2008 . \quad$ Available from: http://bvsms.saude.gov.br/bvs/pnds/img/relatorio_final_PNDS2006_04julh 02008.pdf

12. Ventura AK, Birch LL. Does parenting affect children's eating and weight status? Int J Behav Nutr Phys Act. 2008;5:15.

13. Fisher JO, Mitchell DC, Smiciklas-Wright H, Birch LL. Parental influences on young girls' fruit and vegetable, micronutrient, and fat intakes. J Am Diet Assoc. 2002;102(1):58-64.

14. Savage JS, Fisher JO, Birch LL. Parental influence on eating behaviour: Conception to adolescence. Journal of Law, Medicine and Ethics. 2007. p. 22-34.

15. Blissett J, Meyer C, Haycraft E. Maternal and paternal controlling feeding practices with male and female children. Appetite. 2006;47(2):212-9.

16. Mennella JA, Jagnow CP, Beauchamp GK. Prenatal and postnatal flavor learning by human infants. Pediatrics. 2001;107(6):E88.

17. Zeinstra GG, Koelen M a, Kok FJ, van der Laan N, de Graaf C. Parental child-feeding strategies in relation to Dutch children's fruit and vegetable intake. Public Health Nutr. 2010;13(6):787-96.

18. Prevention C for DC and. Guidelines for School Health Programs to Promote Lifelong Healthy Eating [Internet]. Available from: http://www.cdc.gov/mmwr/preview/mmwrhtml/00042446.htm

19. Lytle LA, Kubik MY. Nutritional issues for adolescents. Best Pract Res Clin Endocrinol Metab [Internet]. Elsevier; 2003 Jun 6 [cited 2015 Jul 14];17(2):177-89. Available from: http://www.bprcem.com/article/S1521690X03000174/fulltext

20. Birch LL, Fisher JO. Development of eating behaviours among children and adolescents. Pediatrics. 1998;101(3 Pt 2):539-49.

21. World Health Organization. Population-based prevention strategies for childhood obesity. Rep WHO forum Tech Meet ... [Internet]. 2010;40. Available from: http://onlinelibrary.wiley.com/doi/10.1002/cbdv.200490137/abstract|nhttp:/ /scholar.google.com/scholar?hl=en\&btnG=Search\&q=intitle:Populationbased+prevention+strategies+for+childhood+obesity\#0

22. Wang $\mathrm{Y}$, Monteiro C, Popkin BM. Trends of obesity and underweight in older children and adolescents in the United States, Brazil, China, and Russia. [Internet]. The American journal of clinical nutrition. 2002 Jun. Available from: http://www.ncbi.nlm.nih.gov/pubmed/12036801 
23. WHO. Global status report on noncommunicable diseases [Internet]. World Health Organization (WHO). Geneva; 2010. Available from: http://whqlibdoc.who.int/publications/2011/9789240686458_eng.pdf

24. Bourdieu P. O-poder-simbolico. Livro. 1989.

25. Russell CG, Worsley A. Do children's food preferences align with dietary recommendations? Public Health Nutr [Internet]. 2007 Nov [cited 2015 Jun 30];10(11):1223-33. Available from: http://www.ncbi.nlm.nih.gov/pubmed/17381898

26. Story M, Neumark-Sztainer D, French S. Individual and environmental influences on adolescent eating behaviours. Journal of the American Dietetic Association. 2002. p. S40-51.

27. Domel SB, Thompson WO, Davis HC, Baranowski T, Leonard SB, Baranowski J. Psychosocial predictors of fruit and vegetable consumption among elementary school children. Health Educ Res [Internet]. 1996;11(3):299-308. Available from: http://her.oxfordjournals.org/cgi/doi/10.1093/her/11.3.299

28. Resnicow K, Davis-Hearn M, Smith M, Baranowski T, Lin LS, Baranowski $J$, et al. Social-cognitive predictors of fruit and vegetable intake in children. Health Psychol. 1997;16(3):272-6.

29. Cooke L. The importance of exposure for healthy eating in childhood: A review. J Hum Nutr Diet. 2007;20(4):294-301.

30. Dattilo AM, Birch L, Krebs NF, Lake A, Taveras EM, Saavedra JM. Need for early interventions in the prevention of pediatric overweight: A review and upcoming directions. Journal of Obesity. 2012.

31. Aldridge V, Dovey TM, Halford JCG. The role of familiarity in dietary development. Developmental Review. 2009. p. 32-44.

32. Cooke LJ, Wardle J. Age and gender differences in children's food preferences. Br J Nutr. 2005;93(5):741-6.

33. Birch LL. Development of food preferences. Annu Rev Nutr. 1999;19:4162.

34. Beauchamp GK, Mennella JA. Early flavor learning and its impact on later feeding behaviour. J Pediatr Gastroenterol Nutr. 2009;48 Suppl 1:S25-30.

35. Birch LL, Davison KK. Family environmental factors influencing the developing behavioural controls of food intake and childhood overweight. Pediatr Clin North Am. 2001;48(4):893-907.

36. Birch LL, Marlin DW. I don't like it; I never tried it: effects of exposure on two-year-old children's food preferences. Appetite. 1982;3(4):353-60. 
37. Birch LL, McPhee L, Shoba BC, Pirok E, Steinberg L. What kind of exposure reduces children's food neophobia? Looking vs. tasting. Appetite. 1987;9(3):171-8.

38. Sullivan SA, Birch LL. Infant dietary experience and acceptance of solid foods. Pediatrics. 1994.

39. Cooke LJ, Wardle J, Gibson EL, Sapochnik M, Sheiham a, Lawson M. Demographic, familial and trait predictors of fruit and vegetable consumption by pre-school children. Public Health Nutr. 2004;7(2):295302.

40. Skinner JD, Carruth BR, Bounds W, Ziegler PJ. Children's food preferences: A longitudinal analysis. J Am Diet Assoc. 2002;102(11):163847.

41. Scaglioni S, Salvioni M, Galimberti C. Influence of parental attitudes in the development of children eating behaviour. Br J Nutr. 2008;99 Suppl 1:S225 .

42. Blissett J. Relationships between parenting style, feeding style and feeding practices and fruit and vegetable consumption in early childhood. Appetite [Internet]. Elsevier Ltd; 2011;57(3):826-31. Available from: http://dx.doi.org/10.1016/j.appet.2011.05.318

43. Birch LL, Fisher JO, Grimm-Thomas K, Markey CN, Sawyer R, Johnson SL. Confirmatory factor analysis of the Child Feeding Questionnaire: a measure of parental attitudes, beliefs and practices about child feeding and obesity proneness. Appetite [Internet]. 2001;36(3):201-10. Available from: http://www.ncbi.nlm.nih.gov/pubmed/11358344/nhttp://www.sciencedirect. com/science/article/pii/S0195666301903988

44. Faith MS, Heshka S, Keller KL, Sherry B, Matz PE, Pietrobelli A, et al. Maternal-child feeding patterns and child body weight: findings from a population-based sample. Arch Pediatr Adolesc Med. 2003;157(9):926-32.

45. Wardle J, Sanderson S, Guthrie CA, Rapoport L, Plomin R. Parental feeding style and the inter-generational transmission of obesity risk. Obes Res. 2002;10(6):453-62.

46. Musher-Eizenman D, Holub S. Comprehensive feeding practices questionnaire: Validation of a new measure of parental feeding practices. J Pediatr Psychol. 2007;32(8):960-72.

47. Baughcum AE, Powers SW, Johnson SB, Chamberlin LA, Deeks CM, Jain $A$, et al. Maternal feeding practices and beliefs and their relationships to overweight in early childhood. J Dev Behav Pediatr. 2001;22(6):391-408.

48. Costanzo PR, Woody EZ. Domain-Specific Parenting Styles and Their Impact on the Child's Development of Particular Deviance: The Example of 
Obesity Proneness. Journal of Social and Clinical Psychology. 1985. p. 425-45.

49. Johnson SL, Birch LL. Parents' and children's adiposity and eating style. Pediatrics. 1994;94(5):653-61.

50. Ogden J, Reynolds R, Smith A. Expanding the concept of parental control: A role for overt and covert control in children's snacking behaviour? Appetite. 2006;47(1):100-6.

51. Faith MS, Berkowitz RI, Stallings VA, Kerns J, Storey M, Stunkard AJ. Parental feeding attitudes and styles and child body mass index: prospective analysis of a gene-environment interaction. Pediatrics. 2004;114(4):e429-36.

52. Fisher JO, Birch LL. Restricting access to palatable foods affects children's behavioural response, food selection, and intake. Am J Clin Nutr. 1999;69(6):1264-72.

53. Francis LA, Hofer SM, Birch LL. Predictors of maternal child-feeding style: maternal and child characteristics. Appetite. 2001;37(3):231-43.

54. Jansen E, Mulkens S, Jansen A. Do not eat the red food!: Prohibition of snacks leads to their relatively higher consumption in children. Appetite. 2007;49(3):572-7.

55. Fisher JO, Birch LL. Eating in the absence of hunger and overweight in girls from 5 to 7 y of age. Am J Clin Nutr. 2002;76(1):226-31.

56. Birch LL, Fisher JO, Davison KK. Learning to overeat: Maternal use of restrictive feeding practices promotes girls' eating in the absence of hunger. Am J Clin Nutr. 2003;78(2):215-20.

57. Coulthard $\mathrm{H}$, Blissett $\mathrm{J}$. Fruit and vegetable consumption in children and their mothers. Moderating effects of child sensory sensitivity. Appetite. 2009;52(2):410-5.

58. Campbell KJ, Crawford DA, Ball K. Family food environment and dietary behaviours likely to promote fatness in 5-6 year-old children. Int $\mathrm{J}$ Obes (Lond). 2006;30(8):1272-80.

59. Klesges RC, Coates TJ, Brown G, Sturgeon-Tillisch J, MoldenhauerKlesges LM, Holzer B, et al. Parental influences on children's eating behaviour and relative weight. J Appl Behav Anal. 1983;16(4):371-8.

60. Matheson DM, Robinson TN, Varady A, Killen JD. Do Mexican-American Mothers' Food-Related Parenting Practices Influence Their Children's Weight and Dietary Intake? J Am Diet Assoc. 2006;106(11):1861-5.

61. Keller KL, Pietrobelli a, Johnson SL, Faith MS. Maternal restriction of children's eating and encouragements to eat as the "non-shared 
environment": a pilot study using the child feeding questionnaire. Int J Obes (Lond). 2006;30(11):1670-5.

62. Powers SW, Chamberlin LA, van Schaick KB, Sherman SN, Whitaker RC. Maternal feeding strategies, child eating behaviours, and child BMI in lowincome African-American preschoolers. Obesity (Silver Spring). 2006;14(11):2026-33.

63. Spruijt-Metz D, Lindquist CH, Birch LL, Fisher JO, Goran MI. Relation between mothers' child-feeding practices and children's adiposity. Am J Clin Nutr. 2002;75(3):581-6.

64. Galloway AT, Lee Y, Birch LL. Predictors and consequences of food neophobia and pickiness in young girls. J Am Diet Assoc. 2003;103(6):692-8.

65. Galloway AT, Fiorito L, Lee Y, Birch LL. Parental pressure, dietary patterns, and weight status among girls who are "picky eaters." J Am Diet Assoc. 2005;105(4):541-8.

66. Gregory JE, Paxton SJ, Brozovic AM. Pressure to eat and restriction are associated with child eating behaviours and maternal concern about child weight, but not child body mass index, in 2- to 4-year-old children. Appetite. 2010;54(3):550-6.

67. Brann LS, Skinner JD. More controlling child-feeding practices are found among parents of boys with an average body mass index compared with parents of boys with a high body mass index. J Am Diet Assoc. 2005;105(9):1411-6.

68. Gregory JE, Paxton SJ, Brozovic AM. Maternal feeding practices predict fruit and vegetable consumption in young children. Results of a 12-month longitudinal study. Appetite [Internet]. Elsevier Ltd; 2011;57(1):167-72. Available from: http://dx.doi.org/10.1016/j.appet.2011.04.012

69. Birch LL, McPheee L, Shoba B., Steinberg L, Krehbiel R. "Clean up your plate": Effects of child feeding practices on the conditioning of meal size. Learning and Motivation. 1987. p. 301-17.

70. Carper JL, Orlet Fisher J, Birch LL. Young girls' emerging dietary restraint and disinhibition are related to parental control in child feeding. Appetite. 2000;35(2):121-9.

71. Batsell WR, Brown AS. Human Flavor-Aversion Learning: A Comparison of Traditional Aversions and Cognitive Aversions. Learn Motiv [Internet]. 1998;29(4):383-96. Available from: http://linkinghub.elsevier.com/retrieve/pii/S0023969098910165

72. Batsell WR, Brown AS, Ansfield ME, Paschall GY. "You will eat all of that!": a retrospective analysis of forced consumption episodes. Appetite. 2002;38(3):211-9. 
73. Wind M, de Bourdeaudhuij I, te Velde SJ, Sandvik C, Due P, Klepp KI, et al. Correlates of Fruit and Vegetable Consumption Among 11-Year-Old Belgian-Flemish and Dutch Schoolchildren. J Nutr Educ Behav. 2006;38(4):211-21.

74. Draxten M, Fulkerson J a., Friend S, Flattum CF, Schow R. Parental role modeling of fruits and vegetables at meals and snacks is associated with children's adequate consumption. Appetite [Internet]. Elsevier Ltd; 2014;78:1-7. Available from: http://dx.doi.org/10.1016/j.appet.2014.02.017

75. Addessi E, Galloway AT, Visalberghi E, Birch LL. Specific social influences on the acceptance of novel foods in 2-5-year-old children. Appetite. 2005;45(3):264-71.

76. Harper L V., Sanders KM. The effect of adults' eating on young children's acceptance of unfamiliar foods. Journal of Experimental Child Psychology. 1975. p. 206-14.

77. Cullen KW, Baranowski T, Rittenberry L, Cosart C, Hebert D, de Moor C. Child-reported family and peer influences on fruit, juice and vegetable consumption: reliability and validity of measures. Health Educ Res. 2001;16(2):187-200.

78. De Bourdeaudhuij I, te Velde S, Brug J, Due P, Wind M, Sandvik C, et al. Personal, social and environmental predictors of daily fruit and vegetable intake in 11-year-old children in nine European countries. Eur J Clin Nutr. 2008;62(7):834-41.

79. Fisher JO, Mitchell DC, Smiciklas-Wright H, Mannino ML, Birch LL. Meeting calcium recommendations during middle childhood reflects motherdaughter beverage choices and predicts bone mineral status. Am J Clin Nutr. 2004;79(4):698-706.

80. Cullen KW, Baranowski T, Owens E, Marsh T, Rittenberry L, de Moor C. Availability, accessibility, and preferences for fruit, $100 \%$ fruit juice, and vegetables influence children's dietary behaviour. Health Educ Behav. 2003;30(5):615-26.

81. Melbye EL, Øverby NC, Øgaard T. Child consumption of fruit and vegetables: the roles of child cognitions and parental feeding practices. Public Health Nutr. 2012;15(06):1047-55.

82. Kristjansdottir AG, Thorsdottir I, De Bourdeaudhuij I, Due P, Wind M, Klepp $\mathrm{K}-\mathrm{I}$. Determinants of fruit and vegetable intake among 11-year-old schoolchildren in a country of traditionally low fruit and vegetable consumption. Int J Behav Nutr Phys Act [Internet]. 2006 Jan 1 [cited 2015 Jun 9];3(article 41):41. Available from: http://www.researchgate.net/publication/6671739_Determinants_of_fruit_ and_vegetable_intake_among_11-yearold_schoolchildren_in_a_country_of_traditionally_low_fruit_and_vegetabl e_consumption 
83. De Bourdeaudhuij I, Yngve A, te Velde SJ, Klepp K-I, Rasmussen M, Thorsdottir I, et al. Personal, social and environmental correlates of vegetable intake in normal weight and overweight 9 to 13-year old boys. Int J Behav Nutr Phys Act [Internet]. 2006 Jan [cited 2015 Jul 25];3:37. Available from: http://www.pubmedcentral.nih.gov/articlerender.fcgi?artid=1635056\&tool= pmcentrez\&rendertype=abstract

84. Birch. Effects of Peer Models ' Food Choices and Eating Behaviours on Preschoolers ' Food Preferences. Child Dev. 1980;51(2):489-96.

85. Hendy HM, Raudenbush B. Effectiveness of teacher modeling to encourage food acceptance in preschool children. Appetite. 2000.

86. Patrick H, Nicklas TA, Hughes SO, Morales M. The benefits of authoritative feeding style: Caregiver feeding styles and children's food consumption patterns. Appetite. 2005;44(2):243-9.

87. Rossi A, Moreira EAM, Rauen MS. Determinantes do comportamento alimentar: Uma revisão com enfoque na família. Rev Nutr. 2008;21(6):739_ 48.

88. O'Connor TM, Hughes SO, Watson KB, Baranowski T, Nicklas T a, Fisher $\mathrm{JO}$, et al. Parenting practices are associated with fruit and vegetable consumption in pre-school children. Public Health Nutr. 2010;13(1):91101.

89. Deci EL, Koestner R, Ryan RM. A meta-analytic review of experiments examining the effects of extrinsic rewards on intrinsic motivation. Psychol Bull. 1999;125(6):627-68; discussion 692-700.

90. Kröller K, Warschburger P. Maternal feeding strategies and child's food intake: considering weight and demographic influences using structural equation modeling. Int J Behav Nutr Phys Act [Internet]. 2009 Jan [cited 2015 Jul 25];6(1):78. Available from: http://www.ijbnpa.org/content/6/1/78

91. Sleddens EFC, Kremers SPJ, De Vries NK, Thijs C. Relationship between parental feeding styles and eating behaviours of Dutch children aged 6-7. Appetite. 2010;54(1):30-6.

92. Birch LL, Marlin DW, Rotter J. Eating as the "means" activity in a contingency: effects on young children's food preference. Child Dev. $1984 ; 55(2): 431-9$.

93. Birch LL, Anzman SL. Learning to eat in an obesogenic environment: A developmental systems perspective on childhood obesity. Child Dev Perspect. 2010;4(2):138-43.

94. Mikula G. Influencing food preferences of children by if-then type instructions. Eur J Soc Psychol. 1989;19:225-41. 
95. Casey R, Rozin P. Changing children's food preferences: parent opinions. Appetite. 1989;12(3):171-82.

96. Newman J, Taylor A. Effect of a means-end contingency on young children's food preferences. J Exp Child Psychol. 1992;53(2):200-16.

97. Birch LL, Zimmerman SI, Hind H. The influence of social-affective context on the formation of children's food preferences. Journal of Nutrition Education. 1981. p. S115-8.

98. Birch LL, Birch D, Marlin DW, Kramer L. Effects of instrumental consumption on children's food preference. Appetite. 1982;3(2):125-34.

99. Jansen E, Mulkens S, Jansen A. How to promote fruit consumption in children. Visual appeal versus restriction. Appetite. 2010;54(3):599-602.

100. Hoerr S, Utech AE, Ruth E. Child control of food choices in Head Start families. J Nutr Educ Behav. 2005;37(4):185-90.

101. Kalantari N, Doaei S. Journal of Pediatric Sciences factors and feeding practices with the dietary. 2014;

102. Kiefner-Burmeister AE, Hoffmann D a., Meers MR, Koball AM, MusherEizenman DR. Food consumption by young children: A function of parental feeding goals and practices. Appetite [Internet]. Elsevier Ltd; 2014;74:611. Available from: http://dx.doi.org/10.1016/j.appet.2013.11.011

103. Faith MS, Allison DB GA. Emotional eating and obesity: Theoretical considerations and practical recommendations. In: : Aspen Publishers; Dalton S, editor Overweight and weight management: The health professional's guide to understanding and practice. Gaithersburg, MD; 1997. p. 439-65.

104. Baños RM, Cebolla A, Moragrega I, Van Strien T, Fernández-Aranda F, Agüera Z, et al. Relationship between eating styles and temperament in an Anorexia Nervosa, Healthy Control, and Morbid Obesity female sample. Appetite. 2014;76:76-83.

105. Braet C, Van Strien T. Assessment of emotional, externally induced and restrained eating behaviour in nine to twelve-year-old obese and nonobese children. Behav Res Ther. 1997;35(9):863-73.

106. Wardle J, Guthrie CA, Sanderson S, Rapoport L. Development of the Children's Eating Behaviour Questionnaire. J Child Psychol Psychiatry. 2001;42(7):963-70.

107. Farrow C V, Haycraft E, Blissett JM. Teaching our children when to eat: how parental feeding practices inform the development of emotional eatinga longitudinal experimental design. Am J Clin Nutr [Internet]. 2015 Mar 18 [cited 2015 Mar 24];101(5):908-13. Available from: http://ajcn.nutrition.org/content/101/5/908.full 
108. Blissett J, Haycraft E, Farrow C. Inducing preschool children's emotional eating: Relations with parental feeding practices. Am J Clin Nutr. 2010;92(2):359-65.

109. Wardle J, Cooke LJ, Gibson EL, Sapochnik M, Sheiham A, Lawson M. Increasing children's acceptance of vegetables; a randomized trial of parent-led exposure. Appetite. 2003;40(2):155-62.

110. Brasil. Guia alimentar para a população brasileira [Internet]. 2nd ed. Brasília; $2014 . \quad$ Available from: http://189.28.128.100/dab/docs/portaldab/publicacoes/guia_alimentar_po pulacao_brasileira.pdf

111. Brasil. Guia alimentar para crianças menores de 2 anos. Ministério da Saúde. Brasília; 2005. 16-23 p.

112. Powell FC, Farrow C V., Meyer C. Food avoidance in children. The influence of maternal feeding practices and behaviours. Appetite [Internet]. Elsevier Ltd; 2011;57(3):683-92. Available from: http://dx.doi.org/10.1016/j.appet.2011.08.011

113. Carnell S, Cooke L, Cheng R, Robbins a., Wardle J. Parental feeding behaviours and motivations. A qualitative study in mothers of UK preschoolers. Appetite [Internet]. Elsevier Ltd; 2011;57(3):665-73. Available from: http://dx.doi.org/10.1016/j.appet.2011.08.009

114. Tan CC, Holub SC. Maternal feeding practices associated with food neophobia. Appetite [Internet]. Elsevier Ltd; 2012;59(2):483-7. Available from: http://dx.doi.org/10.1016/j.appet.2012.06.012

115. Haszard JJ. Parental feeding practices in New Zealand. 2013;

116. Musher-Eizenman DR, de Lauzon-Guillain B, Holub SC, Leporc E, Charles MA. Child and parent characteristics related to parental feeding practices. A cross-cultural examination in the US and France. Appetite. 2009;52(1):89-95.

117. De Lauzon-Guillain B, Musher-Eizenman D, Leporc E, Holub S, Charles MA. Parental Feeding Practices in the United States and in France: Relationships with Child's Characteristics and Parent's Eating Behaviour. J Am Diet Assoc. 2009;109(6):1064-9.

118. Kröller $\mathrm{K}$, Warschburger $\mathrm{P}$. Associations between maternal feeding style and food intake of children with a higher risk for overweight. Appetite. 2008;51(1):166-72.

119. Blissett $J$, Haycraft $E$. Are parenting style and controlling feeding practices related? Appetite. 2008;50(2-3):477-85.

120. Disantis KI, Collins BN, Fisher JO, Davey A. Do infants fed directly from the breast have improved appetite regulation and slower growth during early 
childhood compared with infants fed from a bottle? Int $\mathrm{J}$ Behav Nutr Phys Act [Internet]. 2011 Jan [cited 2015 Jul 25];8:89. Available from: http://www.pubmedcentral.nih.gov/articlerender.fcgi?artid=3170240\&tool= pmcentrez\&rendertype $=$ abstract

121. Gable S, Chang Y, Krull JL. Television watching and frequency of family meals are predictive of overweight onset and persistence in a national sample of school-aged children. J Am Diet Assoc [Internet]. 2007 Jan [cited 2015 Jul 25];107(1):53-61. Available from: http://www.ncbi.nlm.nih.gov/pubmed/17197271

122. Neumark-Sztainer D, Eisenberg ME, Fulkerson JA, Story M, Larson NI. Family meals and disordered eating in adolescents: longitudinal findings from project EAT. Arch Pediatr Adolesc Med. 2008;162(1):17-22.

123. Hammons AJ, Fiese BH. Is frequency of shared family meals related to the nutritional health of children and adolescents? Pediatrics. 2011;127(6):e1565-74.

124. Stanek K, Abbott D, Cramer S. Diet quality and the eating environment of preschool children. J Am Diet Assoc [Internet]. 1990 Nov [cited 2015 Jul 25];90(11):1582-4. Available from: http://www.ncbi.nlm.nih.gov/pubmed/2229855

125. Gillman MW, Rifas-Shiman SL, Frazier AL, Rockett HR, Camargo CA, Field $\mathrm{AE}$, et al. Family dinner and diet quality among older children and adolescents. Arch Fam Med. 2000;9(3):235-40.

126. Monteiro RA. Influência de Aspectos Psicossociais e Situacionais sobre a Escolha Alimentar Infantil. 2009;225p.

127. Criança e consumo. Tempo de crianças e adolescentes assistindo TV aumenta em 10 anos [Internet]. 2015 [cited 2015 Jul 1]. Available from: http://criancaeconsumo.org.br/noticias/tempo-diario-de-criancas-eadolescentes-em-frente-a-tv-aumenta-em-10-anos/

128. Barlow SE. Expert committee recommendations regarding the prevention, assessment, and treatment of child and adolescent overweight and obesity: summary report. Pediatrics. 2007;120 Suppl :S164-92.

129. Zimmerman FJ, Christakis DA, Meltzoff AN. Television and DVD/video viewing in children younger than 2 years. Arch Pediatr Adolesc Med [Internet]. American Medical Association; 2007 May 1 [cited 2015 Jun 5];161(5):473-9. Available from: http://archpedi.jamanetwork.com/article.aspx?articleid=570266

130. Miller SA, Taveras EM, Rifas-Shiman SL, Gillman MW. Association between television viewing and poor diet quality in young children. Int $\mathrm{J}$ Pediatr Obes [Internet]. 2008 Jan [cited 2015 Jul 25];3(3):168-76. Available

from: 
http://www.pubmedcentral.nih.gov/articlerender.fcgi?artid=4249761\&tool= pmcentrez\&rendertype $=$ abstract

131. Halford JCG, Boyland EJ, Cooper GD, Dovey TM, Smith CJ, Williams N, et al. Children's food preferences: effects of weight status, food type, branding and television food advertisements (commercials). Int $\mathrm{J}$ Pediatr Obes [Internet]. 2008 Jan [cited 2015 Jul 25];3(1):31-8. Available from: http://www.ncbi.nlm.nih.gov/pubmed/17963122

132. Field AE, Camargo CA, Taylor CB, Berkey CS, Roberts SB, Colditz GA. Peer, parent, and media influences on the development of weight concerns and frequent dieting among preadolescent and adolescent girls and boys. Pediatrics. 2001;107(1):54-60.

133. Hair JFJ, Black WC, Babin BJ, Anderson RE. Multivariate Data Analysis. 2009. p. 816.

134. Beaton DE, Bombardier C, Guillemin F, Ferraz MB. Guidelines for the process of cross-cultural adaptation of self-report measures. Spine (Phila Pa 1976). 2000;25(24):3186-91.

135. V. C-B, Balbinotti MAA, Teodoro MLM. Tradução e validação de conteúdo: uma proposta para a adaptação de instrumentos. Instrumentação psicológica: fundamentos e práticas. Porto Alegre: Artmed; 2010. p. 50620.

136. Araújo GS, Oliveira KES, Akutsu R, Monteiro RA, Silva AB. Tradução e adaptação cultural de um instrumento de compreensão de práticas alimentares infantis. Universidade de Brasília; 2013.

137. Landis JR, Koch GG. The measurement of observer agreement for categorical data. Biometrics [Internet]. 1977 Mar [cited 2014 Jul 20];33(1):159-74.

http://www.ncbi.nlm.nih.gov/pubmed/843571

138. Souza RD, Oliveira KES, Monteiro RA, Silva AB. Práticas parentais e sua relação com a alimentação infantil - um estudo piloto. Universidade de Brasília; 2013.

139. Molina M del CB, Lopéz PM, de Faria CP, Cade NV, Zandonade E. Socioeconomic predictors of child diet quality. Rev Saude Publica. 2010;44(5):785-92.

140. Mondini L, Levy RB, Saldiva SRDM, Venâncio SI, Aguiar JDA, Stefanini MLR. Prevalência de sobrepeso e fatores associados em crianças ingressantes no ensino fundamental em um município da região metropolitana de São Paulo, Brasil. Cad Saude Publica. 2007;23(8):182534.

141. Castro IRR, Cardoso LO, Engstrom EM, Levy RB, Monteiro CA. Vigilância de fatores de risco para doenças não transmissíveis entre adolescentes: 
a experiência da cidade do Rio de Janeiro, Brasil Surveillance of risk factors for non-communicable diseases among adolescents: the experience in Rio de Janeiro, Brazil. Cad Saúde Pública. 2008;24(10):2279-88.

142. Pasquali L. Análise fatorial para pesquisadores. 1st ed. Brasília: LabPAM; 2012. $281 \mathrm{p}$.

143. Melbye EL, Øgaard T, Øverby NC. Validation of the Comprehensive Feeding Practices Questionnaire with parents of 10-to-12-year-olds. BMC Med Res Methodol [Internet]. BioMed Central Ltd; 2011;11(1):113. Available from: http://www.biomedcentral.com/1471-2288/11/113

144. Tabachnick B, Fidell L. Using multivariate statistics. 6th ed. Boston: Pearson; 2013. $983 \mathrm{p}$.

145. Kim J, Mueller CW. Factor Analysis: Statistical Methods and Practical Issues Sage University Papers Series. Quantitative Applications in the Social Sciences. lowa City: Sage Publications, Inc.; 1978. 87 p.

146. Pereira LP, Sávio K, Akutsu R, Monteiro RA, Silva AB, Gomes A, et al. Cresci, e agora? - Manual prático de alimentação para crianças de 2 a 5 anos [Internet]. Brasília; 2014. p. 24. Available from: https://drive.google.com/file/d/OB2keTw4CliTgbjUwNXI3RmJEZTE2dWtP Skhpa3pkTIEONFY0/view

147. Wardle J, Carnell S, Cooke L. Parental control over feeding and children's fruit and vegetable intake: How are they related? J Am Diet Assoc. 2005;105(2):227-32.

148. Clark HR, Goyder E, Bissell P, Blank L, Peters J. How do parents' childfeeding behaviours influence child weight? Implications for childhood obesity policy. J Public Health (Bangkok). 2007;29(2):132-41.

149. Vásquez PD. Influencia familiar sobre la conducta alimentaria y su relación con la obesidad infantil. Arch ... [Internet]. 2008;58:249-55. Available from: http://www.captura.uchile.cl/handle/2250/6966

150. Lloyd AB, Lubans DR, Plotnikoff RC, Collins CE, Morgan PJ. Maternal and paternal parenting practices and their influence on children's adiposity, screen-time, diet and physical activity. Appetite [Internet]. Elsevier Ltd; 2014;79:149-57. Available from: http://dx.doi.org/10.1016/j.appet.2014.04.010

151. Pulley C, Galloway AT, Webb RM, Payne LO. Parental child feeding practices: How do perceptions of mother, father, sibling, and self vary? Appetite [Internet]. Elsevier Ltd; 2014;80:96-102. Available from: http://dx.doi.org/10.1016/j.appet.2014.05.001 
152. Shohaimi S, Wei WY, Shariff ZM. Confirmatory Factor Analysis of the Malay Version Comprehensive Feeding Practices Questionnaire Tested among Mothers of Primary School Children in Malaysia. 2014;2014.

153. Haszard JJ, Williams SM, Dawson AM, Skidmore PML, Taylor RW. Factor analysis of the Comprehensive Feeding Practices Questionnaire in a large sample of children. Appetite [Internet]. Elsevier Ltd; 2013;62:110-8. Available from: http://dx.doi.org/10.1016/j.appet.2012.11.017

154. Hernandez-Nieto R. Contributions to statistical analysis. Mérida, España: Los Andes University Learning; 2002.

155. Fiske S, Gilbert D, Lindzey G. Handbook of social psychology [Internet]. New Jersey: John Wiley \& Sons; 2010. 896 p.

156. Pasquali L. Instrumentação Psicológica: Fundamentos e práticas. Artmed. Brasília; 2009. 553 p.

157. Iglesias, F., \& Valentini F. Correlações. In C M Faiad, MC Ferreira \& L Pasquali Pesquisas quantitativas: Teoria e práticas. Petrópolis: Vozes;

158. Fisher JO, Birch LL. Restricting access to palatable foods affects children ' $\mathrm{s}$ behavioural response, food selection, and intake $1-3$. Int J Obes Relat Metab Disord. 1999;1264-72.

159. IBGE. Pesquisa Nacional por Amostra de Domicílios Contínua - $1^{\circ}$ trimestre de 2015 [Internet]. 2015. Available from: ftp://ftp.ibge.gov.br/Trabalho_e_Rendimento/Pesquisa_Nacional_por_Am ostra_de_Domicilios_continua/Trimestral/Comentarios/pnadc_201501_tri mestre_comentarios.pdf

160. WHO. Diet, nutrition and the prevention of chronic diseases. World Health Organ Tech Rep Ser [Internet]. 2003;916:i - viii - 1-149 - backcover. Available from: http://eutils.ncbi.nlm.nih.gov/entrez/eutils/elink.fcgi?dbfrom=pubmed\&id=1 2768890\& retmode=ref\&cmd=prlinks/npapers3://publication/uuid/734F6B3 1-260B-4545-A8E4-57F7D35DDEB8

161. World Health Organization. Inequalities in Young People's Health. World Health. 2006;(5):1-224.

162. Bazzano $L$ a. Dietary intake of fruit and vegetables and risk of diabetes mellitus and cardiovascular diseases. 2005;66.

163. Boeing H, Bechthold A, Bub A, Ellinger S, Haller D, Kroke A, et al. Critical review: vegetables and fruit in the prevention of chronic diseases. Eur $\mathrm{J}$ Nutr [Internet]. 2012 Jun 9 [cited 2015 Mar 11];51(6):637-63. Available from:

http://www.pubmedcentral. nih.gov/articlerender.fcgi?artid=3419346\&tool= pmcentrez\&rendertype=abstract 
164. World Cancer Res. Fund (WCRF) AICR (Aicr). Food, Nutrition, Physical Activity, and the Prevention of Cancer: a Global Perspective. WCRF/AICR, Washington, DC. 2007.

165. Bortolini GA, Gubert MB, Santos LMP. Consumo alimentar entre crianças brasileiras com idade de 6 a 59 meses. Cad Saúde Pública [Internet]. 2012 [cited 2015 Jul 13];28(9):1759-71. Available from: http://www.scielo.br/pdf/csp/v28n9/v28n9a14.pdf

166. IBGE. Pesquisa nacional de saude do escolar [Internet]. Rio de Janeiro; $2009 . \quad$ Available from: http://www.ibge.gov.br/home/estatistica/populacao/pense/pense.pdf

167. Birch LL, Savage JJ, Ventura A. Influences on the Development of Children's Eating Behaviours: From Infancy to Adolescence. Can J Diet Pr Res [Internet]. 2007;68(1):2007. Available from: http://www.ncbi.nlm.nih.gov/pmc/articles/PMC2678872/

168. Lien N, Lytle LA, Klepp KI. Stability in consumption of fruit, vegetables, and sugary foods in a cohort from age 14 to age 21. Prev Med (Baltim) [Internet]. 2001 Sep [cited 2015 Feb 19];33(3):217-26. Available from: http://www.ncbi.nlm.nih.gov/pubmed/11522162

169. Kelder SH, Perry CL, Klepp KI, Lytle LL. Longitudinal Tracking of Adolescent Smoking, Physical-Activity, and Food Choice Behaviours. Am J Public Health [Internet]. 1994;84(7):1121-6. Available from: <Go to ISI>://A1994PB87000014

170. Birch L. L. Development of food acceptance patterns. Dev Psychol. 1990;26(4):515-9.

171. Larson N, Story M. A review of environmental influences on food choices. Ann Behav Med [Internet]. 2009 Dec [cited 2015 Jul 24];38 Suppl 1:S5673. Available from: http://www.ncbi.nlm.nih.gov/pubmed/19802648

172. Ryan TP. Estatística Moderna para Engenharia. Rio de Janeiro: Elsevier Ltd; 2011.

173. Vereecken C, Rovner A, Maes L. Associations of parenting styles, parental feeding practices and child characteristics with young children's fruit and vegetable consumption. Appetite. 2010;55(3):589-96.

174. McHale SM, Crouter AC, McGuire SA, Updegraff KA. Congruence between mothers' and fathers' differential treatment of siblings: links with family relations and children's well-being. Child Dev. 1995;66(1):116-28.

175. Kaskoun MC, Johnson RK, Goran MI. Comparison of energy intake by semiquantitative food-frequency questionnaire with total energy expenditure by the doubly labeled water method in young children. Am J Clin Nutr. 1994;60(1):43-7. 
APÊNDICES 


\section{Apêndice A - Instrumento aplicado (Online)}

\section{Cidade}

3. Estado

4. Estado civil

Solteira

Casada

Separada

Divorciada

Viúva

União estável / com companheiro (a)

5. Número de filhos

6. A senhora é mãe de criança que hoje possui idade entre 18 meses e 8 anos e 11 meses?

Sim

Não 
Prezada participante, caso a senhora tenha mais de um filho que se encaixe na faixa etária de 18 meses a 8 anos e 11 meses, por favor, preencha os itens deste questionário considerando o seu filho ou filha mais novo (a) dentro desta faixa etária. No caso de filhos gêmeos, considere o último a nascer (mais novo (a)).

7. Qual a data de nascimento deste(a) seu(sua) filho(a)? (DD/MM/AAAA)

8. Qual o sexo da criança?

( ) Feminino

( ) Masculino

Para responder as questões de 1 a 13, considere a escala de frequência ilustrada a seguir. Marcar 1, mais à esquerda, significa "Nunca", e 5, na extrema direita, significa "Sempre". Quanto mais perto de 5 estiver o valor marcado, mais frequente.

Lembre-se, não há respostas certas ou erradas. Responda de acordo com as suas ações em relação à alimentação de seu filho ou filha mais novo (a) na faixa etária ente 18 meses e 8 anos e 11 meses.

Por favor, para que os seus dados da avaliação sejam considerados, é importante que você preencha o questionário até o final. As questões de 1 a 49 foram adaptadas e traduzidas do instrumento Comprehensive Feeding Practices Questionnaire (MusherEizenman \& Holub, 2007).

Escala de frequência

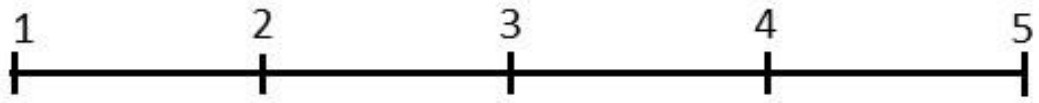

Nunca

Sempre 


\section{Responda de acordo com as suas ações em relação à alimentação de seu filho ou}

filha.

\begin{tabular}{|c|c|c|c|c|}
\hline & Nunca & Raramente Ás vezes & $\begin{array}{l}\text { Quase } \\
\text { sempre }\end{array}$ & Sempre \\
\hline \multicolumn{5}{|l|}{$\begin{array}{l}\text { 1. O quanto voce controla os doces (bala, sorvete, bolo, tortas, docinhos) } \\
\text { que seu filho come? }\end{array}$} \\
\hline \multicolumn{5}{|l|}{$\begin{array}{l}\text { 2. O quanto voce controla os salgadinhos de pacote (Ruffles?, Doritos@, } \\
\text { Cheetos@) que seu filho come? }\end{array}$} \\
\hline \multicolumn{5}{|l|}{$\begin{array}{l}\text { 3. O quanto voce controla os alimentos com excesso de gordura (fritura, } \\
\text { carnes gordas ou com pele, biscoito recheado e outros) que seu filho } \\
\text { come? }\end{array}$} \\
\hline \multicolumn{5}{|l|}{$\begin{array}{l}\text { 4. O quanto você controla a quantidade de bebidas açucaradas } \\
\text { (refrigerantes, suco em pó e de caixinha) que seu filho bebe? }\end{array}$} \\
\hline \multicolumn{5}{|l|}{ 5. Você deixa seu filho comer o que ele quer? } \\
\hline \multicolumn{5}{|l|}{$\begin{array}{l}\text { 6. Nas refeições do almoço e do jantar, você deixa seu filho escolher o } \\
\text { que ele quer dentre aquilo que foi preparado? }\end{array}$} \\
\hline \multicolumn{5}{|l|}{$\begin{array}{l}\text { 7. Quando seu filho fica agitado, a primeira coisa que você faz é dar-lhe } \\
\text { algo para comer ou beber? }\end{array}$} \\
\hline \multicolumn{5}{|l|}{$\begin{array}{l}\text { 8. Você dá a seu filho algo para comer ou beber caso ele esteja sem nada } \\
\text { para fazer, mesmo achando que ele está sem fome? }\end{array}$} \\
\hline \multicolumn{5}{|l|}{$\begin{array}{l}\text { 9. Você dá a seu filho algo para comer ou beber caso ele esteja triste/ } \\
\text { chateado, mesmo achando que ele está sem fome? }\end{array}$} \\
\hline \multicolumn{5}{|l|}{$\begin{array}{l}\text { 10. Se seu filho não gostar do que está sendo servido, você prepara outra } \\
\text { coisa? }\end{array}$} \\
\hline \multicolumn{5}{|l|}{ 11. Você deixa seu filho fazer lanches sempre que ele quer? } \\
\hline \multicolumn{5}{|l|}{$\begin{array}{l}\text { 12. Você permite que seu filho deixe a mesa quando está satisfeito, } \\
\text { mesmo que sua família ainda esteja comendo? }\end{array}$} \\
\hline $\begin{array}{l}\text { 13. Você incentiva essa criança a comer alimentos saudáveis antes dos } \\
\text { não saudáveis? }\end{array}$ & & & & \\
\hline
\end{tabular}


Para responder, considere a escala ilustrada a seguir. Marcar 1, mais à esquerda, significa "Discordo totalmente", e 5, na extrema direita, significa "Concordo totalmente". Quanto mais perto de 5 estiver o valor marcado, maior a concordância.

Lembre-se, não há respostas certas ou erradas. Responda de acordo com as suas ações em relação à alimentação de seu filho ou filha em questão.

Escala de concordância

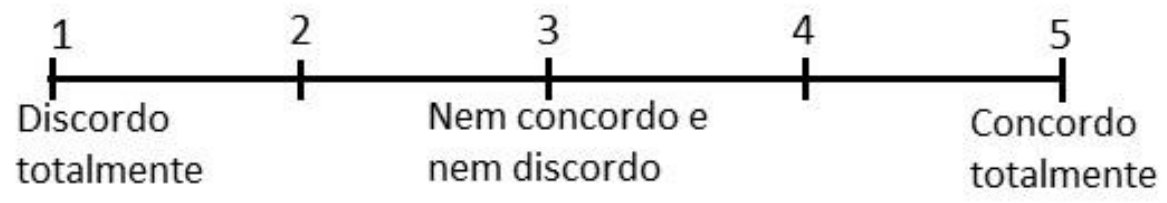




\title{
12. Responda de acordo com as suas ações em relação à alimentação de seu filho ou
} filha, expressando o seu grau de concordância, considerando o mais novo(a).

\author{
Nem \\ concordo, \\ Discordo Discordo nem Concordo Concordo \\ totalmente em parte discordo em parte totalmente
}

14. A maioria dos alimentos disponíveis na minha casa são saudáveis.

15. Eu envolvo meu filho no planejamento das refeições da família.

16. Tenho sempre salgadinhos de pacote (Ruffles $\AA$, Doritos $\AA$,

Cheetos $\left.{ }^{\circledR}\right)$ em minha casa.

17. Meu filho deve sempre comer toda a comida que está em seu prato.

18. Preciso garantir que meu filho coma poucos alimentos gordurosos

(fritura, carnes gordas ou com pele, biscoito recheado e outros).

19. Eu ofereço a meu filho seus alimentos preferidos em troca de um bom comportamento.

20. Eu deixo meu filho ajudar a preparar as refeições da família.

21. Eu controlo a alimentação do meu filho para que ele(a) não coma uma quantidade excessiva de seus alimentos favoritos.

22. Disponibilizo uma variedade de alimentos saudáveis para o meu filho em cada refeição servida na minha casa.

23. Eu ofereço doces (balas, sorvete, bolo, docinhos e outros) para o meu filho como recompensa por bom comportamento.

24. Eu incentivo meu filho a experimentar novos alimentos.

25. Eu converso com meu filho sobre a importância de se comer alimentos saudáveis.

26. Digo a meu filho que alimentos saudáveis são gostosos.

27. Incentivo meu filho a comer menos para que não fique gordo.

28. Se eu não regulasse a alimentação do meu filho, ele comeria muita "besteira" (junk food - alimentos não saudáveis, como refrigerantes, doces e sanduíches).

29. Eu dou a meu filho porções pequenas nas refeições para controlar seu peso.

30. Se meu filho diz: "Não estou com fome", tento fazer com que Coma mesmo assim.

31. Eu converso com meu filho sobre o valor nutricional dos alimentos.

32. Eu estimulo meu filho a participar das compras de supermercado. 
Para responder, considere a escala ilustrada a seguir. Marcar 1, mais à esquerda, significa "Discordo totalmente", e 5, na extrema direita, significa "Concordo totalmente". Quanto mais perto de 5 estiver o valor marcado, maior a concordância.

Lembre-se, não há respostas certas ou erradas. Responda de acordo com as suas ações em relação à alimentação de seu filho ou filha em questão.

12. Responda de acordo com as suas ações em relação à alimentação de seu filho ou filha, expressando o seu grau de concordância, considerando o mais novo(a).

$\begin{array}{ccc} & \text { Nem } \\ \text { concordo, } & \\ \text { Discordo Discordo nem } & \text { Concordo Concordo } \\ \text { totalmente em parte discordo em parte totalmente }\end{array}$

33. Se meu filho come mais do que o normal em uma refeição, tento restringir o que ele come na refeição seguinte.

34. Limito os alimentos que meu filho come e que podem fazê-lo engordar.

35. Proibido meu filho de comer certos alimentos, pois o deixarão gordo.

36. Eu proibido que meu filho coma doces ou seus alimentos preferidos em resposta a um mau comportamento.

37. Tenho sempre doces (bala, sorvete, bolo, torta, docinhos e outros) em minha casa.

38. Estimulo meu filho a comer uma variedade de alimentos saudáveis.

39. Se meu filho come apenas uma pequena porção, tento fazer com que ele coma mais.

40. Tento garantir que meu filho não coma uma quantidade excessiva de seus alimentos favoritos.

41. Não deixo meu filho beliscar entre as refeições porque não quero que ele engorde.

42. Eu digo a meu filho o que ele deve ou não comer, sem explicar o motivo.

43. Procuro garantir que meu filho coma poucos doces (balas, sorvete, bolo ou docinhos).

44. Eu como de forma saudável para servir de exemplo para meu filho.

45. Coloco meu filho de dieta com freqüência para controlar seu peso.

46. Eu como alimentos saudáveis na frente do meu filho, mesmo que não sejam os meus favoritos.

47. Eu tento demonstrar empolgação ao comer alimentos saudáveis.

48. Eu mostro a meu filho o quanto eu gosto de comer alimentos saudáveis.

49. Quando meu filho diz que já terminou de comer, procuro fazer com que ele coma mais colheradas de seu prato. 


\section{Atitudes relacionadas}

Prezada participante, para as seguintes questōes, por favor, continue considerando o seu filho ou filha mais novo(a) dentro da faixa etária indicada.

14. Responda de acordo com as suas açōes em relação à alimentação de seu filho ou filha

Eu sinto que tenho um importante papel no estabelecimento
dos hábitos alimentares ao longo da vida do meu filho(a).

15. Em comparação a outras crianças da mesma idade e sexo, como você avaliaria o peso do seu filho ou sua filha?

\begin{tabular}{|c|c|c|c|c|}
\hline Abaixo do peso & $\begin{array}{l}\text { Um pouco abaixo do } \\
\text { peso }\end{array}$ & Com peso adequado & $\begin{array}{c}\text { Um pouco acima do } \\
\text { peso }\end{array}$ & Com excesso de peso \\
\hline
\end{tabular}

16. Escolha uma posição na escala abaixo que melhor expresse sua opiniāo em relação ao que está sendo apresentado e clique ao lado de cada afirmaçāo.

$\begin{array}{ccc}\text { Um pouco } & \begin{array}{l}\text { Relativamentel } \\ \text { razoavelmente } \\ \text { Despreocupado preocupado Preocupado } \\ \text { preocupado preocupado }\end{array}\end{array}$

O quanto voce se preocupa sobre o(a) seu filho(a) estar comendo muito quando você nä́o está por perto?

O quanto voce se preocupa sobre o(a) seu filho(a) ter que fazer dieta para manter o seu peso adequado?

O quanto vocé se preocupa em seu(sua) filho(a) se tornar obesol excesso de peso?

O quanto voce se preocupa sobre o(a) seu filho(a) ter que comer mais para ter um peso desejável?

O quanto você se preocupa em seu(sua) filho(a) ficar com baixo peso? 
Prezada participante, para as seguintes questões, por favor, continue considerando o seu filho ou filha mais novo(a) dentro da faixa etária indicada.

17. Geralmente, de segunda à sexta, quantas refeições você costuma fazer com o(a) seu filho(a) em um dia? (Considere refeições como café da manhã, almoço, jantar e lanches)

Nenhuma

Uma refeição

Duas refeições

Três refeições

Mais de três refeições

18. A criança costuma comer quando está assistindo à TV, mexendo no celular/ ipod/ tablet?

Não

$\begin{array}{ccccccc}\text { Sim, 1x na } & \text { Sim, 2x na } & \text { Sim, } 3 x \text { na } & \text { Sim, } 4 x \text { na } & \text { Sim, } 5 x \text { na } & \text { Sim, 6x na } & \text { Sim, 7x na } \\ \text { semana } & \text { semana } & \text { semana } & \text { semana } & \text { semana } & \text { semana } & \text { semana }\end{array}$

\section{○}

19. Ontem, a criança comeu assistindo televisão?

Sim

Não 
Prezada participante, para as seguintes questões, por favor, continue considerando o seu filho ou filha mais novo(a) dentro da faixa etária indicada.

17. Nos últimos sete dias, em quantos dias a criança comeu os seguintes alimentos:

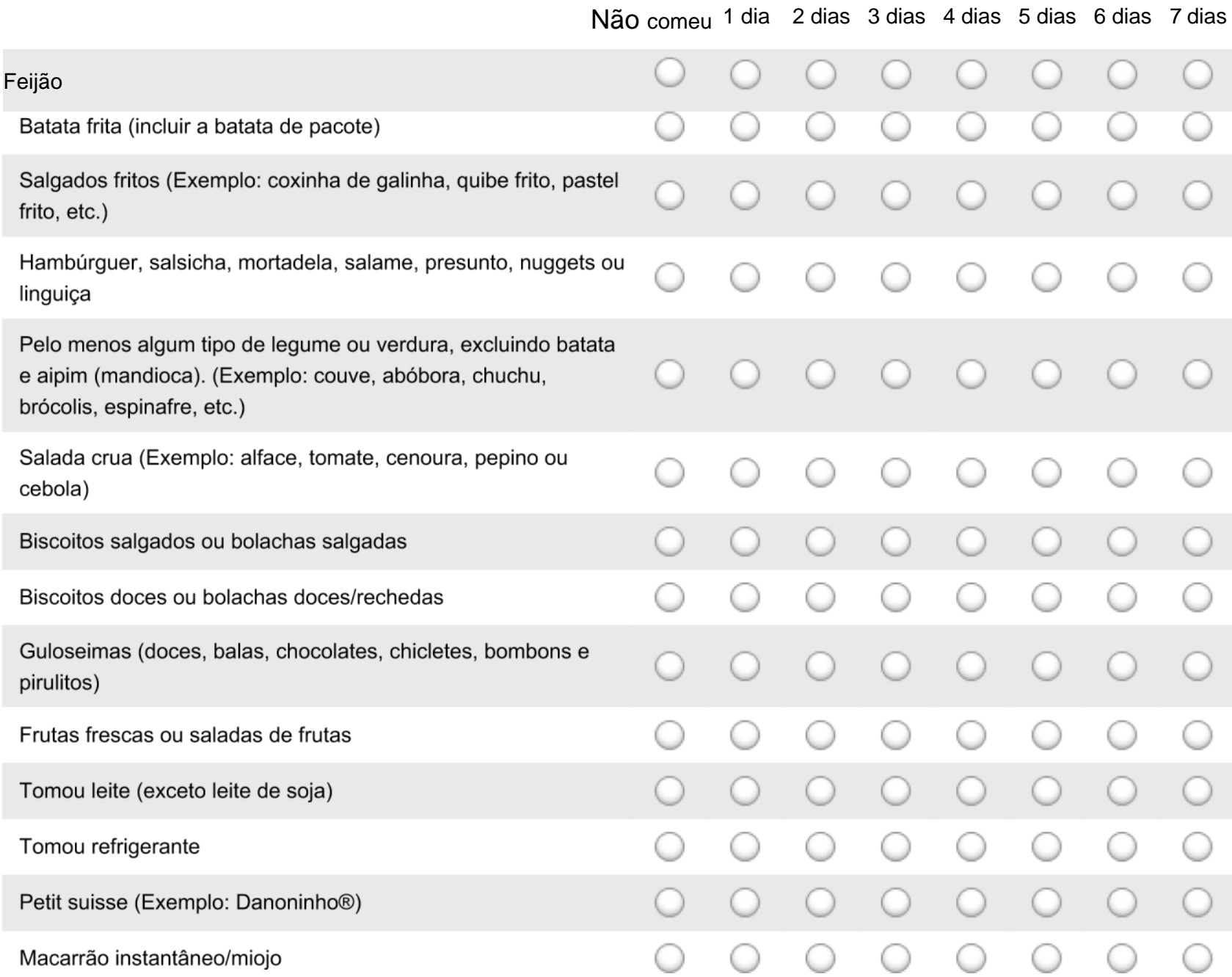




\section{D: \\ 2 Práticas parentais e sua relação com a alimentação infantil}

\section{Dados da criança}

Prezada participante, para as seguintes questões, por favor, continue considerando o seu filho ou sua filha mais novo(a) dentro da faixa etária indicada.

18. Durante o dia, geralmente, onde a criança fica na maior parte do tempo?

Em casa

Casa de parente

Casa de vizinho

Creche/ escola

Outro (especifique)

19. Quem cuida da criança na maior parte do tempo?

Babá

Creche

Avô/avó

Pai da criança

Você

Outro (especifique)

20. Até que idade seu filho ficou em aleitamento materno exclusivo (exclusivo - sem receber outros tipos de alimento ou água)
( ) Não amamentou exclusivamente
( ) Até 4 meses
( ) Até 1 mês
( ) Até 5 meses
( ) Até 2 meses
( ) Até 6 meses
( ) Até 3 meses
( ) $>6$ meses

21. Até qual idade o seu filho mamou no peito? (em meses, exemplo: 24) 
Prezada participante, para as seguintes questões, por favor, continue considerando o seu filho ou sua filha mais novo(a) dentro da faixa etária indicada.

17. A criança faz atividade física na escola ou brinca na rua?

$\operatorname{Sim}$

Não

18. A sua família (dois ou mais integrantes) costuma sentar à mesa nas refeições (almoço e/ou jantar)?

Sim

Não

19. Seu filho costuma pedir os alimentos que vê na TV?

Nunca

Raramente

Às vezes

Quase sempre

Sempre

20. Qual a frequência que a sra costuma comprar os alimentos não saudáveis que seu filho pede?

Nunca

Raramente

Às vezes

Quase sempre

Sempre

21. No último ano, o médico/ pediatra/ nutricionista diagnosticou o seu ficou com baixo peso ou obesidade?

Sim, com baixo peso

Sim, com excesso de peso/ obesidade

Não 


\section{Agora, para as seguintes questões, considere a sua alimentação em um dia/ semana típicos.}

22. Nos últimos sete dias, em quantos dias a sra comeu os seguintes alimentos:

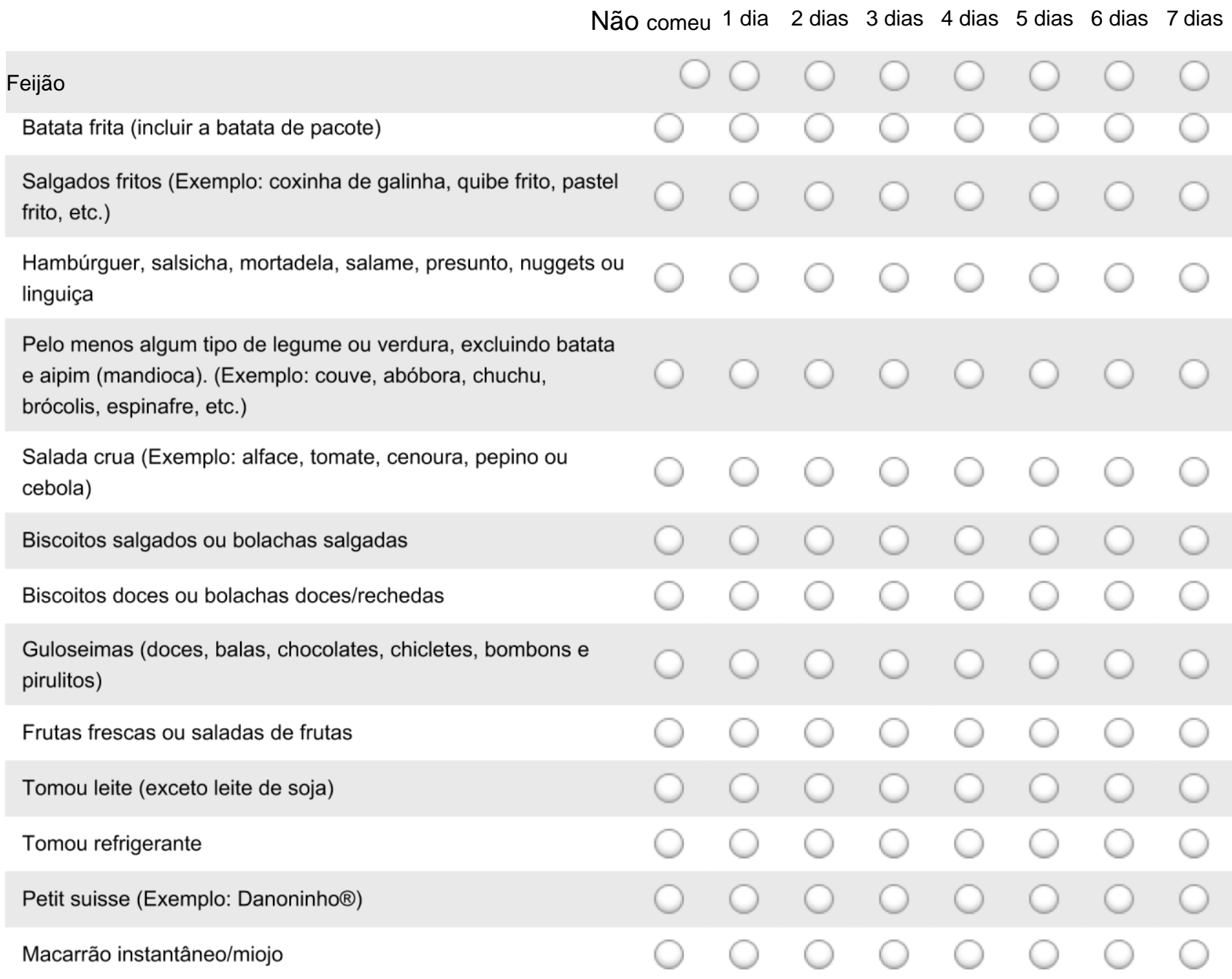

23. A sra costuma comer quando está assistindo à TV, mexendo no celular/ ipod/ tablete

\begin{tabular}{|c|c|c|c|c|c|}
\hline $\begin{array}{l}\text { Sim, 1x na } \\
\text { semana }\end{array}$ & $\begin{array}{l}\text { Sim, } 2 x \text { na } \\
\text { semana }\end{array}$ & $\begin{array}{c}\text { Sim, } 3 x \text { na } \\
\text { semana }\end{array}$ & $\begin{array}{l}\text { Sim, 4x na } \\
\text { semana }\end{array}$ & $\begin{array}{l}\text { Sim, } 5 x \text { na } \\
\text { semana }\end{array}$ & $\begin{array}{c}\text { Sim, } 6 x \text { na } \\
\text { semana }\end{array}$ \\
\hline
\end{tabular}

$\begin{array}{llllllll}0 & 0 & 0 & 0 & 0\end{array}$

24. Ontem, a sra comeu assistindo televisão?

$\operatorname{Sim}$

Não 


\section{Dados da mãe}

25. Qual o seu peso? (em kg, exemplo: $65 \mathrm{~kg}$ )

26. Qual a sua altura? (em cm, exemplo: 165)

Essa é a última parte do questionário. Muito obrigada pela colaboração de ter chegado até aqui!

Para terminar, por favor, complete as questões com dados referentes à senhora e seu filho ou sua filha.

\section{Qual a sua data de nascimento? (DD/MM/AAAA)}

\section{Escolaridade}

Ensino fundamental (1 $\left.{ }^{\circ} \mathrm{Grau}\right)$ incompleto

Ensino fundamental (1ํㅡrau) completo

Ensino médio ( $\left.2^{\circ} \mathrm{Grau}\right)$ incompleto

Ensino médio ( $\left.2^{\circ} \mathrm{Grau}\right)$ completo

Ensino superior incompleto

Ensino superior completo

Pós graduação/ mestrado ou doutorado

Outro (especifique)

29. Somando a sua renda com a renda das pessoas que moram com você, quanto é, aproximadamente, a renda familiar mensal?

Até 1 salário mínimo (até $\mathrm{R} \$ 790,00$ )

De 1 a 3 salários mínimos (de $R \$ 790,01$ até $R \$ 2.370,00$ )

De 3 a 6 salários mínimos (de $\mathrm{R} \$ 2.370,01$ até $\mathrm{R} \$ 4.740,00$ ).

De 6 a 9 salários mínimos (de $R \$ 4.740,01$ até $R \$ 7.110,00$ ).

De 9 a 12 salários mínimos (de $R \$ 7.110,01$ até $R \$ 9.490,00$ ).

De 12 a 15 salários mínimos (de $R \$ 9.490,01$ até $R \$ 11.850,00$ ).

Mais de 15 salários mínimos (mais de $\mathrm{R} \$ 11.850,00$ ). 
Agradeço a sua colaboração! As suas respostas serão muito importante para a melhor compreensão da relação das práticas parentais com a alimentação infantil e o seu desenvolvimento dos hábitos alimentares, ainda pouco exploradas no Brasil.

Caso a senhora tenha alguma dúvida ou queria ter acesso aos resultados desta pesquisa, que estarão disponíveis a partir de julho de 2015, entre em contato com Giovanna Soutinho Araújo pelo telefone: (61) 95350401, no horário de 818h ou pelo e-mail giovannasoutinho@gmail.com ou com a Prof ${ }^{\mathrm{a}}$ Dra. Renata Alves Monteiro pelo telefone (61) 91247400 ou pelo e-mail renatamonteiro@unb.br.

Esta pesquisa faz parte do Departamento de Pós Graduação em Nutrição Humana da

Universidade de Brasília (UnB) - (61) 3107-1779 pgnut@unb.br

Saiba mais! Os seguintes materiais contêm orientações para uma alimentação saudável, que podem auxiliá-la quanto às escolhas alimentares mais saudáveis para a alimentação de seus(suas) filhos(as) e explicar dúvidas comuns sobre a alimentação no dia a dia das crianças:

- Dez passos para uma alimentação saudável para crianças brasileiras menores de dois anos (Ministério da Saúde, 2010)

- Guia Alimentar para a População Brasileira (Ministério da Saúde, 2014)

- Manual "Prática de alimentação para a criança de 2 a 5 anos" - Pereira $\underline{(2014)}(146)$ 
Prezada participante,

A senhora está sendo convidada a participar do estudo: "Práticas parentais e sua relação com a alimentação infantil", que tem como objetivo geral identificar a relação das práticas alimentares realizadas pelas mães com a alimentação de crianças de 18 meses a oito anos.

Gostaria de solicitar a sua colaboração por meio do preenchimento de um questionário. A primeira parte dele busca caracterizar as práticas que influenciam o comportamento alimentar de seu(s) filho(s). A segunda parte é constituída por um questionário de frequência alimentar e a terceira de questões sociodemográficas.

A senhora receberá todos os esclarecimentos necessários antes e no decorrer da pesquisa. Asseguramos que seu nome não aparecerá, sendo mantido o mais rigoroso sigilo através da omissão total de quaisquer informações que permitam identificá-la.

Informamos que a senhora pode se recusar a responder qualquer questão que the traga constrangimento, podendo desistir de participar da pesquisa em qualquer momento, sem nenhum prejuízo para a senhora. Sua participação é voluntária, isto é, não há pagamento por sua colaboração.

Os resultados da pesquisa serão divulgados na Universidade de Brasília, podendo ser publicados posteriormente. Os dados e materiais utilizados na pesquisa ficarão sobre a guarda do pesquisador.

Se a senhora tiver qualquer dúvida em relação à pesquisa, por favor, entre em contato com: Giovanna Soutinho Araújo pelo telefone: (61) 95350401, no horário de 8-18h ou pelo e-mail giovannasoutinho@gmail.com. 
O preenchimento do questionário levará mais ou menos 20 minutos. Para que os seus dados da avaliação sejam considerados, é importante que você preencha completamente o questionário.

Este projeto foi Aprovado pelo Comitê de Ética em Pesquisa da Faculdade de Ciências da Saúde da Universidade de Brasília. As dúvidas com relação à assinatura do TCLE ou os direitos do sujeito da pesquisa podem ser obtidos através do telefone: (61) 3107-1947.

Nós agradecemos a sua colaboração!

* 1. Você concorda em participar desta pesquisa?

( ) Sim, concordo.

( ) Não concordo (Encerra o questionário). 


\section{Apêndice C - Modelo fatorial final: CFPQ adaptado para a população brasileira}

Modelagem parental - Esse fator avalia o quanto os pais servem de modelo à criança em relação ao consumo de alimentos saudáveis;

44. Eu como de forma saudável para servir de exemplo para meu filho.

46. Eu como alimentos saudáveis na frente do meu filho, mesmo que não sejam os meus favoritos.

47. Eu tento demonstrar empolgação ao comer alimentos saudáveis.

48. Eu mostro a meu filho o quanto eu gosto de comer alimentos saudáveis.

Restrição de escolha quantitativa e qualitativa de alimentos ( 9 itens) - Esse fator avalia o quanto os pais restringem ou controlam a alimentação de seus filhos, para manter a saúde e o peso;

27. Incentivo meu filho a comer menos para que não fique gordo.

28. Se eu não regulasse a alimentação do meu filho, ele comeria muita "besteira" (junk food - alimentos não saudáveis, como refrigerantes, doces e sanduíches).

29. Eu dou a meu filho porções pequenas nas refeições para controlar seu peso.

33. Se meu filho come mais do que o normal em uma refeição, tento restringir o que ele come na refeição seguinte.

34. Limito os alimentos que meu filho come e que podem fazê-lo engordar.

35. Proibido meu filho de comer certos alimentos, pois o deixarão gordo.

40. Tento garantir que meu filho não coma uma quantidade excessiva de seus alimentos favoritos.

41. Não deixo meu filho beliscar entre as refeições porque não quero que ele engorde.

45. Coloco meu filho de dieta com freqüência para controlar seu peso

Controle ao acesso de alimentos não saudáveis (4 itens) - Esse fator avalia o quanto os pais controlam a ingestão de alimentos não saudáveis pelas crianças; 
1. Controlo os doces (bala, sorvete, bolo, torta, docinhos e outros) que meu filho come.

2. Controlo os salgadinhos de pacote que meu filho come (Ruffles $\AA$, Doritos $\AA$, Cheetos $\left.{ }^{\circledR}\right)$.

3. Controlo os alimentos com excesso de gordura (fritura, carnes gordas ou com pele, biscoito recheado e outros) que meu filho come.

4. Controlo a quantidade de bebidas açucaradas (refrigerante, suco em pó e de caixinha) que meu filho bebe.

Controle emocional pela comida ( 3 itens) - Esse fator avalia o quanto os pais usam a comida para regular os estado emocional da criança;

7. Quando meu filho fica agitado, procuro dar-Ihe algo para comer.

8. Dou a meu filho algo para comer ou beber caso ele esteja sem nada para fazer, mesmo achando que ele está sem fome.

9. Dou a meu filho algo para comer ou beber caso ele esteja triste, mesmo achando que ele está sem fome.

Pressão para comer ( 3 itens) - Esse fator avalia o quanto os pais pressionam a criança a consumir mais alimentos nas refeições;

30. Se meu filho diz: "Não estou com fome", tento fazer com que coma mesmo assim.

39. Se meu filho come apenas uma pequena porção, tento fazer com que ele coma mais.

49. Quando meu filho diz que já terminou de comer, procuro fazer com que ele coma mais colheradas de seu prato.

Envolvimento da criança com a refeição da família (4 itens) - Esse fator avalia o quanto os pais incentivam o envolvimento da criança no planejamento e preparo das refeições;

15. Eu envolvo meu filho no planejamento das refeições da família

20. Eu deixo meu filho ajudar a preparar as refeições da família.

31. Eu converso com meu filho sobre o valor nutricional dos alimentos.

32. Eu estimulo meu filho a participar das compras de supermercado. 
Uso da comida como recompensa ( 3 itens) - Esse fator avalia o quanto os pais usam a comida como recompensa para o comportamento da criança;

19. Eu ofereço a meu filho seus alimentos preferidos em troca de um bom comportamento.

23. Eu ofereço doces (balas, sorvete, bolo, docinhos e outros) para o meu filho como recompensa por bom comportamento.

36. Eu proibido que meu filho coma doces ou seus alimentos preferidos em resposta a um mau comportamento.

Permissividade e controle infantil (5 itens) - Esse fator avalia o quanto os pais permitem que a criança controle seu comportamento alimentar e as interações de alimentação entre ela e os pais; e

5. Deixo meu filho comer o que ele quer.

6. Nas refeições, eu deixo meu filho escolher o que ele quer dentro daquilo que foi preparado.

10. Se meu filho não gostar do que está sendo servido, preparo outra coisa

11. Deixo meu filho fazer lanches sempre que quer.

12. Permito que meu filho deixe a mesa quando está satisfeito, mesmo que sua família ainda esteja comendo.

Incentivo à experimentação e consumo saudável (4 itens) - Esse fator avalia o quanto os pais incentivam a experimentação de novos alimentos e promovem o consumo de uma alimentação equilibrada, variada e saudável.

24. Eu incentivo meu filho a experimentar novos alimentos.

25. Eu converso com meu filho sobre a importância de se comer alimentos saudáveis

26. Digo a meu filho que alimentos saudáveis são gostosos.

38. Estimulo meu filho a comer uma variedade de alimentos saudáveis. 


\section{Apêndice D - Tabela de Correlação Pearson entre o consumo de verduras cozidas, salada crua e frutas e variáveis Independentes.}

Tabela 15 - Correlação Pearson entre o consumo de verduras cozidas, saladas e rrutas e variáveis independentes.

\begin{tabular}{|c|c|c|c|}
\hline Questão & $\begin{array}{l}\text { Verdura } \\
\text { (Criança) }\end{array}$ & $\begin{array}{l}\text { Salada Crua } \\
\text { (Criança) }\end{array}$ & $\begin{array}{l}\text { Frutas } \\
\text { (Criança) }\end{array}$ \\
\hline Idade da criança & $-0,234^{\star *}$ & $0,097^{\star}$ & $-0,220^{\star *}$ \\
\hline $\begin{array}{l}\text { Papel no estabelecimento dos hábitos } \\
\text { alimentares }\end{array}$ & $0,170^{\star *}$ & $0,098^{*}$ & $0,169^{\star *}$ \\
\hline Responsabilidade tamanho das porções & 0,05 & $0,076^{*}$ & $-0,022$ \\
\hline $\begin{array}{l}\text { Responsabilidade pelo fornecimento de } \\
\text { alimentação saudável }\end{array}$ & $0,115^{\star *}$ & $0,077^{\star}$ & $0,107^{\star *}$ \\
\hline Avaliação do peso do filho & 0,025 & $0,081^{*}$ & 0,031 \\
\hline Prática de comer assistindo TV da criança & $0,124^{\star *}$ & $0,108^{\star *}$ & $0,168^{\star *}$ \\
\hline Feijão (Criança) & $0,204^{\star \star}$ & $0,156^{\star *}$ & $0,163^{\star *}$ \\
\hline Batata frita (Criança) & $-0,119 * \star$ & 0,019 & $-0,090^{\star}$ \\
\hline Salgado (Criança) & $-0,097^{\star}$ & $-0,025$ & $-0,076^{\star}$ \\
\hline Embutidos (Criança) & $-0,202^{\star \star}$ & 0,003 & $-0,204^{\star \star}$ \\
\hline Verdura (Criança) & 1 & $0,345^{\star *}$ & $0,385^{\star *}$ \\
\hline Salada crua (Criança) & $0,345^{\star \star}$ & 1 & $0,306^{\star \star}$ \\
\hline Biscoito doce (Criança) & $-0,133^{\star \star}$ & $-0,002$ & $-0,134^{\star \star}$ \\
\hline Guloseima (Criança) & $-0,168^{\star \star}$ & 0,038 & $-0,112^{\star \star}$ \\
\hline Frutas (Criança) & $0,385^{\star \star}$ & $0,306^{\star *}$ & 1 \\
\hline Leite (Criança) & $-0,045$ & $-0,080^{*}$ & $-0,06$ \\
\hline Refrigerante (Criança) & $-0,191^{\star \star}$ & $-0,033$ & $-0,216^{\star \star}$ \\
\hline Petit suisse (Criança) & $-0,131^{\star *}$ & $-0,012$ & $-0,055$ \\
\hline Miojo (Criança) & $-0,059$ & $-0,013$ & $-0,153^{\star *}$ \\
\hline Duração do aleitamento materno exclusivo & $0,081^{*}$ & 0,022 & 0,047 \\
\hline Duração da amamentação & 0,053 & 0,004 & $0,107^{\star *}$ \\
\hline Prática de atividade física da criança & 0,014 & $-0,092^{\star}$ & $-0,003$ \\
\hline $\begin{array}{c}\text { Costume da família de sentar à mesa nas } \\
\text { refeições }\end{array}$ & $-0,024$ & $-0,073$ & $-0,115^{\star \star}$ \\
\hline $\begin{array}{l}\text { Costume de pedir os alimentos que vê na } \\
\text { TV }\end{array}$ & $-0,169^{\star \star}$ & $0,107^{\star *}$ & $-0,162^{\star \star}$ \\
\hline
\end{tabular}




\begin{tabular}{|c|c|c|c|}
\hline Questão & $\begin{array}{l}\text { Verdura } \\
\text { (Criança) }\end{array}$ & $\begin{array}{l}\text { Salada Crua } \\
\text { (Criança) }\end{array}$ & $\begin{array}{l}\text { Frutas } \\
\text { (Criança) }\end{array}$ \\
\hline $\begin{array}{l}\text { Frequência de compra de alimentos não } \\
\text { saudáveis }\end{array}$ & $-0,212^{\star \star}$ & $-0,029$ & $-0,275^{\star \star}$ \\
\hline Diagnóstico de baixo peso ou obesidade & 0,037 & $0,086^{*}$ & 0,051 \\
\hline Feijão (Mãe) & $0,137^{\star *}$ & $0,137^{\star *}$ & $0,170^{\star *}$ \\
\hline Embutidos (Mãe) & $-0,130^{\star \star}$ & $-0,051$ & $-0,169^{\star *}$ \\
\hline Verdura (Mãe) & $0,496^{\star \star}$ & $0,201^{\star \star}$ & $0,291^{\star *}$ \\
\hline Salada crua (Mãe) & $0,205^{\star \star}$ & $0,473^{\star *}$ & $0,231^{\star \star}$ \\
\hline Frutas (Mãe) & $0,170^{\star \star}$ & $0,232^{\star \star}$ & $0,420^{\star \star}$ \\
\hline Refrigerante (Mãe) & $-0,111^{\star *}$ & $-0,072$ & $-0,125^{\star *}$ \\
\hline Miojo (Mãe) & $-0,106^{\star \star}$ & $-0,069$ & $-0,058$ \\
\hline Prática de comer assistindo TV da mãe & $0,099^{\star *}$ & $0,085^{\star}$ & $0,125^{\star \star}$ \\
\hline Classificação IMC da mãe & $-0,082^{\star}$ & 0,035 & $-0,04$ \\
\hline Pressão para comer & $-0,011$ & $0,083^{\star}$ & 0,019 \\
\hline Duração de tempo de TV da criança & $-0,118^{\star \star}$ & $-0,082^{*}$ & $-0,148^{\star \star}$ \\
\hline Escolaridade da mãe & $0,097^{\star}$ & 0,024 & $0,113^{\star \star}$ \\
\hline Renda familiar mensal & $0,143^{\star \star}$ & 0,053 & $0,165^{\star \star}$ \\
\hline Modelagem Parental & 0,037 & $-0,047$ & 0,025 \\
\hline $\begin{array}{l}\text { Restrição de escolha quantitativa e } \\
\text { qualitativa de alimentos }\end{array}$ & $-0,027$ & $-0,004$ & 0,016 \\
\hline $\begin{array}{c}\text { Controle ao acesso de alimentos não } \\
\text { saudáveis }\end{array}$ & 0,015 & $-0,008$ & 0,035 \\
\hline Controle emocional pela comida & 0,008 & 0,022 & $-0,026$ \\
\hline Pressão para comer & $-0,011$ & $0,083^{*}$ & 0,019 \\
\hline $\begin{array}{l}\text { Envolvimento da criança com a refeição da } \\
\text { família }\end{array}$ & 0,072 & 0,012 & $-0,018$ \\
\hline Uso da comida como recompensa & 0 & $-0,019$ & $-0,034$ \\
\hline Permissividade e controle infantil & $-0,005$ & 0,021 & 0,034 \\
\hline $\begin{array}{c}\text { Incentivo à experimentação e consumo } \\
\text { saudável }\end{array}$ & 0,039 & $-0,012$ & $-0,012$ \\
\hline
\end{tabular}

${ }^{* *} p<0,001$ e * $p<0,05$ 
ANEXO 


\section{Anexo 1 - CFPQ original em inglês}

Comprehensive Feeding Practices Questionnaire (Musher-Eizenman \& Holub, 2007)

Child Control-Parents allow the child control of his/her eating behaviours and parent-child feeding interactions.

5. Do you let your child eat whatever s/he wants?

6. At dinner, do you let this child choose the foods s/he wants from what is served?

10. If this child does not like what is being served, do you make something else?

11. Do you allow this child to eat snacks whenever s/he wants?

12. Do you allow this child to leave the table when s/he is full, even if your family is not done eating?

Emotion regulation-Parents use food to regulate the child's emotional states.

7. When this child gets fussy, is giving him/her something to eat or drink the first thing you do?

8. Do you give this child something to eat or drink if $s / h e$ is bored even if you think $\mathrm{s} /$ he is not hungry?

9. Do you give this child something to eat or drink if $s / h e$ is upset even if you think $\mathrm{s} /$ he is not hungry?

Encourage balance and variety-Parents promote well-balanced food intake, including the consumption of varied foods and healthy food choices.

13. Do you encourage this child to eat healthy foods before unhealthy ones?

24. I encourage my child to try new foods.

26. I tell my child that healthy food tastes good.

38. I encourage my child to eat a variety of foods. 


\section{Environment-Parents make healthy foods available in the home.}

14. Most of the food I keep in the house is healthy.

16. I keep a lot of snack food (potato chips, Doritos, cheese puffs) in my house. $\mathrm{R}$

22. A variety of healthy foods are available to my child at each meal served at home.

37. I keep a lot of sweets (candy, ice cream, cake, pies, pastries) in my house. R Food as reward-Parents use food as a reward for child behaviour.

23. I offer sweets (candy, ice cream, cake, pastries) to my child as a reward for good behaviour.

36. I withhold sweets/dessert from my child in response to bad behaviour.

19. I offer my child his/her favorite foods in exchange for good behaviour.

Involvement-Parents encourage child's involvement in meal planning and preparation.

15. I involve my child in planning family meals.

20. I allow my child to help prepare family meals.

32. I encourage my child to participate in grocery shopping.

Modeling-Parents actively demonstrate healthy eating for the child.

44. I model healthy eating for my child by eating healthy foods myself.

46. I try to eat healthy foods in front of my child, even if they are not my favorite.

47. I try to show enthusiasm about eating healthy foods.

48. I show my child how much I enjoy eating healthy foods.

Monitoring-Parents keep track of child's intake of less healthy foods. 
1. How much do you keep track of the sweets (candy, ice cream, cake, pies, pastries) that your child eats?

2. How much do you keep track of the snack food (potato chips, Doritos, cheese puffs) that your child eats?

3. How much do you keep track of the high-fat foods that your child eats?

4. How much do you keep track of the sugary drinks (soda/pop, kool-aid) this child drinks?

Pressure-Parents pressure the child to consume more food at meals.

17. My child should always eat all of the food on his/her plate.

30. If my child says, "I'm not hungry," I try to get him/her to eat anyway.

39. If my child eats only a small helping, I try to get him/her to eat more.

49. When he/she says he/she is finished eating, I try to get my child to eat one more (two more, etc.) bites of food.

Restriction for Health-Parents control the child's food intake with the purpose of limiting less healthy foods and sweets.

21. If I did not guide or regulate my child's eating, s/he would eat too much of his/her favorite foods.

28. If I did not guide or regulate my child's eating, he/she would eat too many junk foods.

40. I have to be sure that my child does not eat too much of his/her favorite foods.

43. I have to be sure that my child does not eat too many sweets (candy, ice cream, cake, or pastries).

Restriction for weight control-Parents control the child's food intake with the purpose of decreasing or maintaining the child's weight.

18. I have to be sure that my child does not eat too many high-fat foods.

27. I encourage my child to eat less so he/she won't get fat. 
29. I give my child small helpings at meals to control his/her weight.

33. If my child eats more than usual at one meal, I try to restrict his/her eating at the next meal.

34. I restrict the food my child eats that might make him/her fat.

35. There are certain foods my child shouldn't eat because they will make him/her fat.

41. I don't allow my child to eat between meals because I don't want him/her to get fat.

45. I often put my child on a diet to control his/her weight.

Teaching about nutrition-Parents use explicit didactic techniques to encourage the consumption of healthy foods.

25. I discuss with my child why it's important to eat healthy foods.

31. I discuss with my child the nutritional value of foods.

42. I tell my child what to eat and what not to eat without explanation. $\mathrm{R}$

Note. Item numbers indicate the order in which they were presented in the survey. Items numbered 1-13 utilize a 5-point response scale "never, rarely, sometimes, mostly, always." Items numbered 14-49 utilize a 5-point scale with different anchors, "disagree, slightly disagree, neutral, slightly agree, agree."'Items marked with an $\mathrm{R}$ were reverse coded. 